\title{
DOE/ER/54107-3 \\ DEVELOPMENT OF A CHEMICAL KINETIC \\ MEASUREMENT APPARATUS AND \\ THE DETERMINATION OF THE REACTION \\ RATE CONSTANTS FOR \\ LITHIUM-LEAD/WATER INTERACTION
}

Status Report

October 1, 1991 - March 15, 1993

Dr. Paul Orleans Biney

Mechanical Engineering Department

Prairie View A\&M University

Prairie View, Texas 77446

\begin{abstract}
April 1993
\section{PREPARED FOR THE U.S. DEPARTMENT OF ENERGY UNDER GRANT NO DE-FG05-90ER/54107}

\section{DISCLAIMER}

\footnotetext{
This report was prepared as an account of work sponsored by an agency of the United States Government. Neither the United States Government nor any agency thereof, nor any of their employees, makes any warranty, express or implied, or assumes any legal liability or responsibility for the accuracy, completeness, or usefulness of any information, apparatus, product, or process disclosed, or represents that its use would not infringe privately owned rights. Reference herein to any specific commercial product, process, or service by trade name, trademark, manufacturer, or otherwise does not necessarily constitute or imply its endorsement, recommendation, or favoring by the United States Government or any agency thereof. The views and opinions of authors expressed herein do not necessarily state or reflect those of the United States Government or any agency thereof.
} 
PREPARED FOR THE U.S. DEPARTMENT OF ENERGY UNDER GRANT NUMBER DE-FG05-90ER54107

Technical Progress Report For the Period

October 1, 1991 - March 15, 1993

On the Development of a Chemical

Kinetic Measurement Apparatus and

the Determination of the Reaction Rate Constants

For

Lithium-Lead/Steam Interaction

Prepared by:

Dr. Paul Orleans Biney

Department of Mechanical Engineering

P.O. Box 397

Prairie View A\&M University

Prairie View, Tx. 77446

Telephone: 409-857-4023

Fax: 409-857-2222

Submitted to the

OFFICE OF FUSION ENERGY

DEPARTMENT OF ENERGY

Through the

Prairie View A\&M Research Foundation

P.O. Box 3578

College Station, Texas 77843

March 1993

Funded Project Period

09/21/90 - 3/21/93

PRINCIPAL INVESTIGATOR

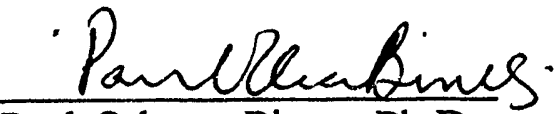

Paul Orleans Biney, Ph.D.

Assoc. Professor

Mechanical Engineering Dept. 


\begin{abstract}
An experimental set-up for accurate measurement of hydrogen generation rate in Lithium-Lead $\left(\mathrm{Li}_{17} \mathrm{~Pb}_{83}\right)$ Steam or water interactions has been designed. The most important features of the design include a pneumatic actuated quick opening and closing high temperature all stainless steel valve used to control the reaction time and the placement of most measuring devices below a water line to minimize leakage of the hydrogen collected. A PC based data acquisition and control system provides remote process sequencing, acquisition and control of all major components of the set-up. Initial tests indicate that the first design objective of maintaining leakproof gas collection chamber has been achieved. Initial pressure tests indicated that the pressure drop over a time span of 30 minutes was within the tolerance of the pressure transducer used to measure the pressure (within $0.690 \mathrm{kPa}$ ) at a nominal system pressure of $685 \mathrm{kPa}$. The experimental system hardware, data acquisition and control programs and data analysis program have been completed, tested and are currently functional.
\end{abstract}




\section{TABLE OF CONTENTS}

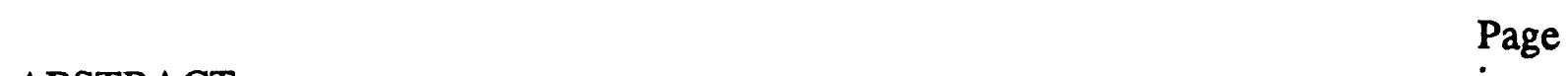

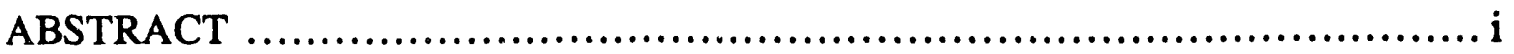

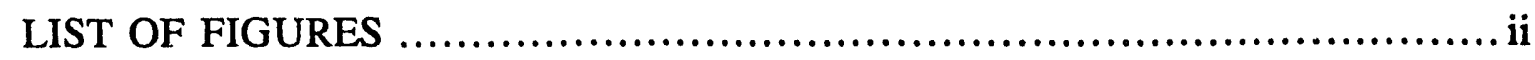

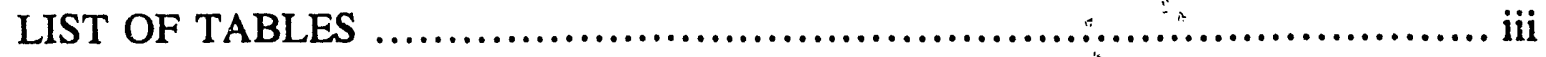

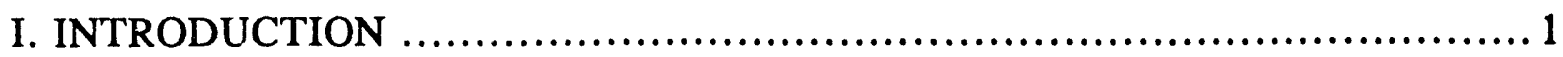

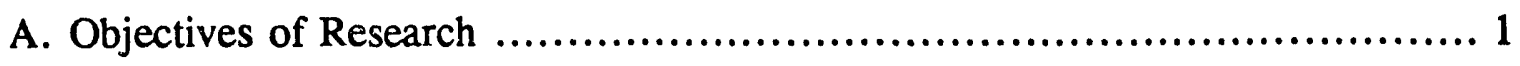

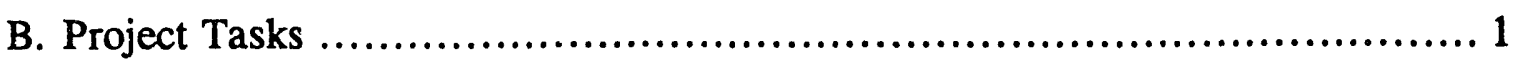

C. Graduate and Undergraduat Research Assistants ............................ 2

II. DESIGN OF EXPERIMENTAL SYSTEM

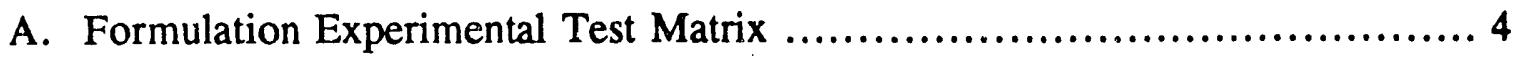

B. Preliminary Determination of Hydrogen Gas Pressure in Gas Region of Upper Chamber ...........................................................

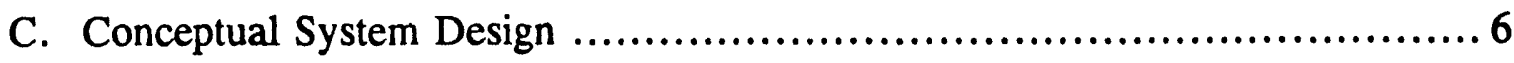

D. Intermediate Experimental System Design................................. 10

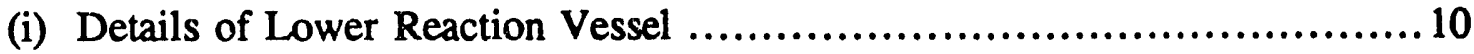

(ii) Liquid Metal Furnace .................................................. 10

(iii) Upper Vessel Details................................................... 14

(iv) Mid-Section Butterfly Valve................................................. 14

(v) Design of Convection Coil............................................ 17

E. Initial Testing of Intermediate Experimental System ....................... 18

F. Final Experimental System Design ...................................... 2

G. Operation of Final Experimental System .................................. 26

H. Lithium Lead Processing \& Handling ................................... 27 


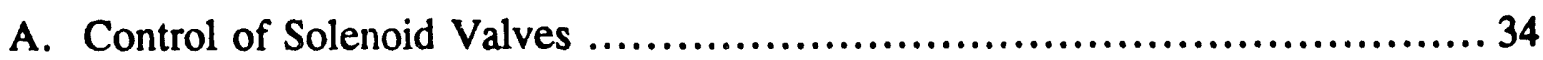

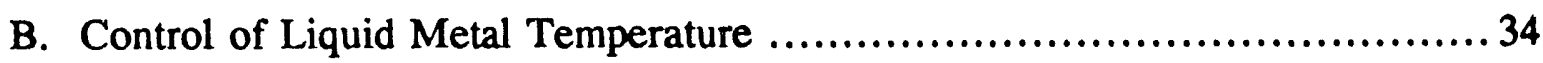

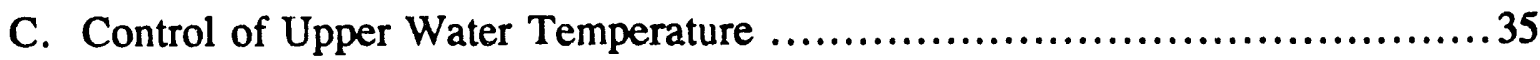

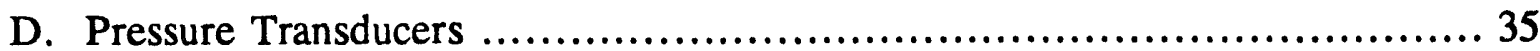

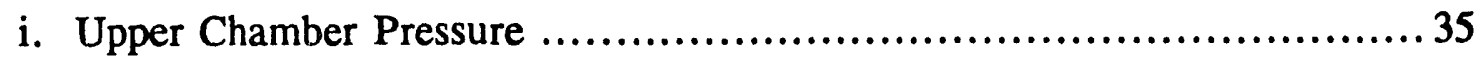

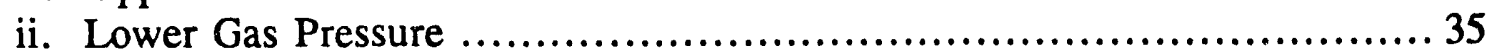

IV. CALIBRATION AND TESTING OF EXPERIMENTAL HARDWARE ........ 37

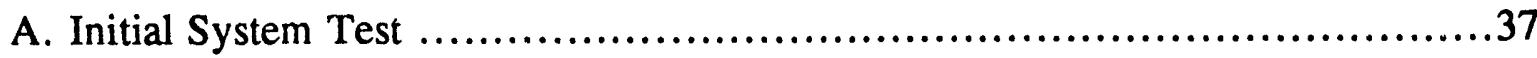

B. Calibration of Upper Gas Volume......................................... 37

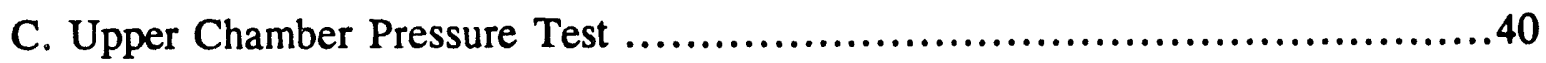

V. DATA ACQUISITION PROGRAMS AND METHOD OF ANALYSIS ........ 41

A. Data Acquisition and Control Program .................................. 41

B. Data Reduction and Analysis .......................................... 46

VI. MODIFIED MASS TRANSFER MODEL FOR LITHIUM-LEAD

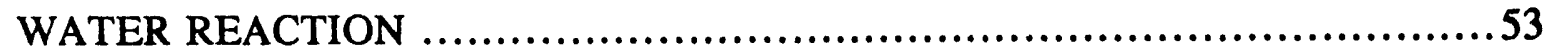

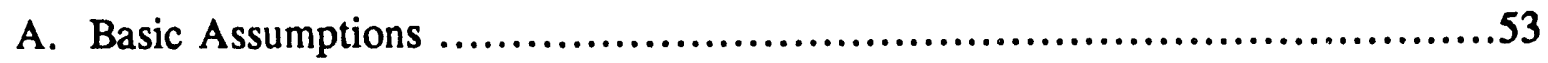

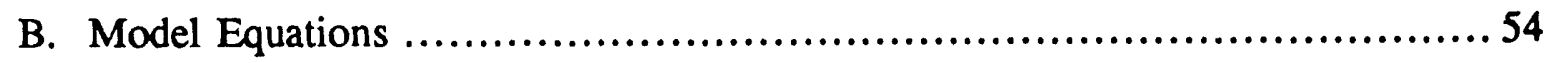

VII. PROBLEMS ENCOUNTERED AND STATUS OF RESEARCH ..............60

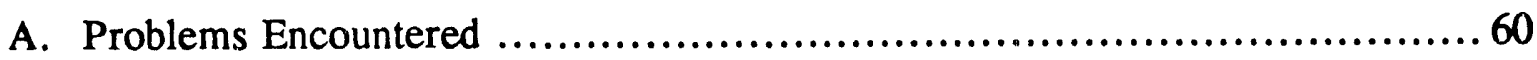

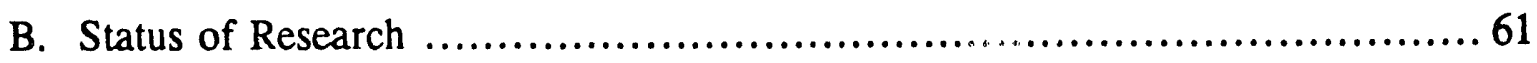

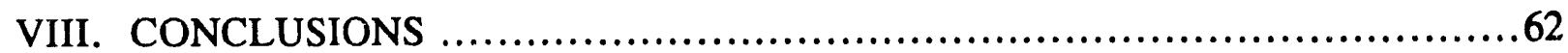


APPENDIX A DETERMINATION OF THEORETICAL HYDROGEN PRESSURE 66

APPENDIX B LISTING OF DATA ANALYSIS PROGRAM .................... 68

APPENDIX C LISTING OF DATA ACQUISITION AND CONTROL

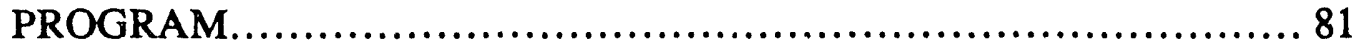




\section{List of Figures}

Figure 1 Conceptual System Design..........................................9

Figure 2 Details of Internal Cooling Channel in Lower Flange .................. 11

Figure 3 Details of Lower Reaction Vessel.................................. 12

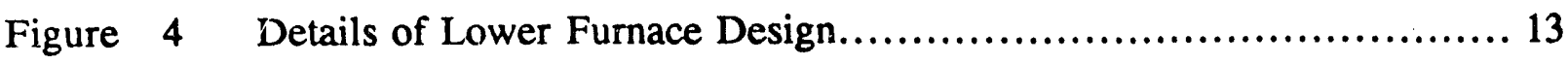

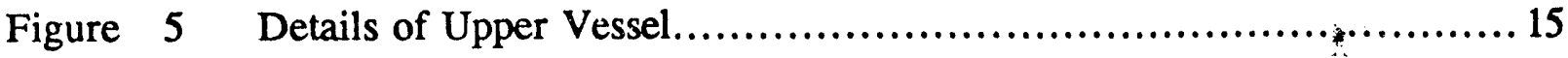

Figure 6 Pneumatic Controlled Butterfly Valve................................ 16

Figure 7 Partial Assembly of Preliminary System.............................. 20

Figure $8 \quad$ Final Design of Lower Vessel...................................... 22

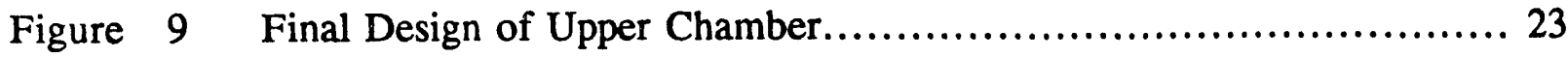

Figure 10a Assembly of Final Experimental Set-Up............................ 24

Figure 10b Apparatus for Melting and Casting Molten Lithium-Lead ............. 25

Figure 11 Photographs of System, Data Acquisition System and Control Panels ... 28

Figure 12 Data Acquisition and Control System................................ 30

Figure 13 Simplified Schematic Control Diagram............................... 33

Figure 14 Set-Up for Calibrating Upper Gas Volume............................ 34

Figure 15 Simplified Flow Chart of Data Acquisition and Control Programs ...... 47

Figure 16 Reference Coordinate System for Mass Transfer Reaction Model ....... 55 


\section{LIST OF TABLES}

Table 1 Final Experimental Test Matrix 7

Table 2 Theoretical Pressure of Hydrogen Generated in the $\mathrm{Li}_{17} \mathrm{~Pb}_{83} /$ Water Reaction 8

Table 3 Design Specifications for Cooling Coil...................................... 19

Table 4 Analog Input/Output Features of Data Acquisition and Control System ... 31

Table 5 Digital Input/Output and Power Control Features of Data Acquisition and Control System 32

Table 6 Summary of Upper Chamber Calibration Results........................... 39

Table 7 Summary of Controlled Equipment and Relays $\ldots \ldots \ldots \ldots \ldots \ldots \ldots \ldots \ldots \ldots . \ldots 2$

Table 8 Summary of Thermocouples and Channel Connections .................. 43

Table 9 Description of the Six Phases of Each $\mathrm{Li}_{17} \mathrm{~Pb}_{83} /$ Water

Reaction Experiment 44 


\section{INTRODUCTION}

This status report covers work done on this project for the period October 1, 1991 through March 15,1993 . The greatest challenge in the design was ensuring a system with minimum leakage rate in order to obtain accurate accounting of reaction product gases. This greatly affects the placement of thermocouples, transducers and other instruments needed in the design.

\section{A. Objectives of Research}

The objectives of the research are:

(i) The design and construction of an experimental set up that can be used to obtain accurate measurements of hydrogen generation rate during the initial and subsequent stages of liquid metal/water or steam reactions.

(ii) The use of data collected in conjunction with an improved liquid metal transport reaction model developed to determine the empirical chemical kinetics reaction rate constants.

(iii) To involve minority graduate and undergraduate studentsin this research.

\section{B. Project Tasks}

To enable the objectives listed above to be met, the overall project was divided into 10 main steps, namely

1. The search for qualified graduate and undergraduate students for the research and their subsequent introduction to the project.

2. Preliminary design of experimental system and determination of experimental test matrix.

3. Identification of manufactures/vendors and price list for all major components in preliminary design.

4. Modification of preliminary design. The final design of the experimental system.

5. Production of Working Drawings. 
6. Procurement of components and modification of Liquid Metal Transport Reaction Model for experimental analysis.

7. Construction of experimental system.

8. Testing \& correction of experimental system.

9. Data Collection on Hydrogen generation rate for liquid Lithium-lead/water reaction

10. Analysis of Data using the modified liquid metal Transport Reaction Model to obtain the empirical reaction rate constants.

11. Preparation of final Research Report.

The details of the work done from phase 1 through 8 of the project are described in this report.

C. Graduate and Undergraduate Research Assistants.

The first phase of the project involved obtaining qualified graduate and undergraduate students to work on the project. In this regard, James Akpan, an MS graduate student in the Mechanical Engineering Department was appointed a graduate Research Assistant for the project. In addition, Robert Tette, the most outstanding undergraduate Mechanical Engineering Junior student, expressed great interest in the research work and was hired as an Undergraduate Assistant in the project.

While James was primarily in charge of the overall research, his concentration was in the more technical aspects of data acquisition, analyses and chemical kinetics of the work. Robert was involved in the design of the system, procurement of components and assembly of the system. James and Robert spent a considerable portion of the first phase of the project in literature research 0 n data acquistion, liquid metal/water/steam reactions, chemical reaction kinetics and fusion safety in general. In addition, Mr. Ali Ekhlassi was assigned to work on the 
project as a Technician for the period June 1, 1992 to August 31, 1992 and Mr. Ali Ekhlassi was responsible for fabrication and assembly of the control panel, and testing of the experimental apparatus. Mr. Ekhlassi is an experienced Technician whose services was extremely beneficial to the project. 


\section{PRELIMINARY DESIGN OF EXPERIMENTAL SYSTEM}

\section{A. Experimental Test Matrix}

To enable us determine the operating condition of the system to be designed, a detailed experimental matrix was initially developed. The matrix has been modified to enable only the most important parameters to be varied. The primary experimental variables are:

1. Initial Liquid Metal Temperature

2. Initial Water Temperature ' $T_{\mathrm{uw}}$

3. Initial System Pressure $P_{\text {iug }}$

4. Total reaction time $\mathrm{t}_{\mathrm{r}}$ and

5. Initial Mass of liquid Metal $M_{\mathrm{lm}}$ (de-emphasized)

To ensure that the surface area for reaction is constant throughout an experiment, the area was selected to be the maximum that prevents Taylor instability. The Secondary variables to be measured include:

1. Reaction product gas temperature $T_{\mathrm{ug}}$.

2. Reaction product gas pressure $\mathbf{P}_{\mathrm{ug}}$.

3. Liquid Metal Temperature $T_{l m}(t)$

4. Lower gas chamber volume $V_{\mathrm{g}}$.

5. Low gas chamber pressure $P_{\mathrm{g}}$. 
6. Lower gas chamber temperature $T_{\mathrm{m}}$.

7. Initial Upper Gas Chamber Volume $V_{\text {iug. }}$

The final experimental test matrix for lithium lead/wate reaction is shown in Table 1

B. Preliminary Determination of Hydrogen Gas Pressuris in the Gas Region of the Upper Chamber

In order to provide estimates of gas pressures and concentration of hydrogen gas in the gas region, a preliminary analysis was made to obtain the range of hydrogen gas concentration and partial pressures that may be encountered in the course of the experiment. The analysis was hased on the following:

1. The mass of liquid metal initially in the lower reaction vessel is known.

2. The percent of metal reacted was varied from $5 \%$ to $100 \%$ (a typical range for such nonmixing reactions)

3. The upper chamber gas region volume was varied by varying the water level in the upper chamber (of diameter $3.81 \mathrm{~cm}$ ) to produce gas volume heights of from $5 \mathrm{~cm}$ to $25 \mathrm{~cm}$

4. Saturated liquid is assumed to be in the upper chamber, and the gas temperature was assumed to be $100^{\circ} \mathrm{C}$.

The above information are used in conjunction with the chemical reaction equation for lithium-lead $\left(\mathrm{Li}_{17} \mathrm{~Pb}_{83}\right) /$ water reaction to determine the theoretical partial pressure of hydrogen generated during the reaction. The details of the calculation are given in Appendix A. Table 2 gives sample calculation results for $\left(\mathrm{Li}_{17} \mathrm{~Pb}_{83}\right) /$ water reaction. From the Table, it is evident that in addition to serving as a reactant and condensing medium for any water vapor generated as a result of the reaction, the water in the upper chamber also can be used to control the the partial 
pressure of the hydrogen produced in the upper gas region by varying its column height. In doing so, we can also have control over the partial pressure or the hydrogen and therefore its concentration. These calculation results also provided us with the upper bounds of pressures to be expected in the system, and this information was used in designing for the minimum thickness of both the upper and lower vessels. Table 2 gives the summary of the results of the calculations, the details of which are given in Appendix A.

\section{Conceptual System Design}

Figure 1 shows the initial conceptual design of the setup. In this design, significant changes were made in the upper chamber and mid-section area of the apparatus. The attachment of the pressure transducers, thermocouples, and the convection coil have been located below the water level to minimize leakage of the hydrogen gas produced. The transducer and thermocouple wells have been modified by replacing them with a design that allows direct contact of the thermocouples with the gas and water regions. The convection coil is passed through a flanged part at the base of the upper chamber and below the water level. The principle behind these changes are that liquid leakages are far easier to control than hydrogen gas leakage. Thus we want to ensure that there are no flanged or screwed joints in the region where the gas collects after the reaction. 
Table 1 Final Experimental Test Matrix for Lithium Lead/Water Reaction

\begin{tabular}{||c|c|c|c||}
\hline $\begin{array}{c}\text { Liquid Metal } \\
\text { Tempcrature } \\
{ }^{\circ} \text { C }\end{array}$ & $\begin{array}{c}\text { Initial Water } \\
\text { Temperature } \\
{ }^{\circ} \mathbf{C}\end{array}$ & $\begin{array}{c}\text { Reaction } \\
\text { Time } \\
\text { s }\end{array}$ & $\begin{array}{c}\text { Liquid Metal } \\
\text { Mass } \\
\text { gm }\end{array}$ \\
\hline 350 & 90 & $5,10,20,200$ & 60 \\
350 & 70 & $5,10,20,260$ & 60 \\
400 & 60 & $5,10,20,200$ & 60 \\
400 & 90 & $5,10,20,200$ & 60 \\
400 & 90 & $5,10,20,200$ & 30 \\
500 & 90 & $5,10,20,200$ & 60 \\
500 & 70 & $5,10,20,200$ & 60 \\
500 & 90 & $5,10,20,200$ & 30 \\
600 & 90 & $5,10,20,200$ & 60 \\
600 & 70 & $5,10,20,200$ & 60 \\
650 & 90 & $5,10,20,200$ & 60 \\
650 & 70 & $5,10,20,200$ & 60 \\
\hline
\end{tabular}


Table 2 Theoretical Pressure of Hydrogen Generated for $\mathrm{Li}_{17} \mathrm{~Pb}_{83} /$ Water Reaction

\begin{tabular}{||c|c|c|c|c||}
\hline \multirow{2}{*}{$\begin{array}{c}\text { Gas Accumulation } \\
\text { Height } \\
\text { in Upper Chamber } \\
\text { (cm) }\end{array}$} & \multicolumn{4}{|c|}{ Gas Pressure (kPa) } \\
\cline { 2 - 5 } & $5 \%$ & $10 \%$ & $20 \%$ & $100 \%$ \\
\cline { 2 - 5 } 5 & 195.5 & 391.1 & 782.1 & 3910.6 \\
10 & 97.8 & 195.5 & 391.1 & 1955.3 \\
15 & 65.2 & 130.4 & 260.7 & 1303.5 \\
20 & 48.9 & 97.8 & 195.5 & 977.7 \\
25 & 39.1 & 78.2 & 156.4 & 782.1 \\
\hline
\end{tabular}




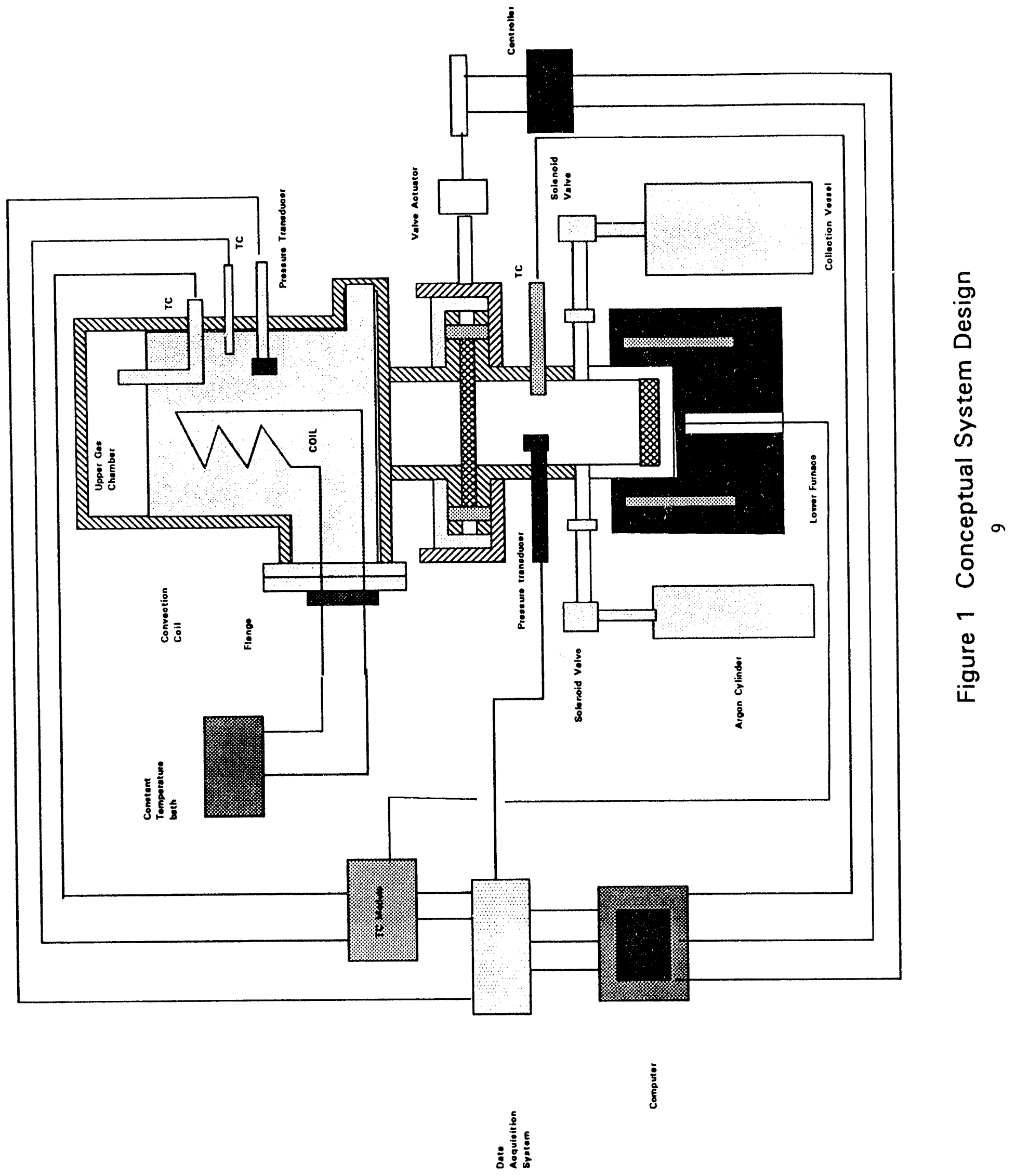




\section{Intermediate Experimental System Design}

Several changes were made in the conceptual design shown in Figure 1, the most important of which is the cooling method for the butterfly valve section. As a result of the high temperatures encountered by the lower reaction chamber and subsequently conducted to the butterfly valve, it is extremely important that the section close to the valve seat be effectively cooled. Provision was made for cooling the valve by incorporating an internal cooling channel in the lower flange connecting the butterfly valve to the lower chamber. The details of this design is shown in Figure 2. The detail design of the various components of the system is described below.

\section{(i) Details of Lower Reaction Vessel}

Figure 3 shows the details of the lower reaction vessel which was designed to contain the liquid lithium lead. The flange at the top was welded to the lower part of this section. The flange has an internal cooling channel just beneath the butterfly valve seat. Chilled water from a bath is circulated through this channel to maintain satisfactory temperatures at the valve section. This section is constructed of stainless steel. At the lower section, a 4 inch long NANMAC eroding tip fast response thermocouple is permanently inserted - The tip of this thermocouple is just $\mathbf{1 . 5}$ $\mathrm{mm}$ below the liquid metal pool and thus closely measures the liquid metal temperature. All basic dimensions of the lower reaction chamber are provided in Figure 3.

(ii) The Furnace

Figure 4 shows the details of the design of the furnace into which the lower section described in Figure 3 containing the lithium-lead is inserted, and heated to required liquid metal 


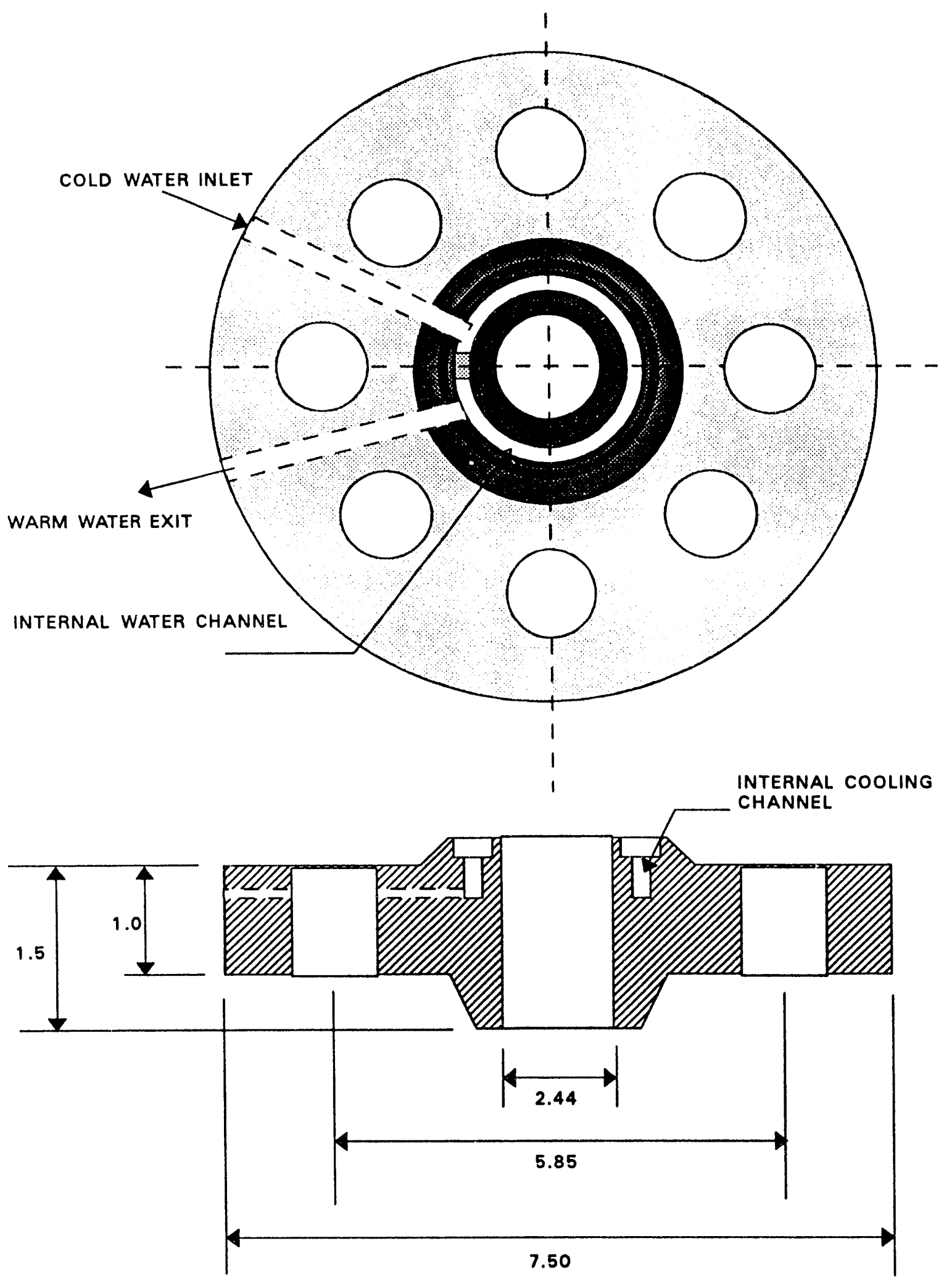

All dimensions are in inches

Figure 2 Details of Internal Cooling Channel in Lower Flange. 


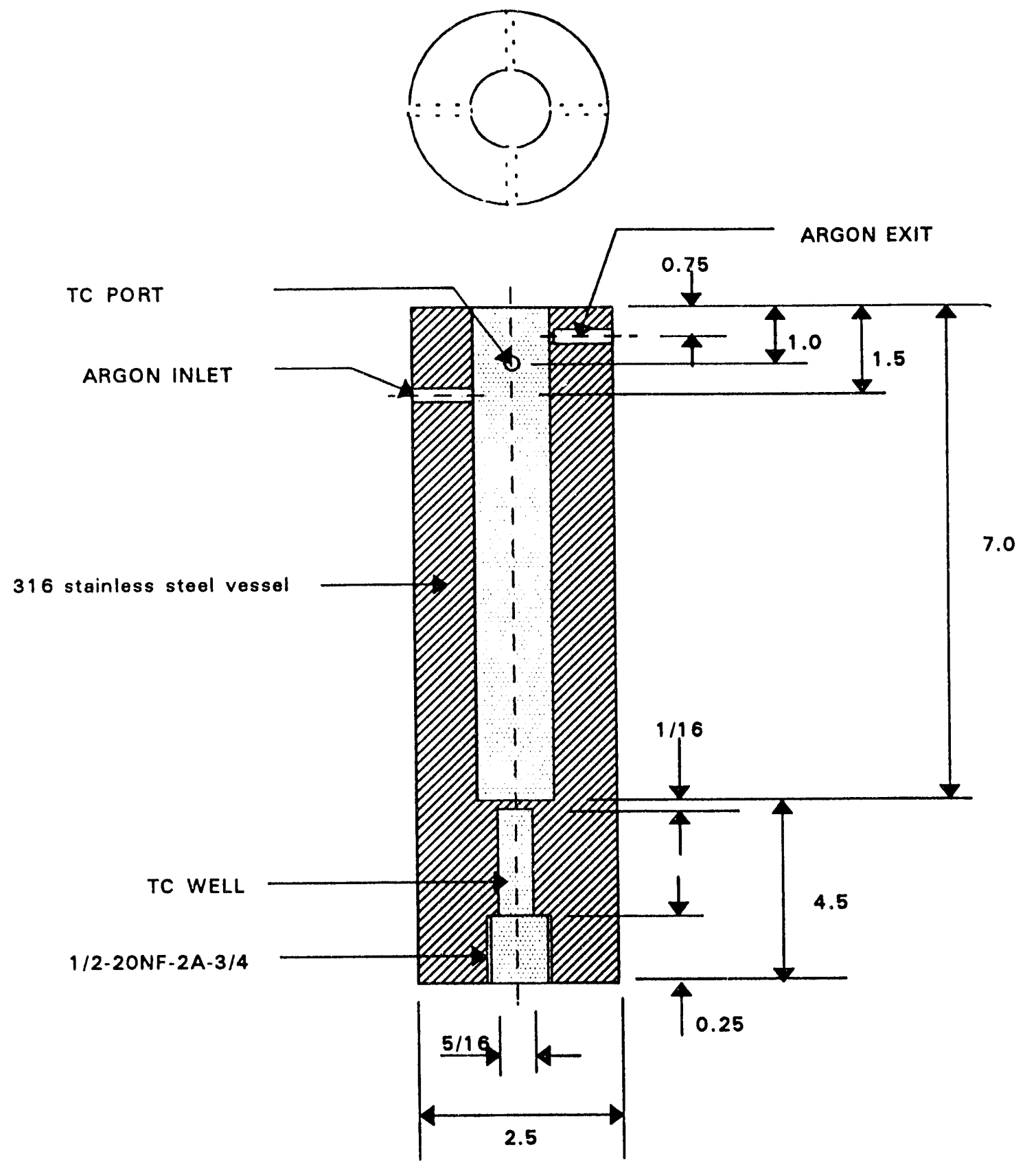

All dimensions are in inches

Figure 3 Details of Lower Reaction Vessel 


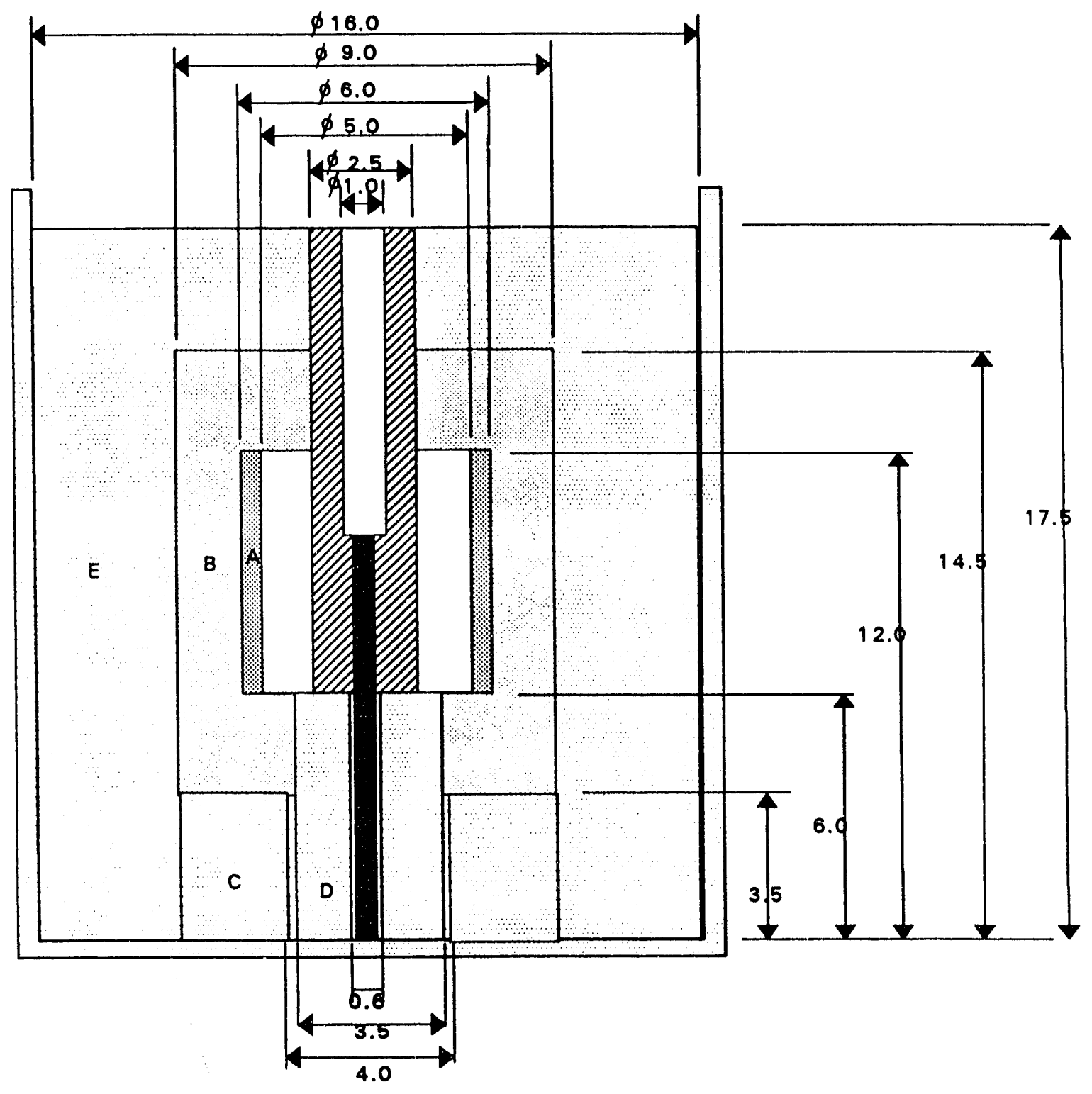

All dimensions are in inches

Figure 4 Details of Lower Furnace Design 
temperature. Parts A and B constitute a Watlow semi cylindrical high watt density ceramic fiber heater ( 750 Watts). Two such heaters are used in the furnace providing a total heating power of 1500 watts. Parts $\mathrm{C}$ and $\mathrm{D}$ are cylindrical ceramic fiber insulation modules used to insulate the lower section of the furnace. Part E is made of ceramic fiber blanket insulation. The outer shell of the furnace is made of stainless steel metal sheet.

\section{(iii) Upper Vessel Details}

The upper vessel, constructed with 316 stainless steel is shown in Figure 5. Initially, space V contains saturated water vapor, whose temperature is measured using an adjustable probe NANMAC right angle thermocouple (not shown)connected to port $\mathrm{A}$, which also eventually measures the upper gas temperature once reaction is initiated. A second thermocouple connected to port $\mathrm{C}$ measures the temperature of the water in the upper chamber. A pressure transducer connected to port $\mathrm{D}$, measures the system pressure in the upper chamber. A convection coil is connected to ports $\mathrm{E}$ and $\mathrm{F}$, and hooked to a constant temperature bath and is used to control the initial temperature of the water. The upper chamber is bolted to the butterfly valve through a flange $F$.

(iv) Mid-Section Butterfly Valve

A pneumatic controlled 2-1/2 inch size 316 stainless steel butter-fly valve, shown in Figure 6 , separates the lower reaction chamber from the upper collection chamber. The valve is an ANSI class 300 high temperature valve. The valve was chosen due to its negligible leakage characteristic, sealing capacity and cycle time $(250 \mathrm{~ms})$. The upper and lower sectons of the 


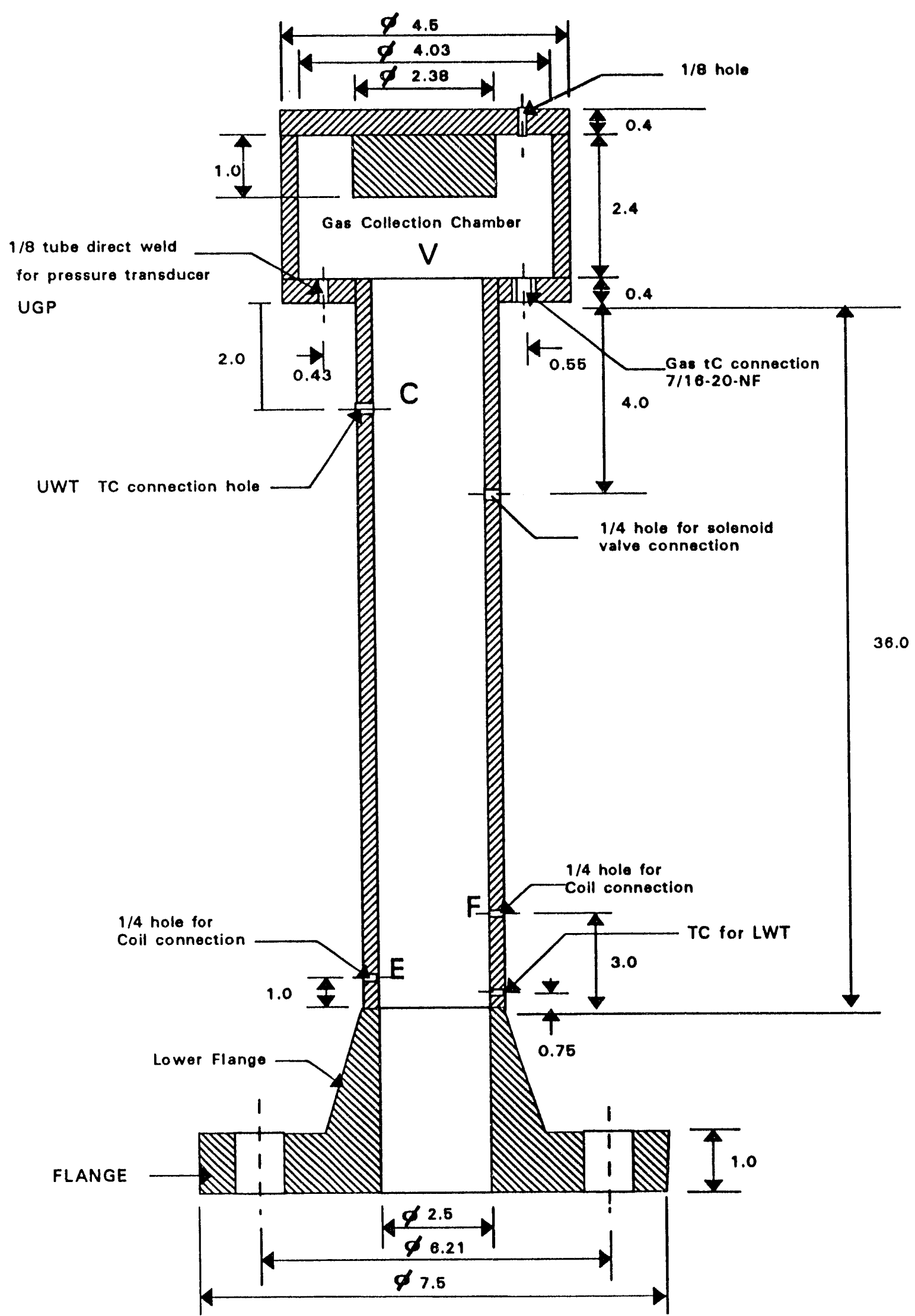

All dimensions in inches

Figure 5 Details of Upper Vessel 

apparatus are connected to the butterfly valve through a flange with grafoil gaskets used to prevent leakage. The flange connection also facilitates easy disconnection of the lower portion of the apparatus for the purpose of loading and unloading the liquid-metal into and out of the vessel in a glove box. To ensure that the butterfly valve and its actuator are operated within their specified temperature range, the valve section is water-cooled internally as described earlier.

\section{(v) Design of Convection Coil}

The experimental determination of the rate of hydrogen production during Lithium-Lead/Water reaction involves two distinct stages, the heating stage and the reaction stage. During the heating stage, the lower portion of the apparatus is electrically heated to melt the lithium-lead and to bring it to the required initial temperature $\mathrm{T}_{\mathrm{LM}}$. The reaction stage begins when the butterfly valve is opened and water from the upper chamber makes contact with the liquid metal in the lower section. This stage ends when the butterfly valve is closed at the end of a pre-determined reaction time, $t_{R}$. During the heating stage, it is important to ensure that both the butterfly valve and the electrical resistance heating elements are maintained within their stated operating temperature range. It is also important to ensure that right size heaters and adequate insulation is provided to obtain a reasonable heating time (30-45 minutes). These require that a heat transfer analysis be done at the early design stages of the system to ensure that the system under design will satisfy the required constraints. A two-dimensional finite element analysis has been used to analyze the heat transfer characteristics of the lower portion of the apparatus during the heating stage. During the heating stage of the experiment, heat is transfered from the lower chamber to the upper chamber, and subsequently by convection to the water in that chamber. 
This heat has to be removed to maintain a constant water temperature in the upper chamber. The description below gives summary of analysis performed to ensure that the convection coil selected has adequate heat transfer area to remove this heat. Finite element analysis described earlier indicated a total of 375 Watts of heat will have to be removed. Based on this a number of constant temperature baths were reviewed to provide the cooling capacity and flow. Also the pump characteristics of the baths were noted. From the experimental test matrix given earlier in Table 1, the temperature of the pool of water outside the coil ranges from $60^{\circ} \mathrm{C}$ to $90^{\circ} \mathrm{C}$. The above information, together with an assumed bulk inlet temperature of $5^{\circ} \mathrm{C}$ at the inlet of the coil were used to estimate the heat transfer area, the length of tube required, the head loss in the cooling coil circuit and the flow rate for the given system characteristics. The results of the coil design calculator are summarized in Table 3.

Figure 7 shows a partial assembly of the furnace, the lower reaction chamber, the mid-section pneumatic controlled butterfly valve, the cooling coil and the upper collection chamber.

\section{E. Initial Testing of Intermediate Experimental System}

In July 1992, the assembly of the experimental setup shown in Figure 7 was completed. The first test performed was the system pressure tests, and during this test, it was found that the system could not hold pressure. Systematic pressure test performed on the individual component 
Table 3 Design Specifications for Cooling Coil

\begin{tabular}{|l|l|}
\hline Tube Material & 316 Stainless Steel \\
\hline Tube Inside Diameter & $3 / 16$ Inch \\
\hline Tube Outside Diameter & $1 / 4$ Inch \\
\hline Minium Tube Length Required & 28 Inches \\
\hline Design Tube Length & 40 Inches \\
\hline Mean Coil Diameter & $13 / 8$ Inches \\
\hline Bulk Fluid Inlet Temp & $5^{\circ} \mathrm{C}$ \\
\hline Flow Rate Through Tube & 5 Liters/Min \\
\hline
\end{tabular}




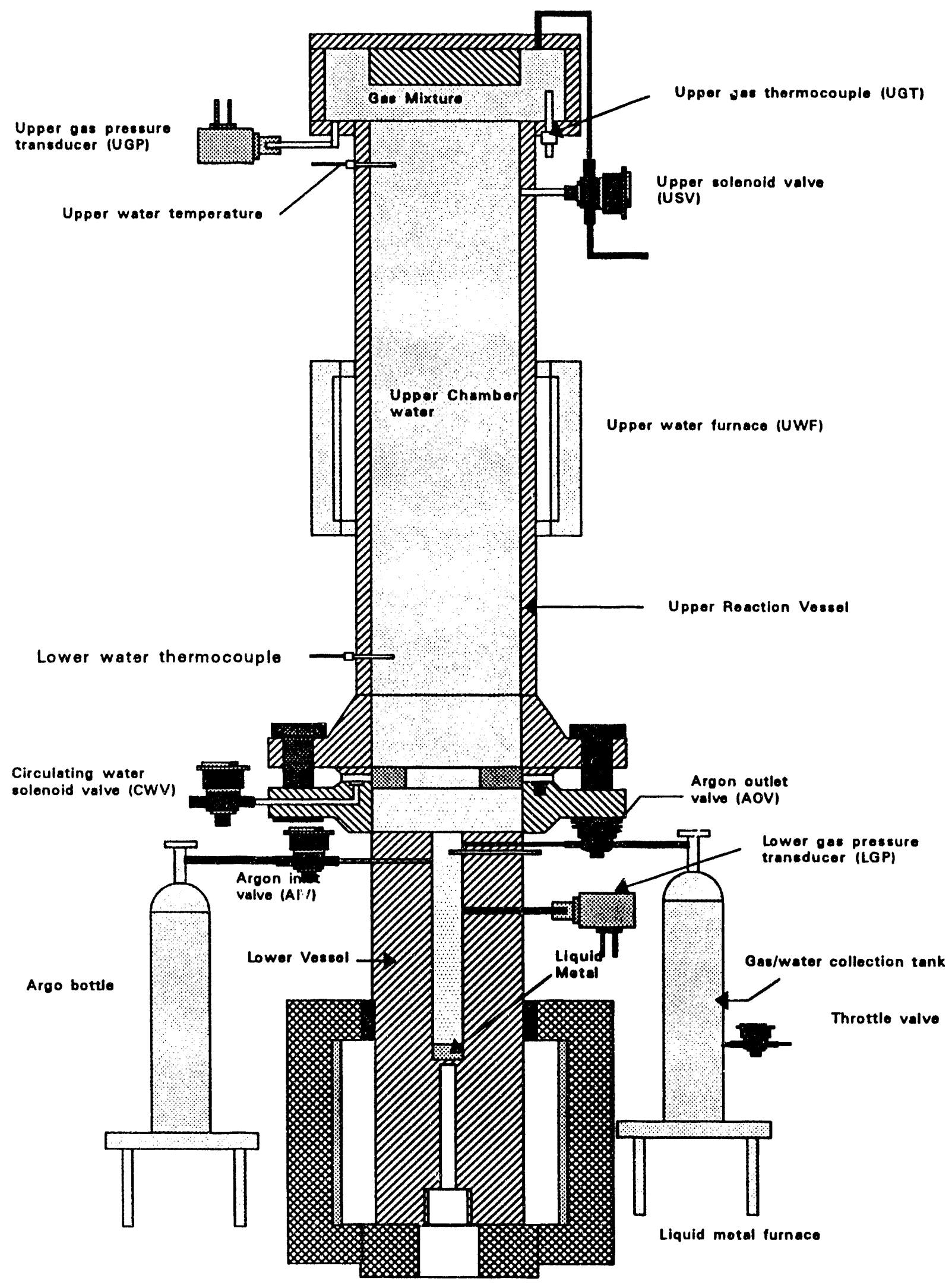

Figure 7 Partial Assembly of Preliminary System 
indicated a welding imperfection on the cooling coil. It was also found that the butterfly valve had a higher leakage rate than specified. The failure of the butterfly valve to perform to specification was a big blow to the progress of the research. A represenative of the valve manufacturer was brought on sight and upon inspection, found the valve to be defective. The manufacturer recommended the use of a zero-leak all sainless steel Vitron ball valve. It was

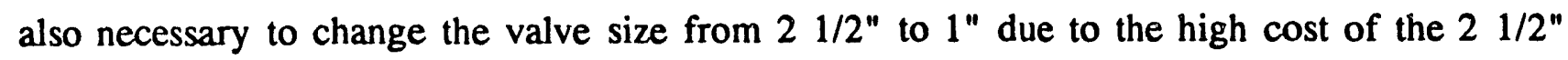
Vitron ball valve. This valve was ordered to be manufactured in August 1992. The new valve was not received until December, 1992. Upon inspection, it was found that a wrong valve stem length was attached. It was returned to the manufacturer. The final valve with the right specification was received in January 15, 1993. As a result of a change in valve size from 2 $1 / 2$ inches to 1 inch, several modifications had to be made in both the lower and upper vessels.

\section{F. Final Experimental System Design}

A new upper vessel was designed and fabricated to match the new valve between January 15 th and March 1, 1993. Several modifications were made in the lower vessel to fit the new valve. Figure 8 shows the details of the modified lower vessel. Due to the reduction in size of the valve and its flanges the details of the internal cooling was modified as shown in the Figure 8. Figure 9 shows the details of the final upper chamber design. The enlarged section previously on top of this chamber was eliminated to reduce fabrication cost and for simplicity. All the good leakage prevention features in the preliminary design were retained in this final design. The new experimental design has been assembled and all instrumentation attached. Figure 10a shows a schematic assembly of the final experimental system. Figure 10b shows 

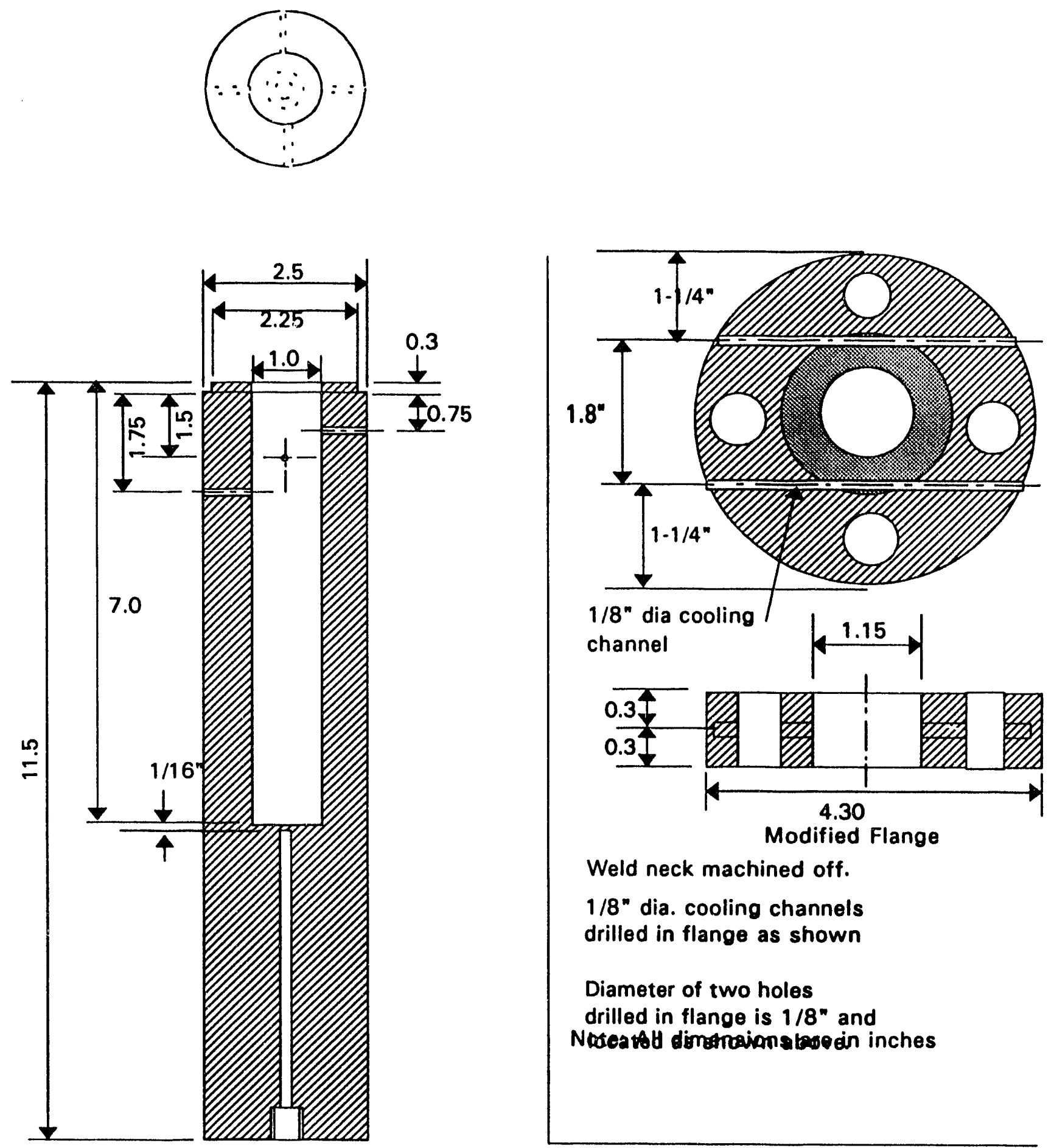

Weld neck machined off.

$1 / 8^{\prime \prime}$ dia. cooling channels drilled in flange as shown

Diameter of two holes drilled in flange is $1 / 8^{\prime \prime}$ and

Noreatat dimotraionatoogin inches

Figure 8 Final Design Details of Lower Vessel 


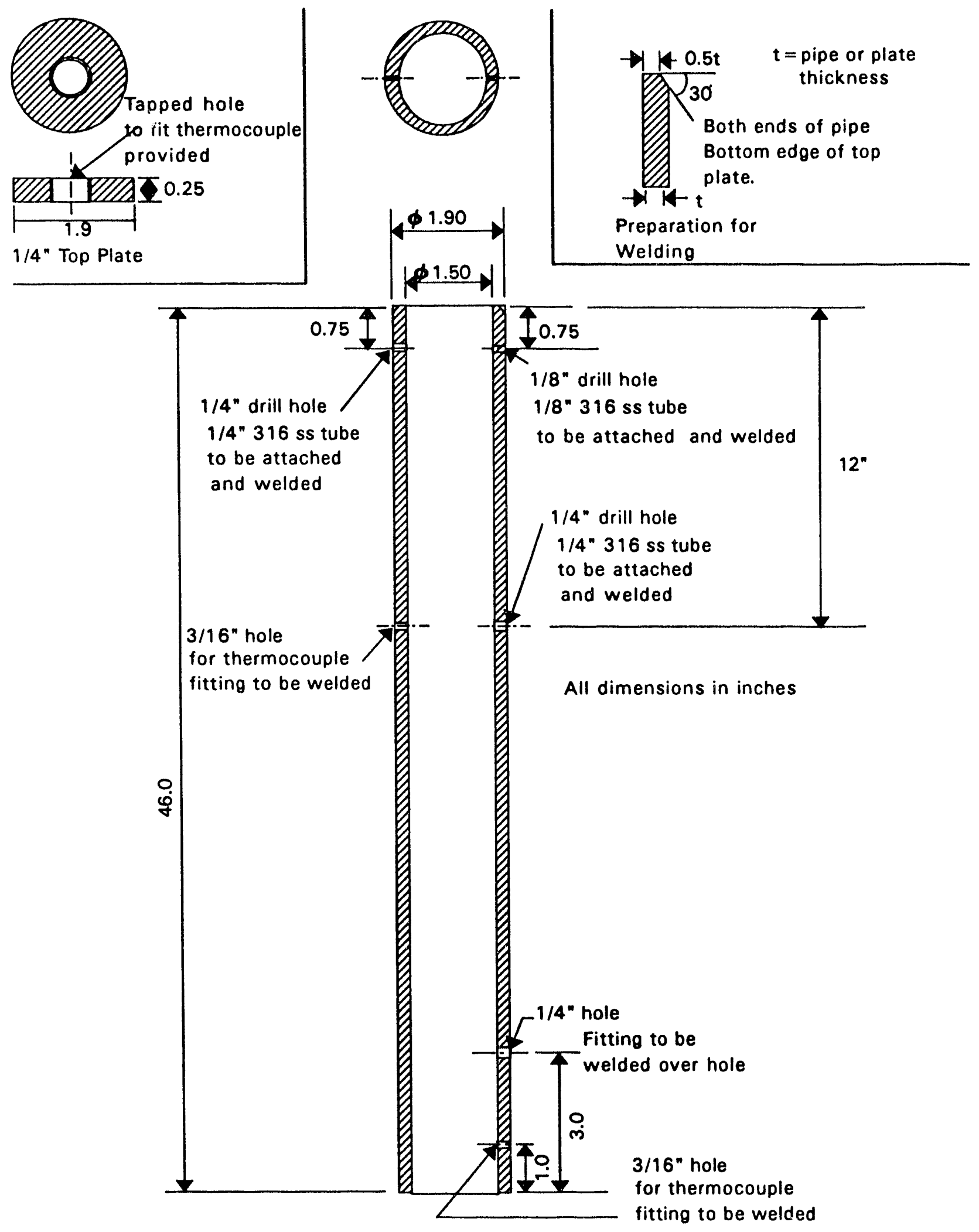

Figure 9 Final Design Details of Upper Vessel 


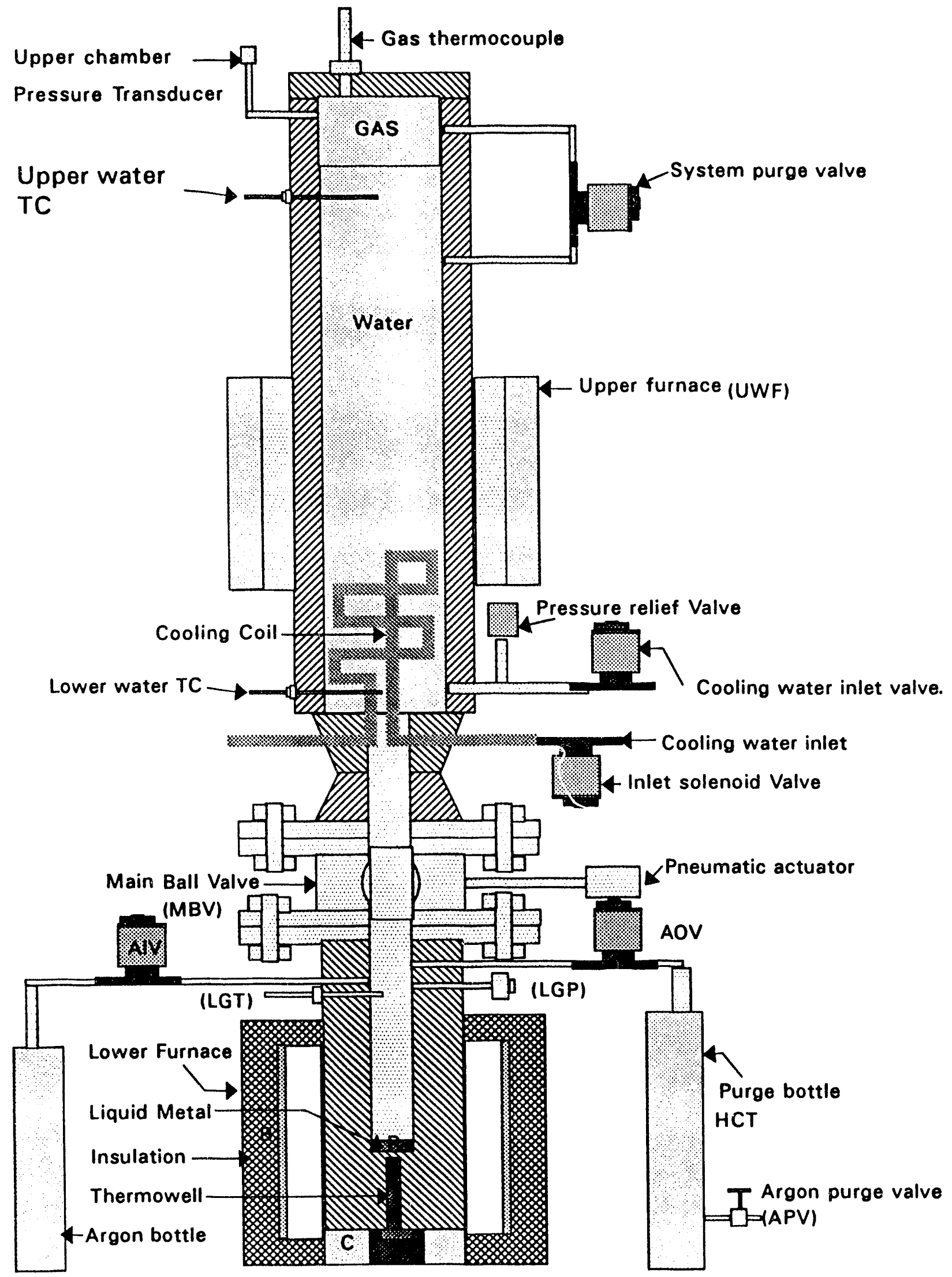

Figure 10a Assembly of Final Experimental System 


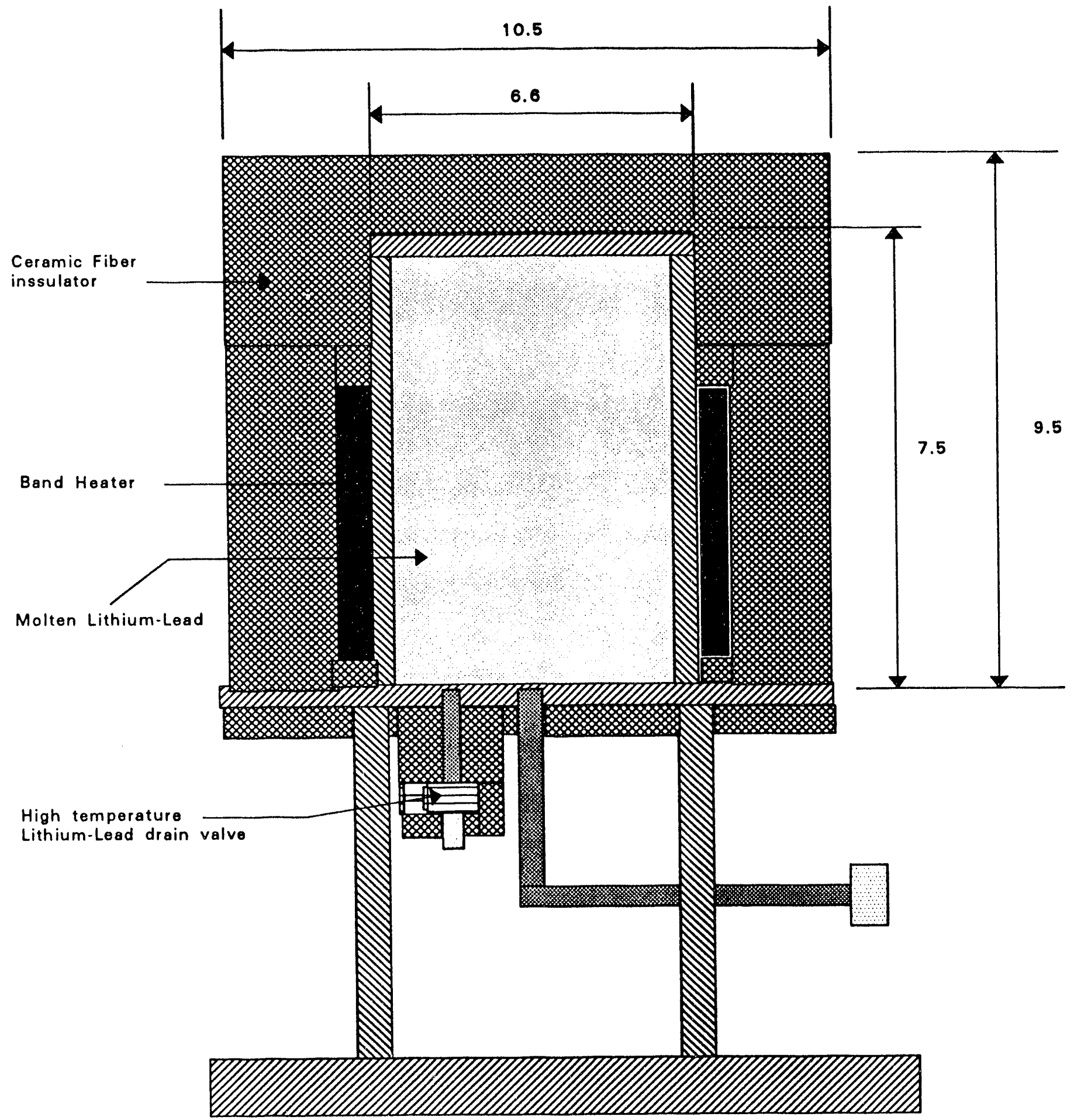

Figure 10-b Apparatus for Melting and Casting Molten Lithium-Lead 
photographs of the system, the control panel and the data acquisition and control sytems when they were being assembled.

\section{G. Operation of Final Experimental System}

Figure 10a shows a partial assembly of the system. The furance sections, the lower section, and the upper sections have been previously described. During the liquid metal heating phase of the experiment, the furnace is on, and the sample of lithium lead in lower reaction chamber $\mathbf{R}$ is heated to a predetermined temperature. The main ball valve is closed and argon flows through the Argon Inlet solenoid valve (AIV) through the lower chamber and exits through the argon outlet solenoid valve (AOV). The argon purge valve (APV, is also opened and the system pressure in the lower chamber monitored by the lower gas pressure transducer (LGP) and temperature by lower gas temperature thermocouple (LGT). A 60 seconds count down time is planned prior to the opening of the main ball valve. At the beginning of this count down period, valves AIV and AOV are closed to stop the argon flow at which time pressure transducer LGP and thermocouple LGT monitor the pressure and temperature of the closed lower argon space in the lower chamber. Data obtained during this countdown phase is used to determine the mass of argon in the lower chamber. At the end of the countdown period, valve APV is closed, the main ball valve (MBV) is opened and reaction between the lithium-lead and water is initiated. The reaction is made to continue for a pre-determined period of time $\left(t_{R}\right.$ after which the butterfly valve is closed, Valvse AOV opened and APV closed. Any hydrogen produced after that time is made to flow into a collection tank (HCT). During the reaciton period, the hydrogen produced collects above the water in the upper chamber, where the temperature and 
pressure are measured by UGT and UGP respectively. The timing, sequencing and control of all the solenoid valves and the pneumatic controlled butterfly valve are done through Keithly Measurement and Control System Model 575-2.

H. Lithium Lead Processing and Handling

Lithium-lead metal was received in December 1992 from Oakridge National Lab in a 1 gallon container. In March 1993, a heater and valve system were assembled on the lithium lead container. Figure 11 shows the schematic design of the melting system. We attempted to melt and cast the metal into small discs under argon atmosphere, ready to be used in the experiments. The metal was heated to about $400^{\circ} \mathrm{C}$ and after casting some few discs, the valve failed and the liquid metal poured into the glove box uncontrollably. This damaged the rubber gloves enabling air to enter the chamber, causing the molten metal to be contaminated.

We are currently awaiting for new supply of the lithium lead from Oak Ridge Naional Lab to continue and complete the work. 

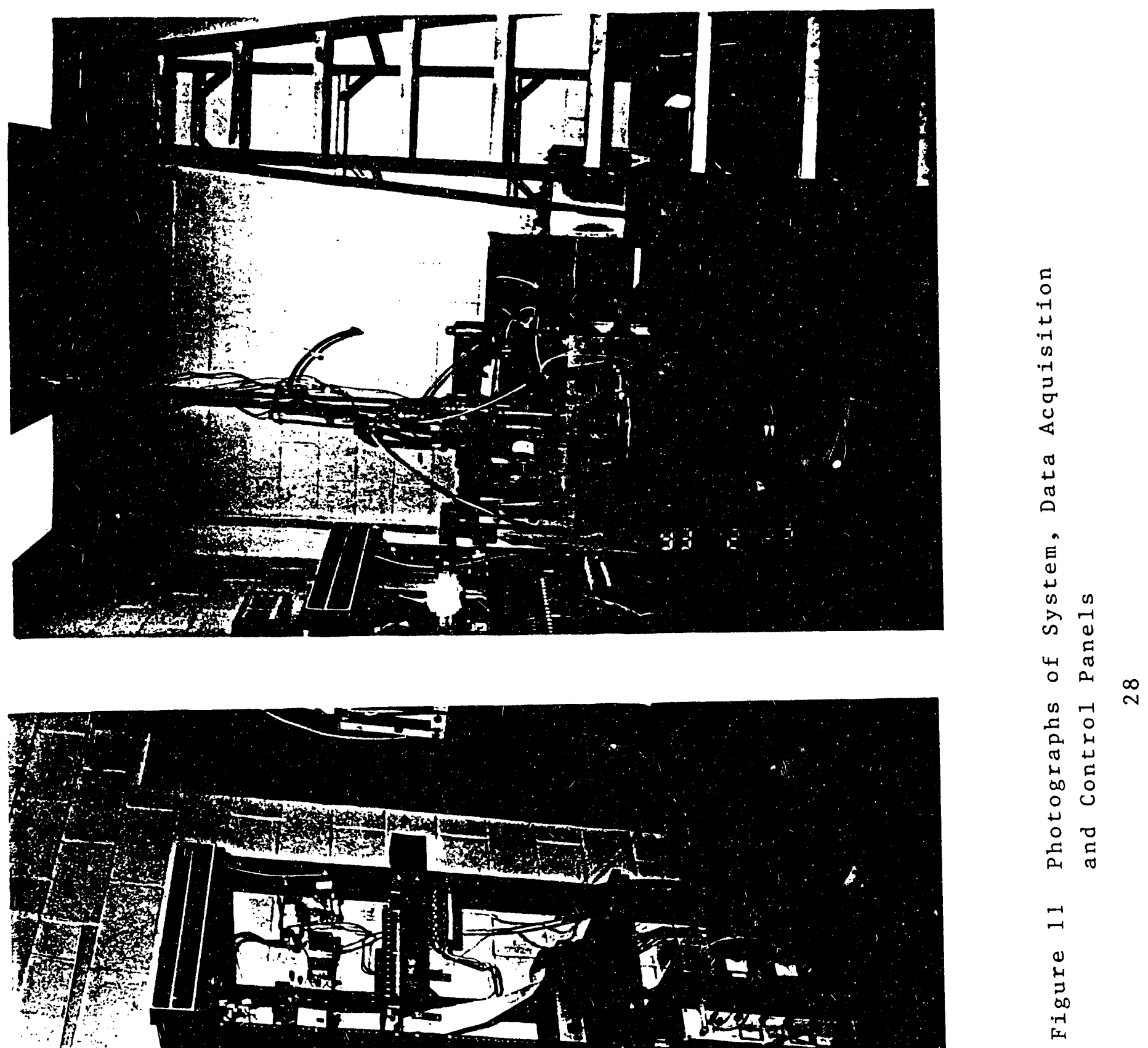


\section{DATA ACQUISITION AND CONTROL HARDWARE}

In this chapter, the hardware used for the acquisition of data and control of the experiment are described.

At the heart of the data acquisition and control system is a Keithley Model 575-2 Measurement and Control unit shown in Figure 12. A summary of the analog input/output and digital input/output features of the unit are given in Tables 4 and 5 respectively. Sixteen of the 32 digital input/output channels are dedicated for power control of on/off devices including all solenoid valves and the ball valve through the use of a power control module and relay board. The power control module (PCM-3) is a general purpose remote relay card for the control of power AC and DC devices. It permits direct interface of relays, heaters, meters, actuators, and other $\mathrm{AC}$ and $\mathrm{DC}$ devices over the full range of voltages from 10 to $280 \mathrm{~V}$. A 16-channel thermocouple module capable of handling J,K,S,T,B,E and R single or mixed thermocouples and having an iso-thermal block is used for all temperature measurements. Figure 13 Shows the simplified schematic control diagram. The solid state relays SSR-0 through SSR-6 are operated through software, (the Data Acquisition and control program (DACP) developed for this work) and serve as the main on-off switches for all equipment. 


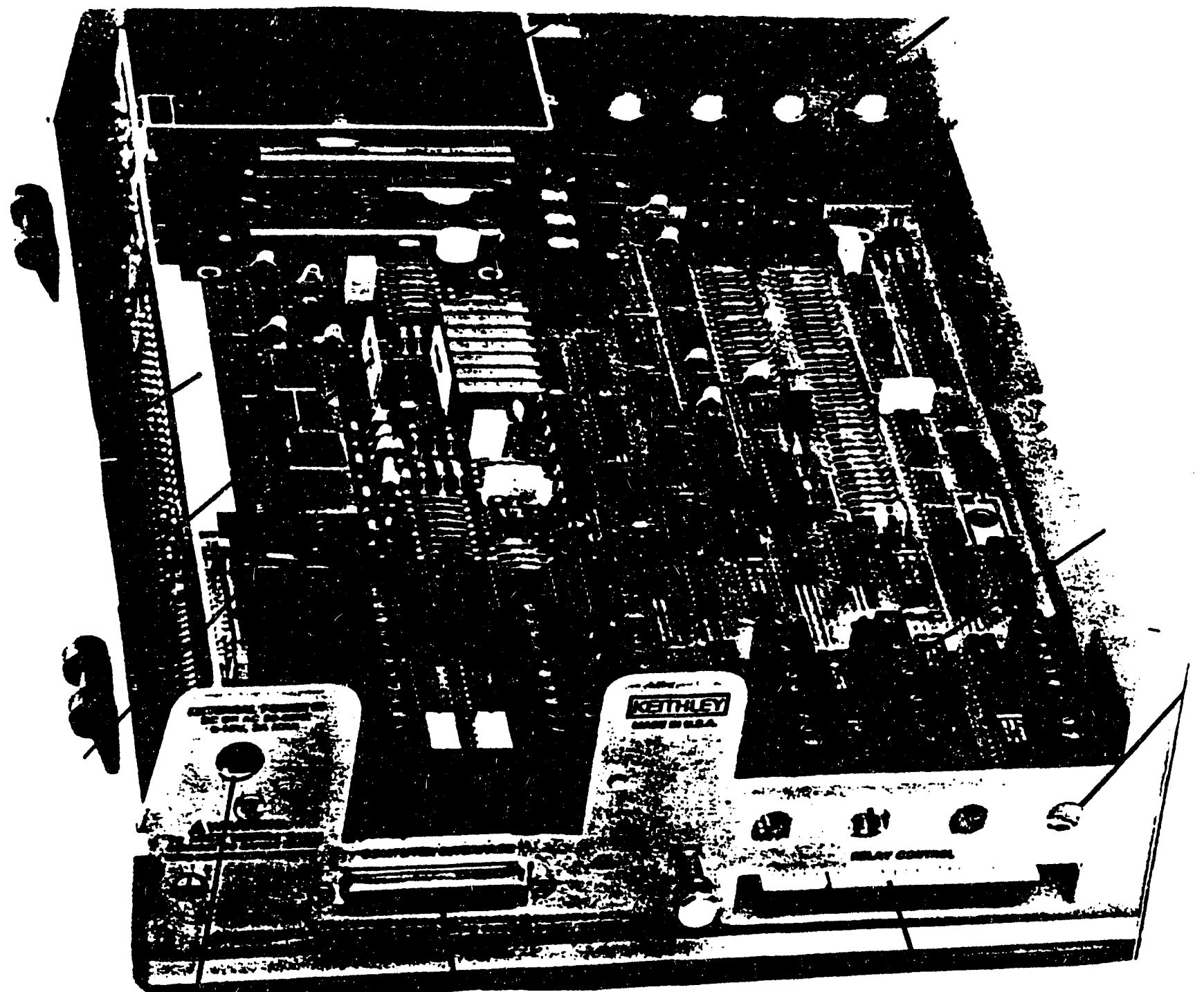

Figure 12 Data Acquisition and Control system 
Table 4 Analog Input/Output Features of Data Acquisition and Control System

\begin{tabular}{|l|l||}
\hline Feature & Description/Range \\
\hline SPEED & 50,000 READINGS/S \\
RESOLUTION & $16 \mathrm{BITS}$ \\
FULL SCALE RANGES & $+100 \mathrm{mV},+200 \mathrm{mV},+500 \mathrm{mV}$ \\
& $+1 \mathrm{~V},+2 \mathrm{~V},+5 \mathrm{~V},+10 \mathrm{~V}$ \\
CHANNELS & 8 DIFFERENTIAL \\
& 16 SINGLE ENDED PLUS \\
& 8 ADDITIONAL SINGLE ENDED \\
& \\
ANALOG OUTPUT & 2, SINGLE ENDED \\
CHANNELS & $+10 \mathrm{~V},+5 \mathrm{~B},+2 \mathrm{~V},+1 \mathrm{VITS}$ \\
OUTPUT RANGES & 13 RSOLTION
\end{tabular}


Table 5 Digital Input/Output and Power Control Features of Data Acquisition and Control System

\begin{tabular}{|c|c|}
\hline Feature & Description/Range \\
\hline CHANNELS & $\begin{array}{l}32 \text { NON-ISOLATED, } \\
\text { PROGRAMMABLE FOR INPUT OR } \\
\text { OUTPUT IN GROUPS OF } 8 \\
\text { CHANNELS. } 16 \text { CHANNELS CAN } \\
\text { DRIVE POWER CONTROL RACK } \\
\text { FOR ON/OFF CONTROL OF POWER } \\
\text { DEVICES. }\end{array}$ \\
\hline TRIGGER FUNCTIO & \\
\hline CHANNELS & 1, DIFFERENTIAL INPUT \\
\hline TRIGGER SOURCE & $\begin{array}{l}\text { EXTERNAL INPUT, ANY INPUT } \\
\text { CHANNEL, OR SOFTWARE STORBE. }\end{array}$ \\
\hline RANGES & $\begin{array}{l}0 \mathrm{TO}-10 \mathrm{~V}, 0 \mathrm{TO}-\mathrm{IV}, 0 \text { TO } 10 \mathrm{~V} \\
0 \mathrm{TO}-10 \mathrm{~V}\end{array}$ \\
\hline RESOLUTION & 8 BIT \\
\hline INPUT COUPLING & AC OR DC \\
\hline
\end{tabular}




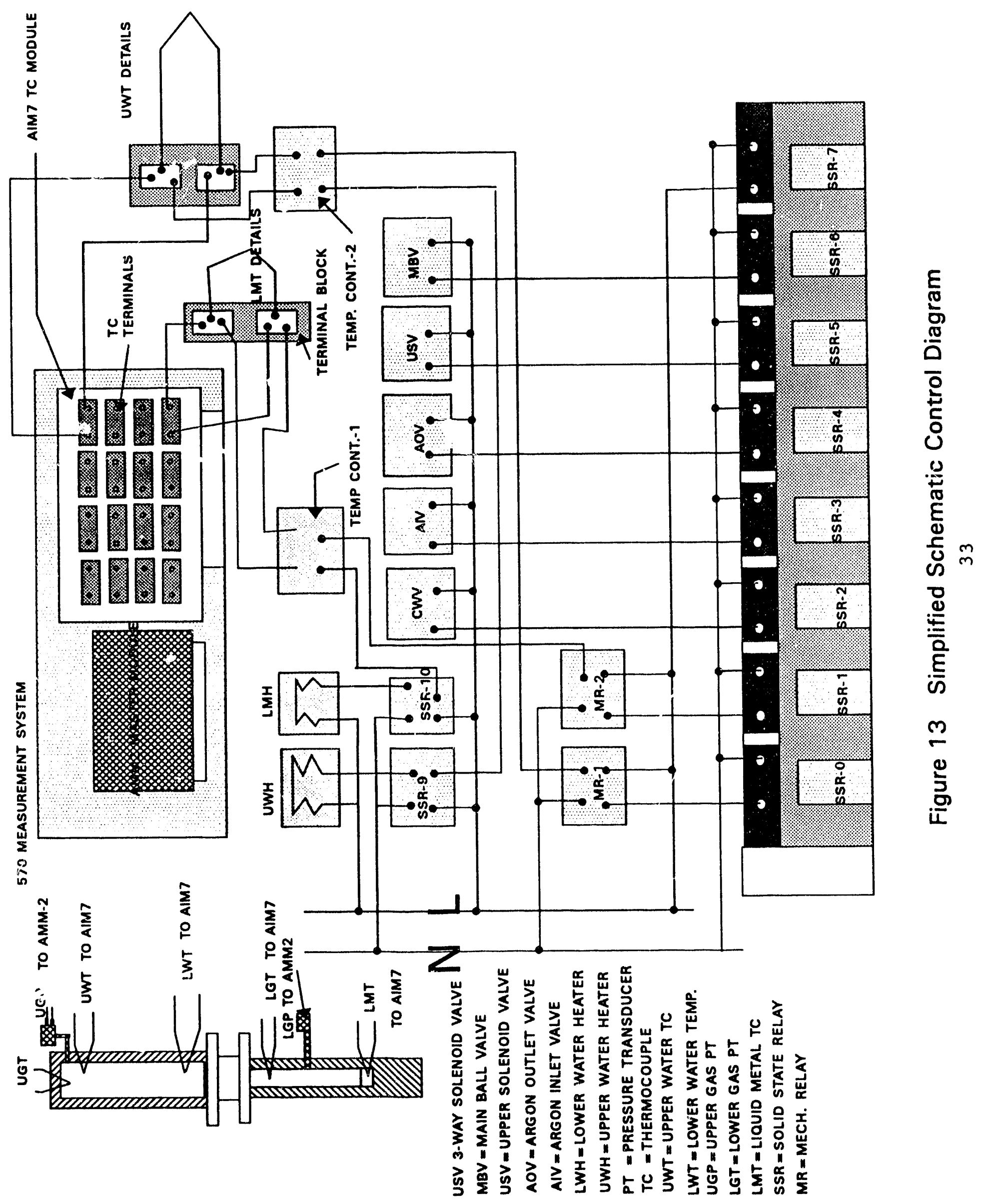




\section{A. Control of Solenoid Valves}

Relays SSR-2 though SSR-6 contrc' the on-off states of the cooling coil/flange circulating water (CWV), the argon inlet valve (AIV), the argon outlet valve (OAV), the upper-purge valve (UPV), and the main ball valve (MBV) respectively. The sequencing timing and duration of operation of these valves are done through DACP.

\section{B. Control of Liquid Metal Temperature}

Liquid metal thermocouple (LMT) reads the liquid metal temperature. LMT terminates on a terminal strip from where two sets of thermocouple extension wires take off, one set to a temperature controller (Temp. Cont.-1) and the other set to the temperature measurement module in the 575-2 DAC System. The preset liquid metal temperature is programmed into Temp. Cont. -1 , and this controller uses the temperature output of the LMT to control the liquid metal heater $\mathrm{LMH}$, and thus the liquid metal temperature. LMH could not be directly connected to SSR-1 due to the high current pulled by the heater. High line curent solid state relay (SSR-10) was initially connected between SSR-1 and the heater, thereby enabling SSR-1 to emergize SSR10 to turn the LMH on. That arrangement did not work due to the leakage current of the two solid state relays SSR-1 and SSR-10. It became necessary to install a mechanical relay MR-2 between SSR-1 and SSR-10. The signal to energize SSR-1 is obtained from the temperature reading on the lower fumace thermocouple (LFT) which reads the heater surface temperature that has been preset to protect the heater element from overheating. As long as the experiment has been initiated and LFT is below the setpoint, the DAP energizes SSR-1 which in turn energizes MR-2 and MR-2 energizes SSR-10. The dynamic control of liquid metal temp through 
on/off power regulation of LMT is done by the programmable temperature controller Temp. Cont.-1.

C. Control of upper water temperature

The control of the upper water temperature is identical to the control of the liquid metal temperature. The solid state realys involved are SSR-0, MR-1, SSR-9 and temperature controller T-C2. The thermocouples involved are the upper water thermocouple (UWT) and the upper furnance thermocouple (UFT)

D. Pressure Transducers

Two pressure transducers are used to measure the major pressures of the system. As shown in Figure 10-a.

\section{(i) Upper Chamber Pressure}

The upper chamber system pressure is the pressure of the gas mixture above the water level in the upper chamber and it is measured by a high accuracy Setra absolute pressure transducer (UGP). The 0-5 VDC linear output of the transducer is connected to the 575-2 DAC system and converted to kilopascals by DACP. This transducer requires 15-24 Volts DC Supply for excitation.

(ii) Lower Gas Pressure

The lower gas pressure is the pressure of the argon gas in the space between the main ball valve 
and the liquid metal as shown in Figure 10-a. This pressure is used in conjunction with the temperature of the gas in that chamberand the total volume of the chamber to calculate the amount of argon gas initially in the system. This pressure is measured by a Setra absolute pressure transducer (LGP). The 0-5 VDC linear output is also converted to kilopascals by the DACP through the 575-2 DAC system. 


\section{CALIBRATION AND TESTING OF EXPERIMENTAL HARDWARE}

\section{A. Initial System Test}

The initial system tests performed include check of continuity of all electrical connections, testing of all instruments with and without the use of data acquisition and control system, calibration of upper and lower vessel volumes.

\section{B. Calibration of Upper Gas Volume}

In order to obtain an accurate measurement of the gas space above the water in the upper chamber, it was necessary to accurately calibrate or calculate the volume and to determine the mean and standard deviation of the measurement for statistical analysis of the final experimental data. Figure 14 shows the experimental set up for calibration of the upper gas volume. With the upper solenoid valve (USV) closed, upper pressure transducer (UGP) and upper gas thermocouple (UGT) removed, the upper chamber is filled (through valves A and B with water until the system is completely filled. The chamber is slowly drained through valves A and B into a finely graduated cylinder. The volumes and mass of water collected at different water levels on finely graduated indicator on thye upper chamber are recorded. The measured results are then compared to the calculated results obtain from dimensions of the vessel and tubes. Table 6 summarizes the results of the upper chamber calibration tests. The experimental values of the volumes agree well with those calculated using vessel and tube dimensions. In the useful water level range of 0-9 inches, the maximum standard deviation is 


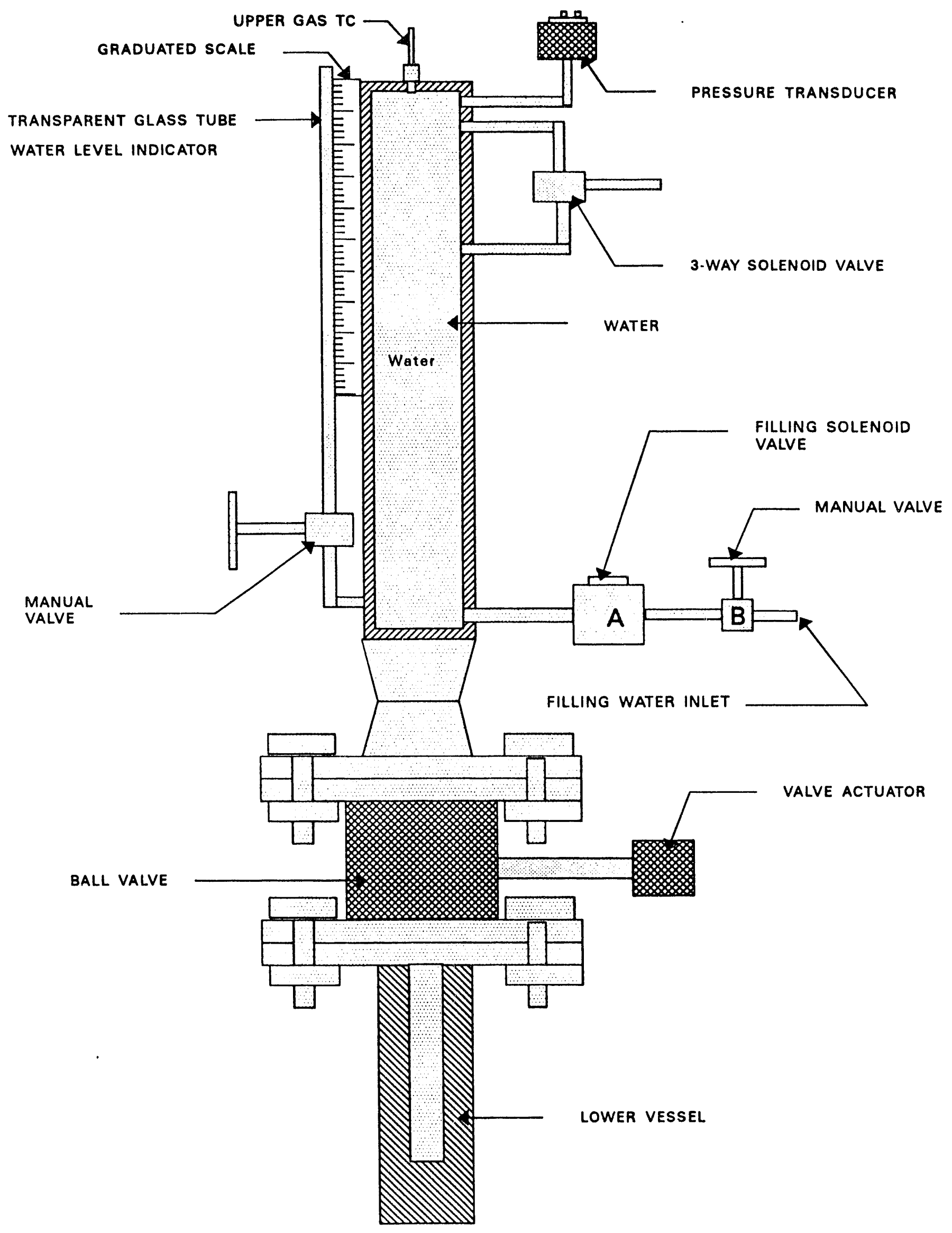

Figure 14 Setup for Calibrating Upper Gas Volume 
Table 6 Summary of Upper Chamber Calibration Results

\begin{tabular}{||l|l|l|l|l|l|l||}
\hline $\begin{array}{l}\text { Water } \\
\text { Level } \\
\text { Inches }\end{array}$ & $\begin{array}{l}\text { Expt } \\
\text { Volume } \\
\text { CC }\end{array}$ & $\begin{array}{l}\text { Expt } \\
\text { Volume } \\
\text { CC }\end{array}$ & $\begin{array}{l}\text { Expt } \\
3 \\
\text { Volume } \\
\text { CC }\end{array}$ & $\begin{array}{l}\text { Calculated } \\
\text { Volume } \\
\text { CC }\end{array}$ & Mean & $\begin{array}{l}\text { Standard } \\
\text { Deviation }\end{array}$ \\
\hline 1 & 29.0 & 28.5 & 28.5 & 27.93 & 28.48 & 0.14 \\
\hline 2 & 57.5 & 58.0 & & 56.88 & 57.26 & 0.25 \\
\hline 3 & 86.0 & 86.5 & 86.5 & 85.85 & 86.21 & 0.09 \\
\hline 4 & 114.5 & 115.5 & 115.1 & 114.80 & 114.98 & 0.14 \\
\hline 5 & 144.0 & 144.0 & 143.1 & 143.76 & 143.84 & 0.03 \\
\hline 6 & 172.5 & 173.0 & 172.5 & 172.72 & 172.68 & 0.04 \\
\hline 7 & 201.5 & 202.0 & 201.5 & 201.68 & 201.67 & 0.04 \\
\hline 8 & 230.0 & 230.5 & 230.0 & 230.64 & 230.29 & 0.08 \\
\hline 9 & 259.5 & 260.5 & 258.5 & 259.60 & 259.53 & 0.50 \\
\hline 10 & 285.0 & 286.0 & 286.3 & 288.55 & 286.46 & 1.68 \\
\hline 11 & 315.5 & 316.5 & 315.5 & 317.51 & 316.25 & 0.69 \\
\hline 12 & 346.0 & 346.0 & 344.0 & 346.47 & 345.62 & 0.91 \\
\hline 13 & 375.5 & 375.5 & 373.0 & 375.43 & 374.86 & 1.15 \\
\hline
\end{tabular}


$0.5 \mathrm{cc}$. Thus all upper gas volumes will be repeated as $\mathrm{xxx} . \mathrm{xx}+0.50 \mathrm{cc}$. The total volume of the space in upper chamber was measured to be $1386 \mathrm{cc}$. The calculated value obtained from system dimensions is $1388 \mathrm{cc}$. The volume used in all calculations is the average of the two, $1387.6 \mathrm{cc}+1 \mathrm{cc}$.

The total vaolume of space in the lower chamber below the main ball valve (when in closed position) was to be $114.2 \mathrm{cc}$ and the calculated valve is $114.3 \mathrm{cc}$. This volume is repeated as 114.25. The total volume of space in the lower chamber with the ball valve opened (volume in ball included) is $137.1 \mathrm{cc}$.

\section{Upper Chamber Pressure Test}

Two pressure tests were performed on the upper chamber to check for leakages and the ability of the vessel to hold pressure. In the first test, with the ball valve closed the upper vessel was pressurized to $650 \mathrm{kPa}$. The pressure was monitored for three hours. The total pressure drop during this period was $5.5 \mathrm{kPa}$.

In the second test, the upper chamber was filled with water to a level just below the purge line and the system pressurized to $650 \mathrm{kPa}$. After three hours, the pressure drop was $0.52 \mathrm{kPa}$, well within the tolerance of the pressure transducer accuracy. Froom the pressure test, we were satisfied with the ability of the experimental set-up hold pressure over extended period of time. 


\section{DATA ACQUISITION PROGRAMS AND METHOD OF EXPERIMENTAL ANALYSIS}

\section{A. Data Acquisition and Control Program}

A brief description of the important features of a basic program for acquisition and control of the experiment is described in this section. The important equipment to be controlled are connected to relays on a Keithley PCM3 Relay Board. Table 7 gives the description of the relay connections. Seven thermocouples (TC) are installed in the system and directly connected to the thermocouple module (AIM7). Two extension wires carry signals from the liquid metal TC temperature and the upper water temperature TC to two temperature controllers. Table 8 givesa summary of thermocouples and channel connections. The two setra pressure transducers are directly connected to the AMM2 master module. Each experiment is divided into six phases, and Table 9 gives the summary of the important features of these phases.

\section{Phase 1}

During this phase, the upper water, the liquid metal heater and the circulating bath are turned on to heat the water in the upper chamber to a pre-determined temperature at which time a vacuum pump is used to control the pressure to obtain a saturated liquid in the upper chamber.

\section{Phase 2}

This phase involves activation of the liquid metal heater and the liquid metal heated to a predetermined temperature. 
Table 7 Summary of Controlled Equipment and Relays

\begin{tabular}{|c|c|l||}
\hline Relay Number & Input/Output Name & $\begin{array}{c}\text { Description of Equipment } \\
\text { Attached }\end{array}$ \\
\hline 0 & UWH & Upper water heater \\
Liquid metal heater \\
2 & LWH & Circulating water valve \\
3 & AIV & Argon inlet valve \\
4 & AOV & Argon outlet valve \\
5 & USV & Upper solenoid valve \\
6 & MBV & Main ball valve \\
\hline
\end{tabular}


Table 8 Summary of Thermocouples and Channel Connections

\begin{tabular}{|l|c|c|c|}
\hline Description & $\begin{array}{l}\text { Input/Output } \\
\text { Names }\end{array}$ & Channel Number & Thermocouple type \\
\hline Upper Gas Temp. & UGT & 1 & E \\
Upper Water Temp. & UWT & 2 & K \\
Upper Water Temp-C & Controller-2 & - & K \\
Lower Water Temp. & LWT & 3 & E \\
Lower Gas Temp. & LGT & 4 & K \\
Liquid Metal Temp. & LMT & 5 & K \\
Liquid Metal Temp-C & Controller-1 & - & K \\
Upper Furnace Temp. & UFT & 6 & K \\
Lower Furnace Temp. & LFT & 7 & \\
\hline
\end{tabular}


Table 9 Description of the Six Phases of

Each Lithium-Lead/Water Reaction Experiment

\begin{tabular}{|c|c|c|c|c|c|}
\hline \multirow[t]{2}{*}{ Phase \# } & \multirow[t]{2}{*}{ Phase Description } & \multirow{2}{*}{$\begin{array}{l}\text { Time Interval } \\
\text { Between } \\
\text { Readings } \\
\text { (Seconds) }\end{array}$} & \multirow{2}{*}{$\begin{array}{l}\text { No. of Data } \\
\text { Acquired } \\
\text { (Maximum) }\end{array}$} & \multicolumn{2}{|c|}{ Data } \\
\hline & & & & $\begin{array}{l}\text { Saved } \\
\text { for } \\
\text { Analysis }\end{array}$ & $\begin{array}{l}\text { Not } \\
\text { Saved }\end{array}$ \\
\hline 1 & Upper Water Heating & 20 & 100 & & $\mathbf{x}$ \\
\hline 2 & Liquid Metal Heating & 20 & 150 & & $\mathbf{x}$ \\
\hline 3 & Water \& Metal Temp. Control & 20 & 90 & & $\mathbf{x}$ \\
\hline 4 & Count down to Reaction & 1 & 60 & $\mathbf{x}$ & \\
\hline 5 & Chemical Reaction & .2 & 100 & $\mathbf{x}$ & \\
\hline 6 & Equilibrium Period & 20 & 100 & $\mathbf{x}$ & \\
\hline
\end{tabular}




\section{Phase 3}

This phase involves controlling the upper water and the liquid metal temperatures until they are within a given tolerance of their preset values. This step was found necessary for repeatability of the experiments to ensure an accurate generation of the reaction rate curves from different experiments with identical values of the liquid metal \& upper water temperatures. When these two temperatures are within their proper range, phase 4 is activated automatically by the DACP.

\section{Phase 4}

This is the count down phase. There is a 60 seconds countdown, during which all pressures and temperatures are read every 1 second and stored later. The average values of each set of reading is used to establish the initial conditions in the system. Particularly, the temperature and the pressure of the argon gas in the lower chamber, which is completely closed at this time, is used to determine the amount of argon in the system. At the end of the 60 seconds countdown, the fifth phase is initiated.

\section{Phase 5}

This phase, the reaction phase, begins with the automatic opening of the main ball valve, to initiate the reaction. The valve remains open for a preset reaction time period after which the valve closes, indicating end of reaction. All temperature and pressure readings are recorded and saved during the reaction phase. 


\section{Phase 6}

Phase 6 involves recording of pressure and all temperatures in the upper chamber for a period of 10 to 20 minutes or until the temperature in the chamber is uniform. The data at this phase is used to obtain the average value of the total amount of hydrogen generated during the reaction time period. Figure 15 gives a simplified flow chart of the Data Acquisition and Control Program. The complete program is given in Appendix C.

\section{B. Data Reduction and Analysis}

The data collected from the experiment, the physical inside dimensions of system, the leakage characteristics of the system and information on the solubility of Argon and hydrogen in water are used to determine the amount of hydrogen generated

during the reaction. This is done by accounting for all calculable components of pressure in the system.

(i) Mass of Argon before Reaction

The mass of argon in the system just before the reaction can be calculated from the equation

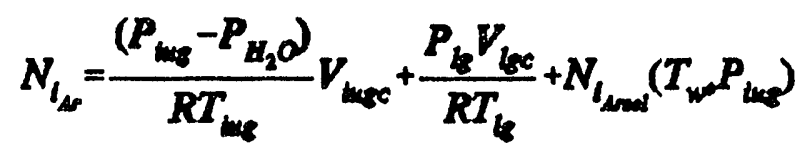



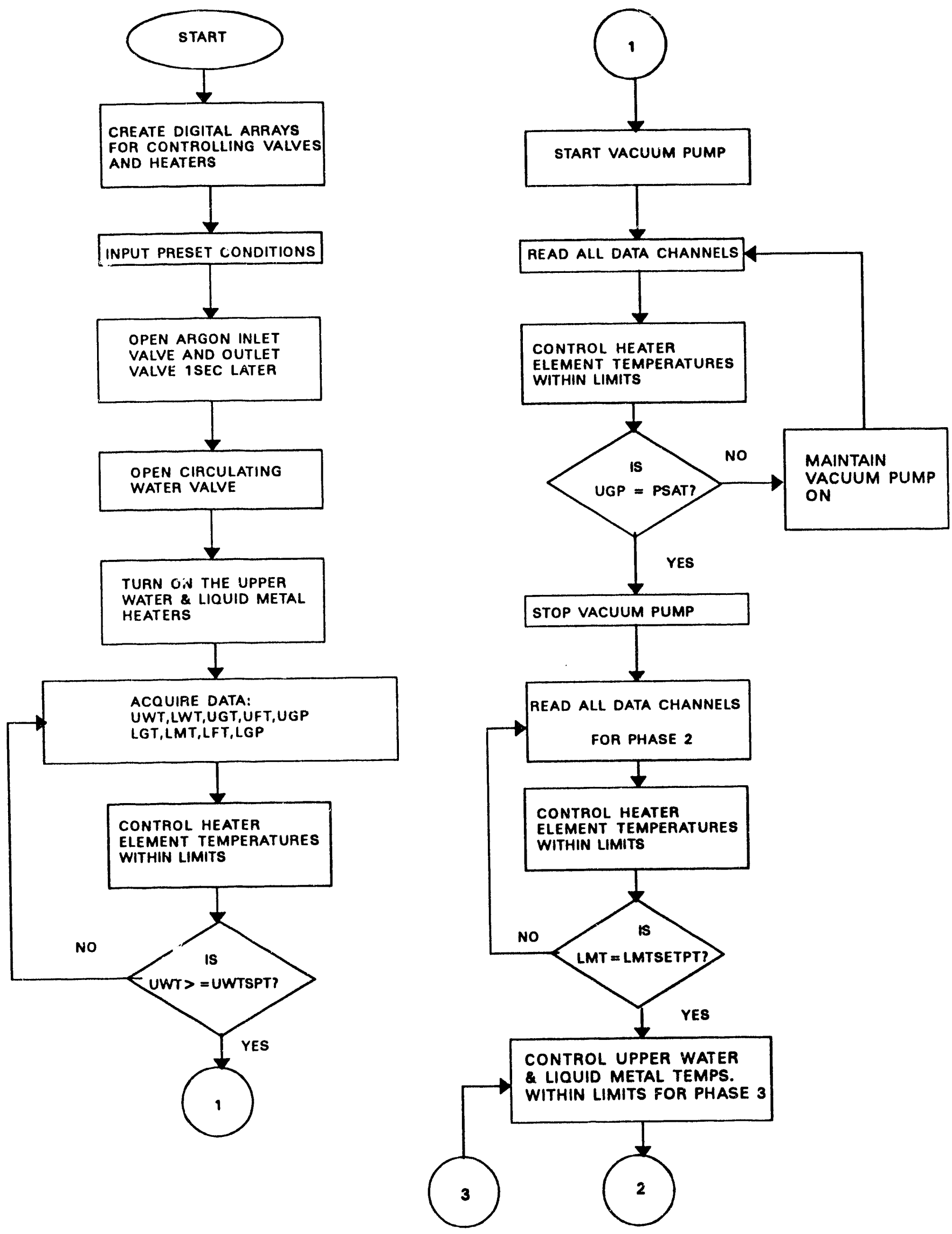

Figure 15 Simplified Flow Chart of Data Acquisition and Control Program 

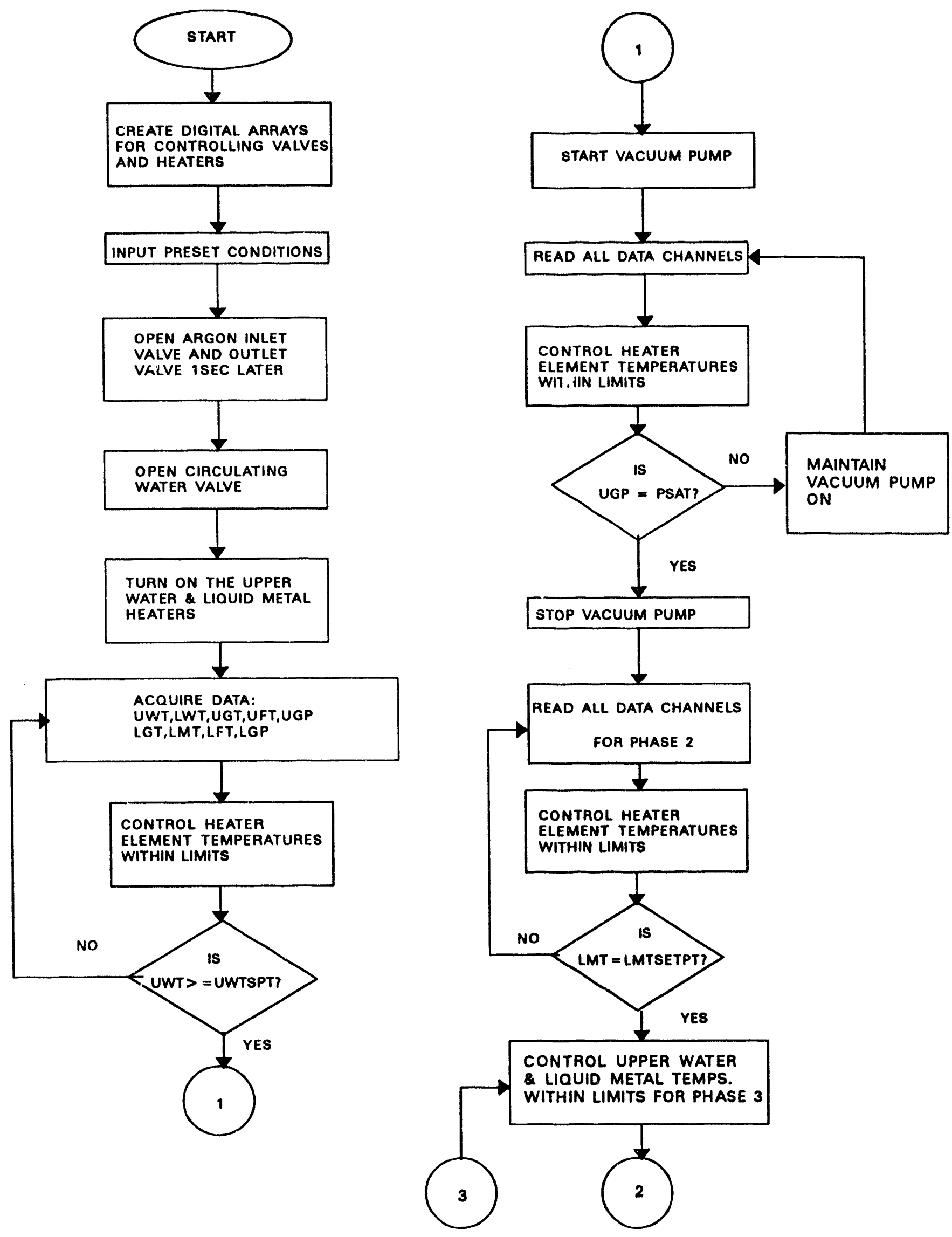

Figure 15 Simplified Flcw Chart of Data Acquisition and Control Program 


$$
N_{B_{2}}=0
$$

The amount of Argon in solution is calculated using information on the solubility of argon in water at $25^{\circ} \mathrm{C}$ and $1 \mathrm{~atm}$, and the fact that the soiubility reduces to zero at $T_{\text {sat }}=100^{\circ} \mathrm{C}$ and 1 atm. Thus by interpolation, the solubility of argon, $X_{A r}$ is given by

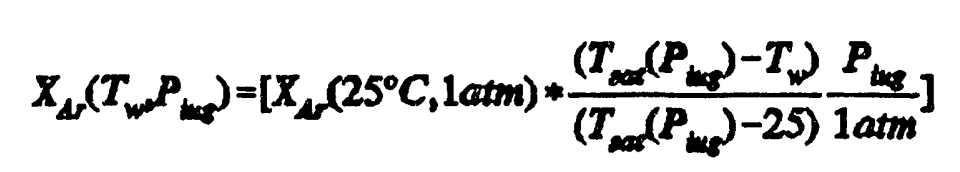

where

$T_{w} \quad$ is the water temperature and

$N_{H 2 O}$ is the amount of water in the upper chamber.

$P_{\text {iug }} \quad$ is the total initial system pressure in the upper gas region,

$\boldsymbol{P}_{\mathrm{H} 2 \mathrm{O}}$ is the vapor pressure of water at upper gas temperature

$T_{\text {iug }} \quad$ is the initial upper gas temperature

$R \quad$ is the universal gas constant, 
$P_{l} \quad$ is the pressure in the lower chamber just before the reaction,

$T_{l g} \quad$ is the temperature of the argon in the lower chamber just before reaction,

$V_{l g c} \quad$ is the volume of argon in the lower chamber,

$V_{\text {iugc }} \quad$ is the initial volume of the upper gas chamber and

$N_{\text {Arsol }}\left(T_{w}, P_{i \text { iug }}\right)$ is the amount of argon in the solution in the upper chamber at the given system pressure and upper water temperature.

$T_{\text {sat }}\left(P_{\text {iug }}\right) \quad$ is the saturation pressure evaluated at the initial upper gas pressure.

The amount of argon in solution is then calculated using

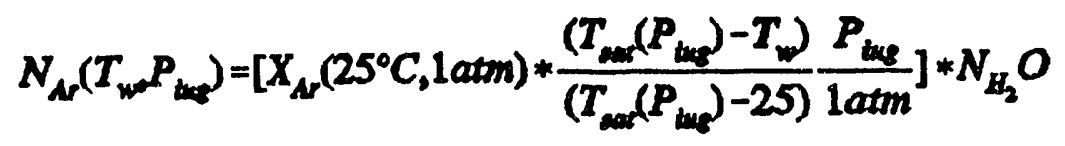

where $\mathrm{N}_{\mathrm{H} 20}$ is the amount of water in the upper chamber.

(ii) Mass of Argon and Hydrogen after initiation of Reaction

Once the reaction has been initiated, the mass of argon at any time is given by

$$
N_{\Delta r}=\left(N_{b_{L}}-N_{A r}\right)
$$

The argon pressure is then given by

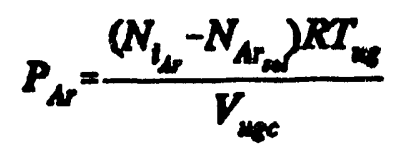


From the above information, the partial pressure of hydrogen is given by

$$
P_{\mathrm{H}_{2}}=P_{\mathrm{Ha}}-\boldsymbol{P}_{\mathrm{H}_{2} \mathrm{O}}-\boldsymbol{P}_{\mathrm{Ar}} \quad(7)
$$

The mass of hydrogen generated is then calculated using

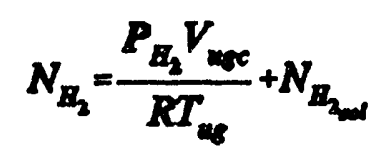

Where $N_{H 2 S o l}$ is the amount of hydrogen generated that goes into solution and is determined in a similar manner as the determination of amount of Argon in Solution. $N_{H 2 s o}$ is calculated using

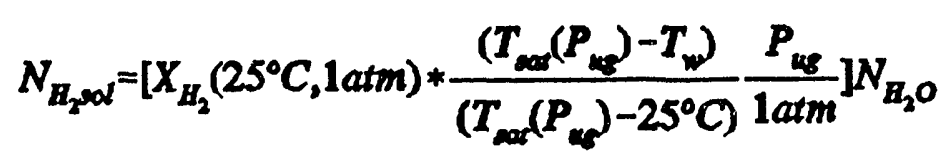

\section{(iii) Gas Leakage Corrections}

Even though system pressure tests indicate neglegible leakage, it may be necessary to correct the amounts of hydrogen accounted for in the upper chamber and in solution for leakage in order to accurately ascertain the amount of hydrogen produced from the reaction. Before each experiment, a pressure test is performed to determine the leakage rate of the system. A curve-fit is obtained for the pressure test data and used to determine the leakage rate using the following 
equations. The total amount of argon leakage from tome 0 to $t_{f}$ is given by

$$
N_{A r_{\text {met }}}(t)=\sum_{i=1}^{W}\left(t_{i}-t_{i-1}\right) *\left[-\frac{d P\left(t_{i}\right)}{d t}\right] * \frac{P\left(t_{P}\right)_{A r}}{P\left(t_{i}\right)_{\Delta P}}
$$

Similarly, the amount of hydrogen leakage from time 0 to $t_{f}$ is also given by

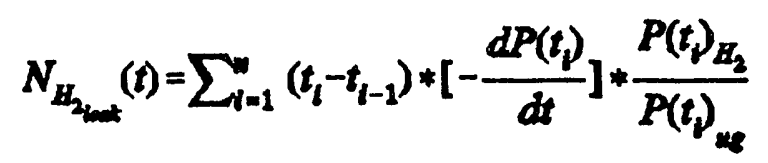

The corrected total amount of hydrogen generated from time $t=0$ to $t_{f}$ is then given by

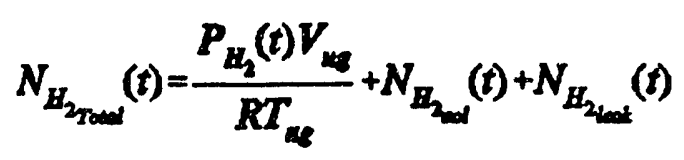

and the argon inventory at any time given by

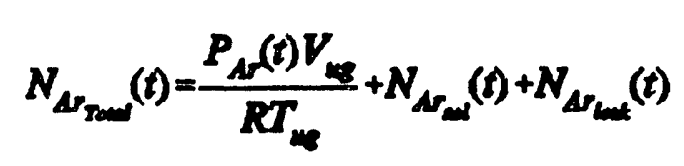

The equation for the inventory of Argon is used to determine the accuracy of pressure 
accounting and repeatability of the experiment. A leakage test on the system indicate the leakage correction can be neglected without loss of accuracy. A complete Fortran program that reads the raw experimental data and calculates the hydrogen generation as a function of time is given in Appendix B. 


\section{MODIFIED MASS TRANSFER MODEL FOR LITHIUM-LEAD/WATER REACTION}

A liquid metal transport reaction model developed by Herzog [1] has been improved and being used to estimate the empirical chemical reaction rate and diffusion parameters for the lithiumlead/water chemical reaction. This model is based on the premise that the rate of reaction during lithium-lead/water interactons is primarily controlled by the rate of diffusion of lithium atoms to and products away from the liquid metal surface right from the beginning of the reaction. One of the most difficult aspects of using the model is the requirement of determining the initial hydrogen generation rate. The experimental data during the first fewseonds from the present research will provide reliable data for determining the initial hydrogen generation rate for use in the liquid metal transport model. This model proposed by Herzog [1], is discussed in detail by Biney et al [2].

\section{A. Basic Assumptions}

The liquid metal transport reaction model is based on the following assumptions: (1) the reaction occurs only at the surface, (2) the system is assumed to be one dimensional since the driving force of diffusion will result in an axial variation of molar concentration of reactants and products, (3) the concentration of lead is assumed to be approximately constant throughout the interaction since there are about 5 atoms of lead to 1 atom of lithium in the alloy and lead is chemically inert during the interaction, (4) the liquid metal is incompressible, (5) the gases 
produced during the reaction are ideal, (6) there is no convective motion in either the gas or liquid metal pool and (7) there is no bulk mixing within the liquid metal pool. In the tests, the diameter of the liquid metal surface was stable relative to the Taylor unstable wavelength and thus the reaction surface area remains approximately constant. Figure 16 shows the reference coordinate system used for the model.

In the figure, the interaction surface is shown located a distances from the bottom of the liquid metal pool. Hypothetical concentrations of the products and reactants are also indicated on the Figure. A vapor film of thickness $\delta$ is shown above the interaction surface and a pool of subcooled water above the vapor film.

B. Model Equations

The basic equations are reviewed here. A complete description can be found in References 2 and 3.

\section{Continuity Equations}

For a multi-component system the continuity equation is given [5] by:

$$
\frac{\partial C_{l}}{\partial t}=-\frac{\partial}{\partial c}\left(C_{i} V+J\right)
$$

which when applied to the reactant and product results in the following two equations:

$$
\frac{\partial C_{u}}{\partial t}=D_{\underline{m}} \frac{\partial^{2} C_{u}}{\partial z^{2}}-C_{u} \frac{\partial V}{\partial z}-V \frac{\partial C_{u}}{\partial z}
$$




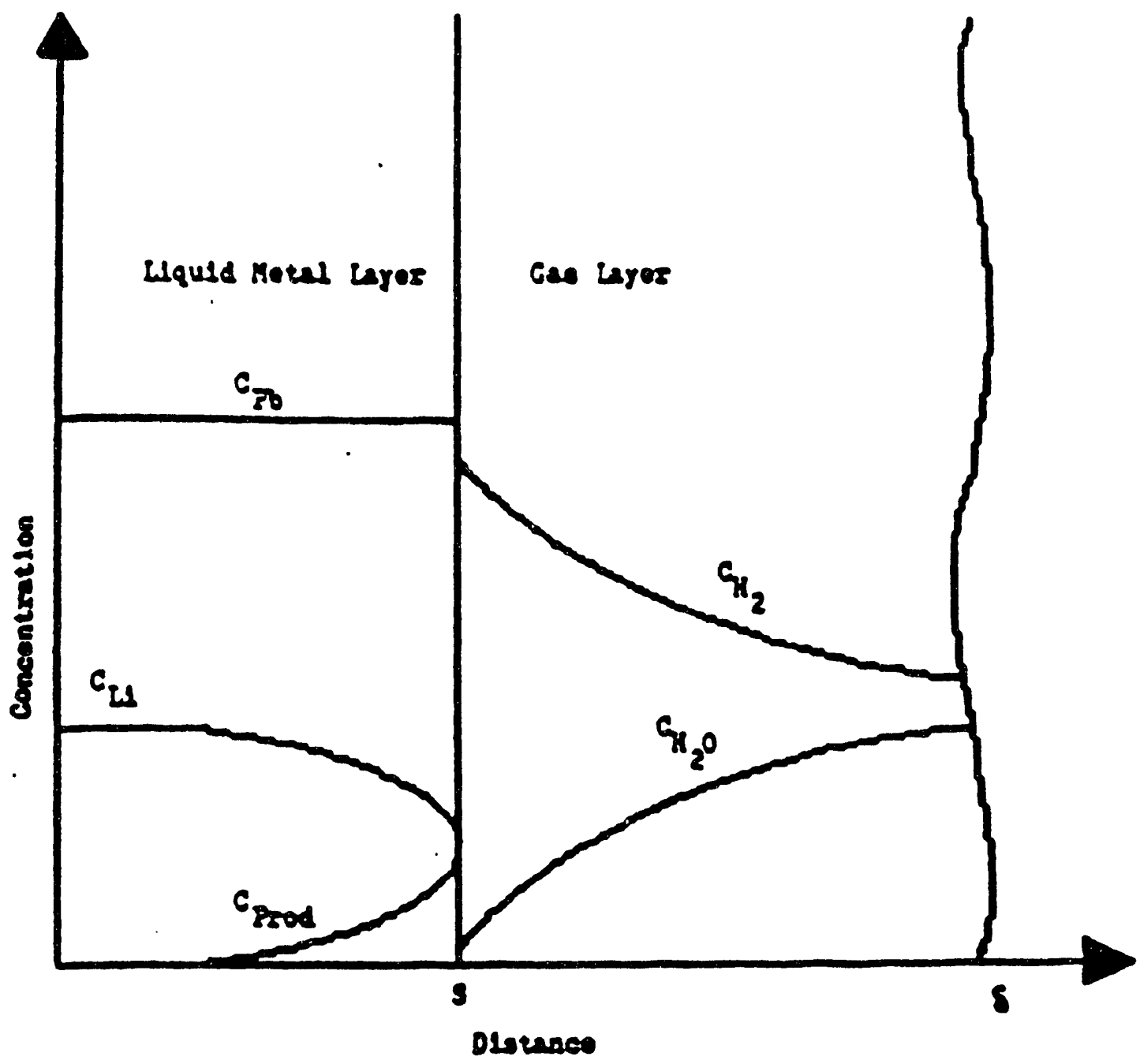

$\begin{array}{cl}\text { Figure } 16 & \text { Reference Coordinate System for Mass } \\ & \text { Transfer Reaction Mode } 1\end{array}$ 


$$
\frac{\partial C_{\mu d}}{\partial t}=D_{b} \frac{\partial^{2} C_{\mu d}}{\partial z^{2}}-C_{\alpha d} \frac{\partial V}{\partial z}-V \frac{\partial C_{\mu d}}{\partial z}
$$

The boundary conditions for the continuity equations are :

$$
\text { At } z=0, \frac{\partial C_{u}}{\partial z}=0 ; \text { at } z=s, C_{u}=0
$$

and the initial condition is :

$$
C_{u}(z, 0)=C_{u \max }
$$

Under assumptions 3 and 4, the equation of energy for the liquid metal pool is given by the equation

$$
\rho \frac{D H}{D t}=-\frac{\partial}{\partial z}\left(k_{-} \frac{\partial T}{\partial z}+M_{\gamma} H_{J_{l}}\right)+\frac{D P}{D t}
$$

Substituting the relation $\mathrm{H}=\mathrm{U}+\mathrm{PV}$ and simplifying, we obtain the equation 


$$
\begin{aligned}
& \rho c_{p}\left(\frac{\partial T}{\partial t}+V \frac{\partial T}{\partial z}\right)=k_{\lim } \frac{\partial^{2} T}{\partial z^{2}}-\left(\left(J_{L} M_{L L}<p_{k}+J_{p} M_{p f_{p}}\right) \frac{\partial T}{\partial z}\right. \\
& \left.+M_{L} H_{L} \frac{\partial U_{u}}{\partial z}+M_{p d} H_{\mu \alpha} \frac{\partial J_{\rho d}}{\partial z}\right)
\end{aligned}
$$

where

$$
\begin{aligned}
J_{t} & =-D_{l m} \frac{\partial C_{t}}{\partial z} \text { and } \\
D_{l_{m}} & =D_{0} \exp \left(-\frac{\Delta E_{d}}{R T}\right)
\end{aligned}
$$

and where $C, V, J, M, D_{l m}, T$ and $P$ are the molar concentration, velocity, molar flux, molecular weight, liquid metal diffusion coefficient, temperature and pressure respectively. The boundary conditions for the energy equation are: $T(0, t)=T c(t)$, a knciwn temperature at the base of the metal pool; at $z=s, q_{c o n d}+q_{g e n}=q_{c o n v}$ where $q_{c o n d}$ is the heat transfer by conduction from the base to the surface, $q_{8 m}$ is the heat generated at the surface as a result of the exothermic reaction and $q_{c o n v}$ is the heat transfer by convection from the reaction surface to the vapor film given respectively by:

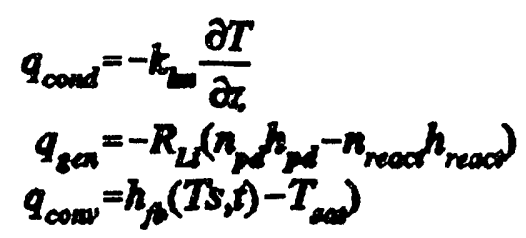


The stable film boiling heat transfer coefficient $h_{f}$ is obtained from theory of film boiling on flat horizontal surface. Collier [3] gives the following equations for calculating this coefficient.

$$
h_{f o}=h_{c}+0.75 h_{\text {rod }}
$$

where

$$
h_{c}=0.62\left[\frac{g\left(p_{f}-p_{g}\right) \rho_{g} k^{3} i_{f g}}{\lambda_{c} \mu_{g}\left(T_{g}-T_{2 a p}\right)}\right]^{\frac{1}{2}}
$$

and

$$
\lambda_{c}=2 \pi\left[\frac{a}{8\left(\rho_{f}-\rho_{f}\right)}\right]^{\frac{1}{2}}
$$

is the unstable Taylor wavelength. The corrected latent heat of vaporization $i_{f g}^{\prime}$, is given by:

$$
i_{A R}=i_{A}\left[1+0.68\left(\frac{c_{N B} \delta T}{t_{k}}\right)\right]
$$

The two continuity equations and the one energy equation constitute three equations with five unknowns: $T(z, t), C_{L i}(z, t), C_{p d}(z, t), D_{0}$ and $E_{d}$. Assumptions 2 and 3 imply that the molar flow rates of lithium and product $(\mathrm{LiOH})$ are equal but opposite in direction. Thus the sum of the molar concentrations will be a constant equal to the initial lithium concentration in the alloy $C_{\text {Limax }}$. Thus equation (16) can be replaced with 


$$
C_{p d}(z, t)+C_{u}(z, t)=C_{u}
$$

Finally the model is made to match two other conditions obtained from experimental results, namely the initial rate of hydrogen production, and a steady state amount of hydrogen generated $t_{4}$ seconds into the reaction. These last two conditions bring the set of equations to 5 with 5 unknowns The initial rate of hydrogen generation $\mathbf{S}$, is calculated using experimental data

$$
\frac{d N_{H_{2}}}{d}=S
$$

The experimental results will be used to determine the moles of hydrogen produced at the end of $t$ seconds. The initial rate of hydrogen generation will be determined from the experimental data. These two pieces of experimentally derived information will be supplied to the liquid metal transport reaction model and the reaction rate constants $\mathrm{B}$ and $\mathrm{E}$ in the parabolic rate equation

$$
\frac{\partial}{\partial t}\left[\frac{m}{A}\right]^{n}=B \exp \left[-\frac{\Delta E}{R T}\right]
$$

as well as the constants in the Arrhenius equation $D_{0}$ and $\Delta E_{d}$ determined. One should note that mechanistically these constants $B$ and $\Delta E$ are directly related to $D_{o}$ and $\Delta E_{d}$ in the liquid metal diffusivity, Equation (6). 


\section{PROBLEMS ENCOUNTERED AND STATUS OF RESEARCH}

\section{A. Problems Encountered}

Two major problems were encountered during the first six months of the project, all being the result of the project contract date occuring almost a month after beginning of the semester. The principal investigator was unable to obtain release time to actively work on the project in the Fall Semester of 1990 'August 28 - December 31, 1990) because of the late contract date. A college technician could nut be assigned to work on the project in the Fall Semester of 1990 as a result of the late contract date. We could also not get the college technician to work on the project in the Spring Semester of 1991 (January - May 1991) due to heavy work load already being assigned by the college. In the summer of 1992, a technician was assigned to the project. By this time all he design and equipment acquisition had been completed. The complete system (including lower and upper chambers, all, heaters solenoid values, butterfly valve and the data acquisition system) was assembled. In July 1992, pressure leakage tests was conducted on the vessels and the butterfly valve was found to be leaking in the closed position. Also the cooling coil had defective welding joint. Upon discussion with the valve manufacturer, the butterfly valve was returned, and a zero szakage all metal valve was ordered in August 1992 for replacement. The valve size for this valve had to be charged to $1^{\prime \prime}$ due to cost. The valve was not received until January 15,1993 . The change in the valve size necessitated redesign of the upper chamber and modifications in the lower chamber. The modifications and assembly of the 
new system were completed in February 15, 1993 and successfully tested. We are currently in touch with Oakridge National Lab for replacement metal to enable the actual experiments to proceed.

\section{B. Status of Research}

Currently, the experimental set-up has been completed, tested and operational. We have been running experiments with the little lithium lead salvaged during the spill in scoping tests while awaiting for a new supply of uncontaminated metal. A request for a 3 months no-cosi extension has been submitted to enable the research to be completed. 


\section{CONCLUSIONS}

This status report has given the details of the work done up to March 31, 1993. While this is not the final report, it is clear that all the work involved in the design, assembly and testingof the experimental system have been completed. The three main programs for data acquisition and control, data analysis and liquid metal transport reaction models have been completed, tested and ready to be used for the research. The Oak Ridge National Lab is in the process of sending the needed supply of the lithium-lead metal. As a result of the delays, a request for a no cost extension to August 31, 1993 has been submitted. This will allow ample time for all the experiments to be run and analyzed and the final report completed. 


\section{REFERENCES}

[1] Herzog, J.P., "Lithium-Lead/Water Interactions: Experiments and Analysis", Ph.D. Dissertation, Fusion Technology Institute, Nuclear Engineering and Engineering Physics Department, University of Wisconsin - Madison.

[2] Biney, P.O., Corradini, M.L. Lomperski, S. and Krueger, J., "A Mass Transport Model for Hydrogen Generation During Lithium-Lead/Water Interactions". Presented at the 13th Symposium of Fusion Energy, Knoxville, TN October 1989.

[3] Collier, J., Convective Boiling and Condensation, McGraw-Hill 1972 pp 124-133. 


\section{NOMENCLATURE}

$\begin{array}{ll}\text { A } & \text { Surface area } \\ \text { B }_{1} & \text { Arrhenius rate constant } \\ \text { C } & \text { Molar Concentration } \\ \text { D }_{\text {o }} & \text { Diffusion Coefficient proportionlity constant } \\ \text { D }_{\text {tm }} & \text { Diffusion Coefficient of liquid metal } \\ \text { E } & \text { Activation energy } \\ \text { H } & \text { Enthalpy } \\ \text { h } & \text { Molar enthalpy also as heat transfer coefficient } \\ \text { J } & \text { Molar flux } \\ \text { k } & \text { Thermal conductivity } \\ \text { M } & \text { Molecular weight } \\ \text { P } & \text { Pressure } \\ \text { g } & \text { Heat flux } \\ \text { R } & \text { Universal gas constant } \\ \text { S } & \text { Experimentally determined initial reaction rate } \\ \text { T } & \text { Absolute temperature } \\ \text { t } & \text { time } \\ \text { V } & \text { Velocity } \\ \text { Z } & \text { Principal coordinate direction } \\ \text { P } & \text { density } \\ \end{array}$




\section{SUBSCRIPTS}

$\begin{array}{ll}\text { pd } & \text { products } \\ \text { Im } & \text { liquid metal } \\ \text { cond } & \text { conduction } \\ \text { gen } & \text { generated } \\ \text { conv } & \text { convective } \\ \text { sat } & \text { saturated } \\ \text { Ar } & \text { Argon } \\ \text { fb } & \text { film boiling }\end{array}$




\section{APPENDIX A \\ DETERMINATION OF THEORETICAL HYDROGEN PRESSURE}

The chemical reaction equation is given by

$$
\mathrm{Li}_{17} \mathrm{~Pb}_{83}+.17 \mathrm{H}_{2} \mathrm{O} \Rightarrow .17 \mathrm{LiOH}+.085 \mathrm{H}_{2}+.83 \mathrm{~Pb}
$$

Here we have assumed there is enough water for the reaction to form lithium hydroxide. Assuming the lithium-lead in the lower chamber has a depth of $1 \mathrm{~cm}$, then the valve is

$$
\begin{aligned}
V & =\pi D^{2} L / 4 \\
& =\pi(2.54)^{2}(1) / 4 \\
& =5.07 \mathrm{~cm}^{3}=5.07 \times 10^{-6} \mathrm{~m}
\end{aligned}
$$

The molecular weight of lithium lead is calculated using

$$
M_{\text {LiPt }}=0.17(7)+0.83(207)=173 \mathrm{~kg}
$$

The density of lithium lead is then given by

$$
\begin{aligned}
\rho_{L i .17 P t .18} & =(0.00688)(530)+(0.99312)(10444) \\
& =10375.8 \mathrm{~kg} / \mathrm{m}^{3}
\end{aligned}
$$

The mass of lithium lead is then given by

$$
\begin{aligned}
m_{L i 17 P 683} & =\rho_{\text {Lil7Pb83 }} V \\
& =\left(10375.8 \mathrm{~kg} / \mathrm{m}^{3}\right)(5.07)\left(10_{\mathrm{m}}^{6}\right) \\
& =0.0526 \mathrm{~kg}
\end{aligned}
$$

Mass of $\mathrm{H}_{2}$ Produced by reaction of $.0526 \mathrm{~kg}$ of $\mathrm{Li}_{1}, \mathrm{~Pb} \mathrm{~b}_{83}$ is given by

$$
\begin{aligned}
m & =0.17 \times 0.0526 / 173 \\
& =5.17 \times 10^{5} \mathrm{~kg}
\end{aligned}
$$


The hydrogen produced is assumed to behave as an ideal gas with gas constant

$$
\begin{aligned}
R_{H Z} & =R / M_{H 2} \\
& =8.3143 / 2 \\
& =4.1572 \mathrm{~kJ} / \mathrm{kg}-K
\end{aligned}
$$

The hydrogen produced bubbles into the gas space in the upper chamber of inside diameter $\left(1.5^{\prime \prime}\right)$. The height of the gas space above the water level in the upper chamber is varied for 5 $\mathrm{cm}$ to $25 \mathrm{~cm}$. The volume of $\mathrm{H}_{2}$ per centimeter height is given by

$$
\begin{aligned}
V_{1} & =\pi D^{2}(1) / 4 \\
& =\pi(1.5 \times 2.54)^{2}(1) / 4=11.401 \mathrm{cc} \\
& =11.401 \times 10^{6} \mathrm{~m}^{3}
\end{aligned}
$$

The pressure of hydrogen is then given bt

$$
P_{H 2}=M_{H 2} R T / V
$$

The maximum planned gas temperature is $100^{\circ} \mathrm{C}$

Thus

$$
\begin{aligned}
P_{H 2} & =(0.0526)(4.1572)(373.15) /\left(11.401 \times 10^{-6}\right) \\
& =19553 \mathrm{kPa}
\end{aligned}
$$

Table 2 gives the summary of the results of the calculations in this Appendix. 


\section{APPENDIX B}

\section{Listing of Data Analysis Program}

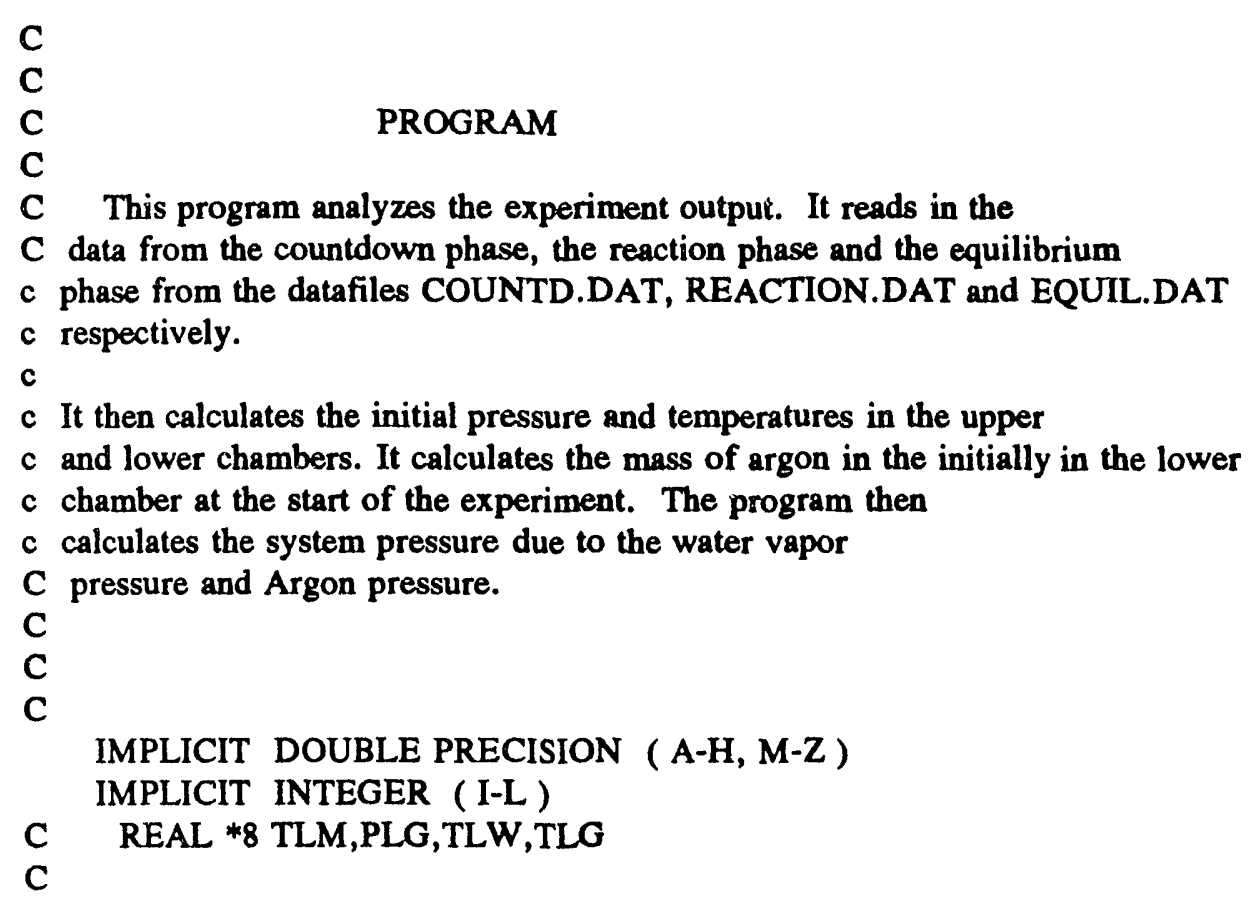

C

IMPLICIT DOUBLE PRECISION ( $\mathrm{A}-\mathrm{H}, \mathrm{M}-\mathrm{Z}$ )

IMPLICIT INTEGER ( I-L)

C REAL *8 TLM,PLG,TLW,TLG

C

DIMENSION TIME(500),UGT(500),TLG(500),UWT(500),TLW(500)

DIMENSION TLM(500),UGP(500),PLG(500)

COMMON/FACTOR/C(9)

CHARACTER*15 FILENM1

CHARACTER*15 FILENM2

CHARACTER *15 FILENM3

CHARACTER *15 FILEDP

C

CHARACTER*1 RESPON

C

C***** PROGRAM CONSTANTS ******

C***** VUPFINAL IS THE FINAL GAS SPACE ABOVE LIQUID LEVEL AFTER EXPT.

C***** MEASURED FROM THE LIQUID LEVEL GAUGE AFTER THE EXPERIMENT.

$C^{* * * * *}$ VDN $=$ VOLUME OF THE LOWER CHAMBER BELOW THE LOWER FLANGE

C***** VDEAD1 $1=$ VOLUME OF DEAD SPACE IN VALVE

C***** VDEAD2 $=$ VOLUME OF DEAD SPACE IN FLANGES AND THROUGH GASKET THICKNESS

C***** BELOW BALL OF CLOSED VALVE

C***** VUPTOTAL $=$ TOTAL VOLUME OF THE UPPER CHAMBER

C***** FWL $=$ FINAL WATER LEVEL IN INCHES

C 


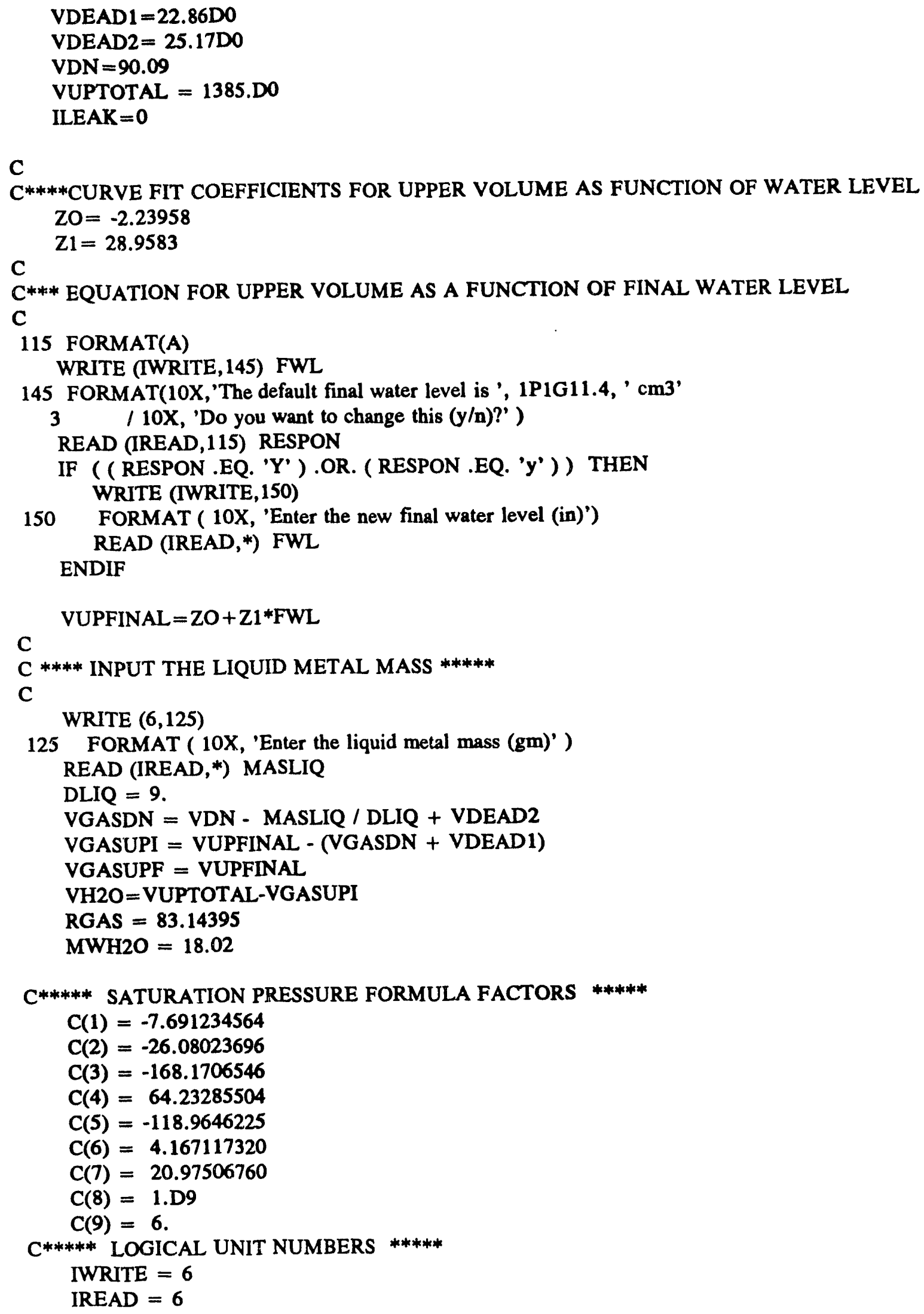




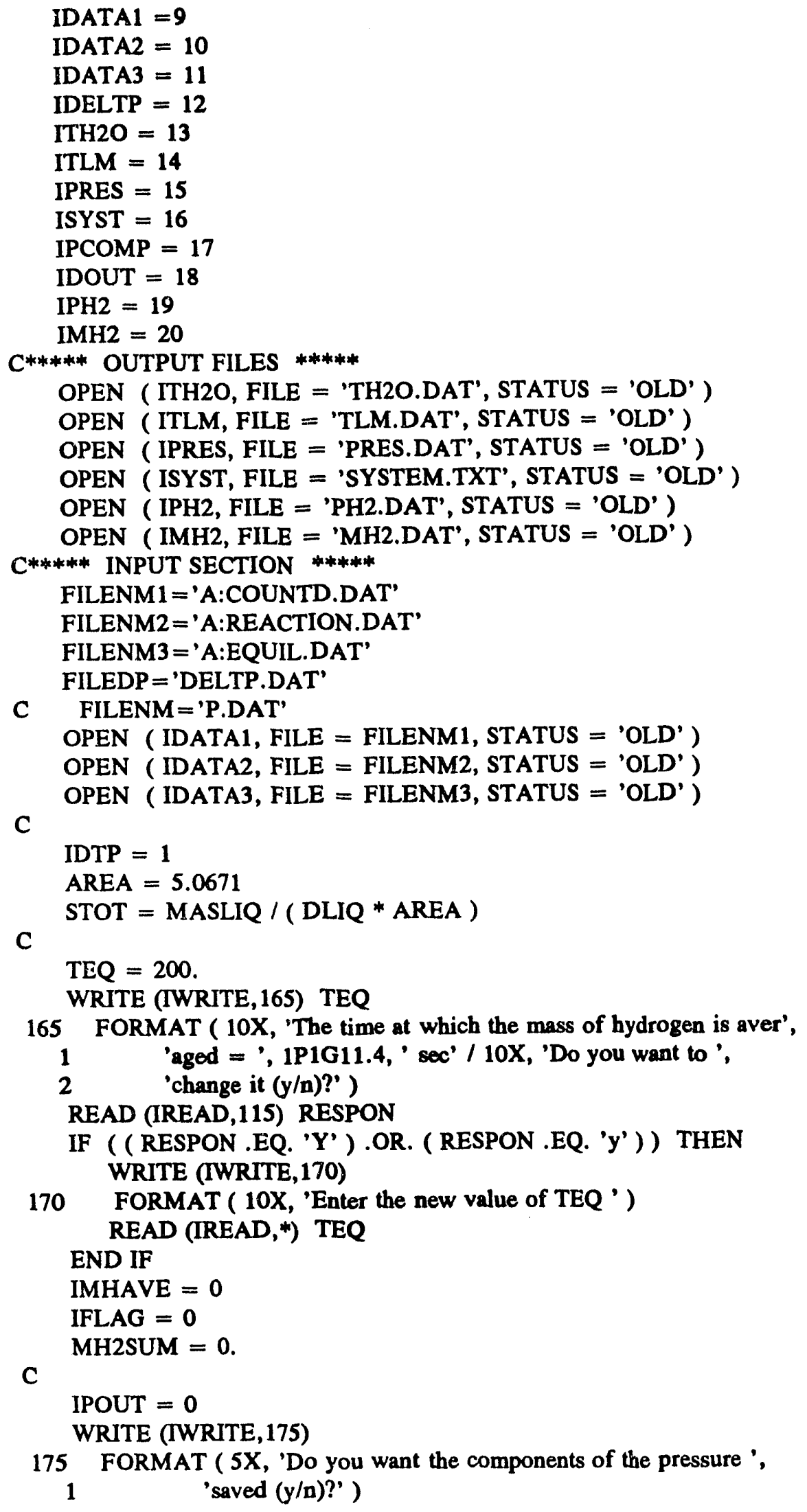




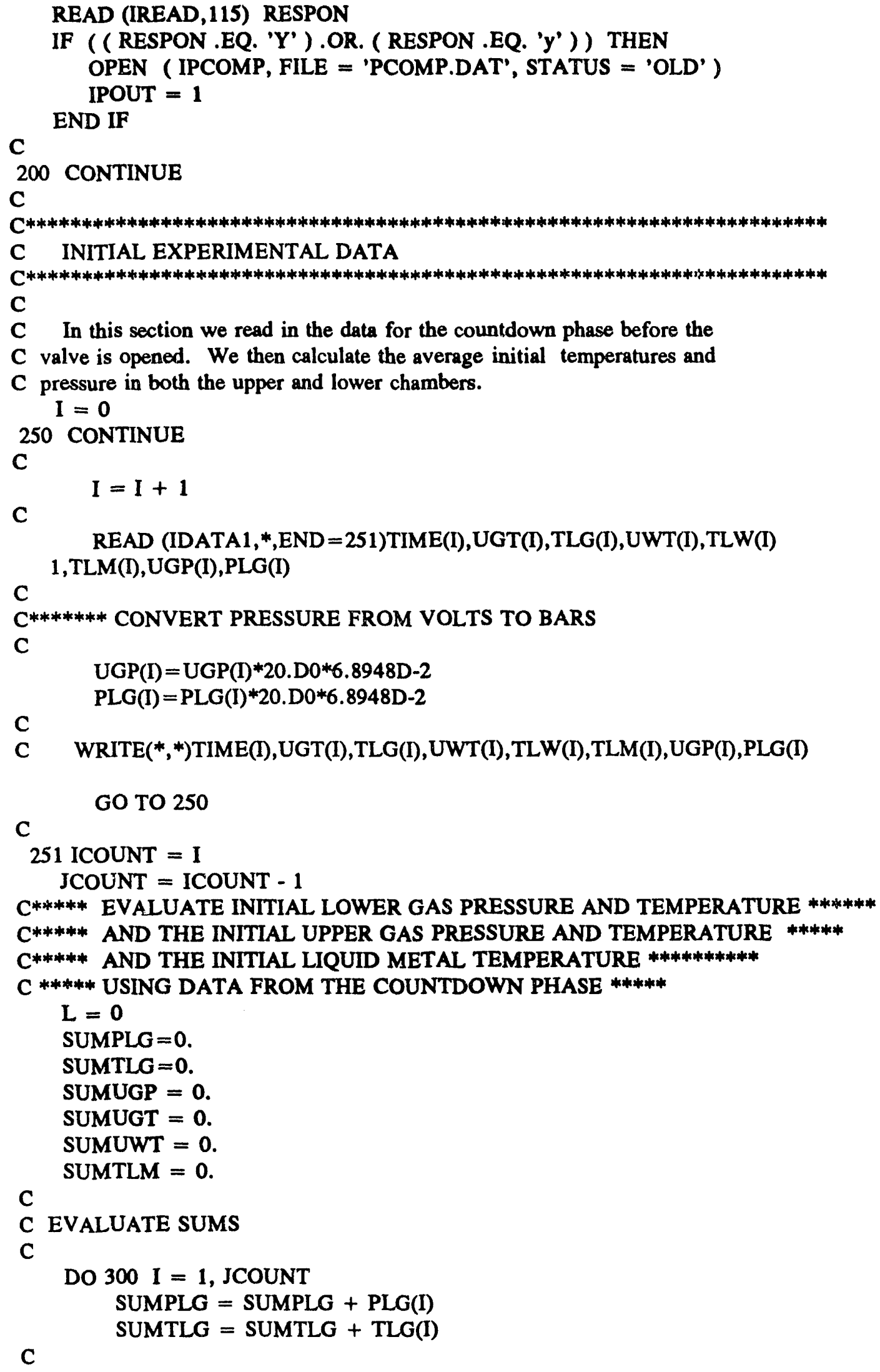

$$
I=I+1
$$$$
\text { READ (IDATA1, *,END = 251)TIME(I),UGT(I), TLG(I),UWT(I),TLW(I) }
$$ 


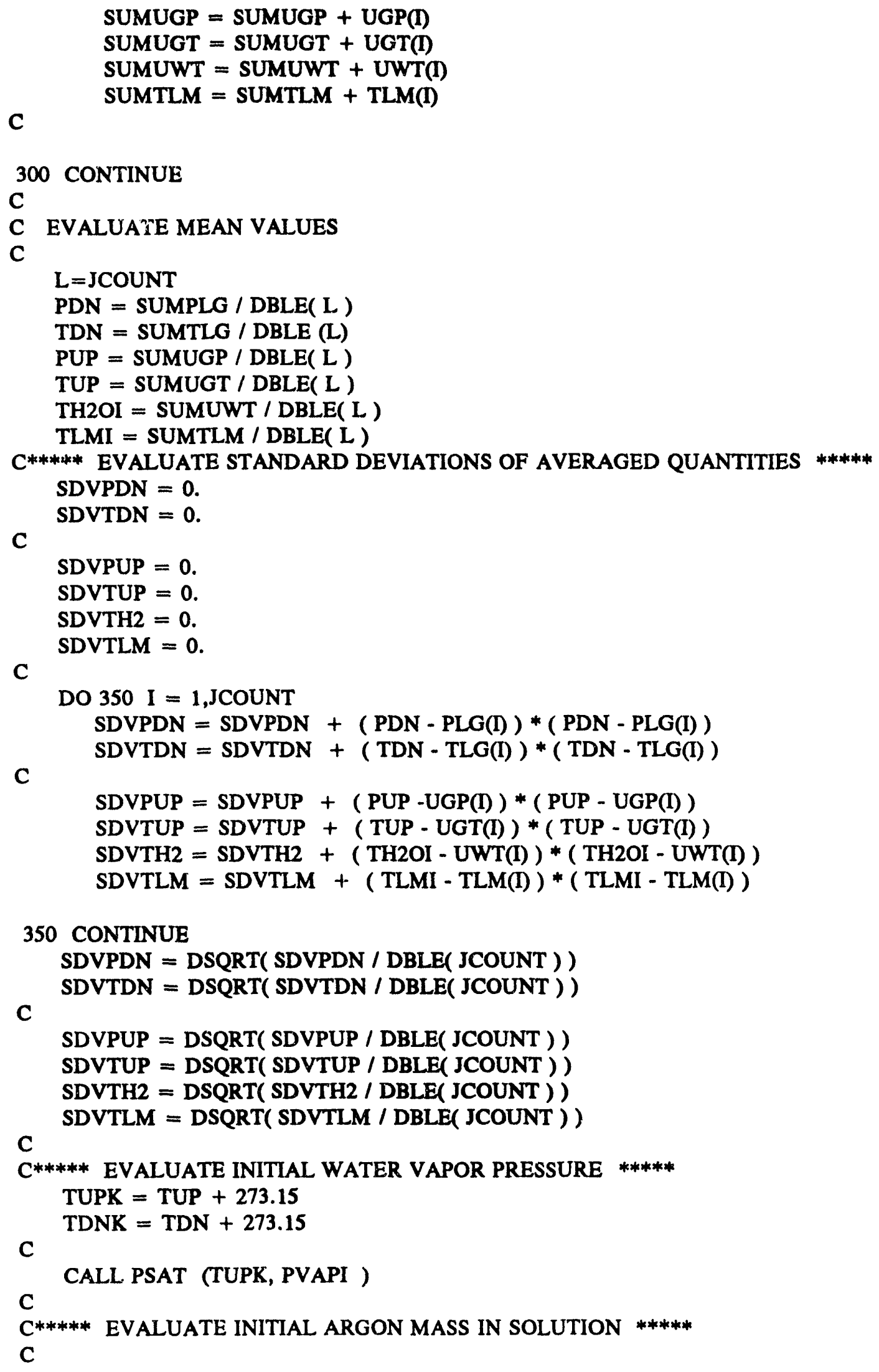


C First we evaluate the initial Ar solubility and water density.

TSATK $=373.998 *($ PUP**(.07144015) $)$

TSAT $=$ TSATK -273.15

$\mathrm{XAR}=3.7 \mathrm{D}-7 *(\mathrm{TSAT}-\mathrm{TH} 2 \mathrm{OI}) *($ PUP - PVAPI $) / 1.013$

IF(XAR .LT.0.0) XAR $=0.0$

C

$\mathrm{DENH} 2 \mathrm{O}=1.0098-4.86871 \mathrm{D}-4 * \mathrm{TH} 2 \mathrm{OI}$

C

MARSOL $=$ XAR * VH2O * DENH2O $/$ MWH2O

MARUP = ( PUP - PVAPI ) * VGASUPI / (RGAS*TUPK)

MARDOWN = PDN * VGASDN / (RGAS*TDNK)

MAR = MARUP + MARDOWN + MARSOL

C***** OUTPUT INITIAL VALUES

C

C First we output problem parameters to the screen.

WRITE (IWRITE,400) FILENM1,FILENM2,FILENM3

WRITE (ISYST,401) FILENM1,FILENM2,FILENM3

400 FORMAT ( I// 5X, 'For the system pressure files ', 3A12 /)

401 FORMAT ( 5X, 'For the system pressure files ', 3A12/)

C

IF (IDTP .EQ. 0 ) THEN

C WRITE (IWRITE,405) FILEDP

C WRITE (ISYST,405) FILEDP

405 FORMAT ( 5X, 'And the DELTAP pressure file ', A12 /)

END IF

C

WRITE (TWRITE,410) TLMI, SDVTLM, TH2OI, SDVTH2, MASLIQ, STOT

WRITE (ISYST,410) TLMI, SDVTLM, TH2OI, SDVTH2, MASLIQ, STOT

410 FORMAT( 5X, 'The experimental parameters are: $\%$

$15 \mathrm{X}$, 'initial liquid metal temp. $=$ ', $1 \mathrm{P} 1 \mathrm{G} 11.4,{ }^{\prime}+/ \mathrm{-}^{\prime}$,

$2 \quad 1 P 1 G 11.4, C^{\prime}$,

$35 \mathrm{X}$, 'initial water temperature $=$, $1 \mathrm{P} 1 \mathrm{G} 11.4,{ }^{\prime}+/ \mathrm{-}^{\prime}$,

$4 \quad 1 \mathrm{P} 1 \mathrm{G} 11.4, \mathrm{e}^{\prime} \mathrm{C} \cdot 1$

$55 \mathrm{X}$, 'liquid metal mass $=$, 1P1G11.4, $\mathrm{gm} \%$

$65 X$, 'and the metal has a depth $=$ ', 1P1G11.4, ${ }^{\prime} \mathrm{cm}$ '/)

C

WRITE (IWRITE,415) TUP, SDVTUP, VGASUPI, TDN, VGASDN

WRITE (ISYST,415) TUP, SDVTUP, VGASUPI, TDN, VGASDN

415 FORMAT(10X, 'with initial upper Ar temp = ', 1P1G11.4, ' +/- ',

1 1P1G11.4, ' C ' /

$210 \mathrm{X}$, 'the upper gas layer volume $=$ ', 1P1G11.4, $\mathrm{cm} 3 \%$

$310 \mathrm{X}$, 'with initial lower Ar temp $=$ ', 1P1G11.4,' C '/

C

$410 X$, 'the lower gas layer volume $=$, 1P1G11.4, ${ }^{\prime} \mathrm{cm} 3$ 'n

WRITE (IWRITE,420) PUP, SDVPUP, PDN, SDVPDN

WRITE (ISYST,420) PUP, SDVPUP, PDN, SDVPDN

420 FORMAT(10X, 'the initial upper pressure $=$ ', 1P1G11.4, ' +/- ',

2 1P1G11.4,' bar ' '

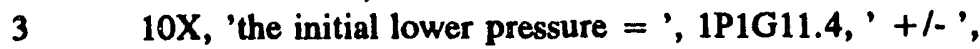

4 1P1G11.4, 'bar' II)

C

WRITE (IWRITE,425) MAR, MARUP, MARDOWN, MARSOL 
WRITE (ISYST,425) MAR, MARUP, MARDOWN, MARSOL 425 FORMAT(10X, 'the total argon mass =', 1P1G11.4,' mole'/

$110 \mathrm{X}$, 'the upper chamb argon mass = ', 1P1G11.4,' mole'/

$110 \mathrm{X}$, 'the lower chamb argon mass $=$ ', 1P1G11.4,' mole'/

$110 X$, 'the argon mass in solution $=$ ', 1P1G11.4, " mole's

C

C Now to output the initial values to the data files.

PAR = PUP - PVAPI

MHLEAK $=0$.

IF ( IPOUT .EQ. 1 ) THEN

WRITE (IPCOMP,998) TIME(JCOUNT), PAR, PVAPI, MARSOL, MHLEAK

END IF

$\mathrm{PH} 2=0$.

MH2TOT $=0$.

C WRITE (IPH2, 499 ) TIME(JCOUNT), PH2

C WRITE (IMH2,999) TIME(JCOUNT), MH2TOT

C

TIMEO $=0.0$

C

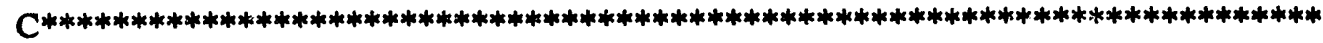

C MAIN CALCULATIONAL LOOP

C THIS SECTION READS IN THE DATA FOR THE REACTION PHASE AND CALCULATES

C THE MASS OF HYDROGEN GENERATED DURING THE PHASE AS A FUNCTION OF

C TIME. ZORRECTION FOR LEAKAGE IS MADE USING LEAKAGE INFORMATION

C FROA. $\therefore$ SEPARATE FILE

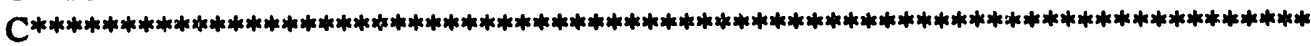

C

C INNER LOOP

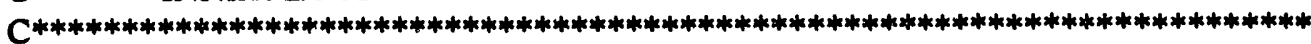

C

C***** DATA INPUT SECTION ******

C

$\mathbf{K}=\mathbf{0}$

2000 CONTINUE

C

$K=K+1$

READ (IDATA2,*,END =2500)TIME1,TGAS1,TLG1,TH201,TLW1,TLM1

1 ,PRES1,PLG1

C

C ******* CONVERT PRESSURE FROM VOLTS TO BARS *******

C

PRES1 $=$ PRES $1 * 20$. D0*6.8948D-2

PLG1 $=$ PLG1*20.D0*6.8948D-2

C READ (IDATA,*,END=2500) TIME1, PRES1, TGAS1, TIi2O1, TLM1

C

C***** EVALUATE PVAP(TGAS1) *****

TGASK $=$ TGAS1 + 273.15 


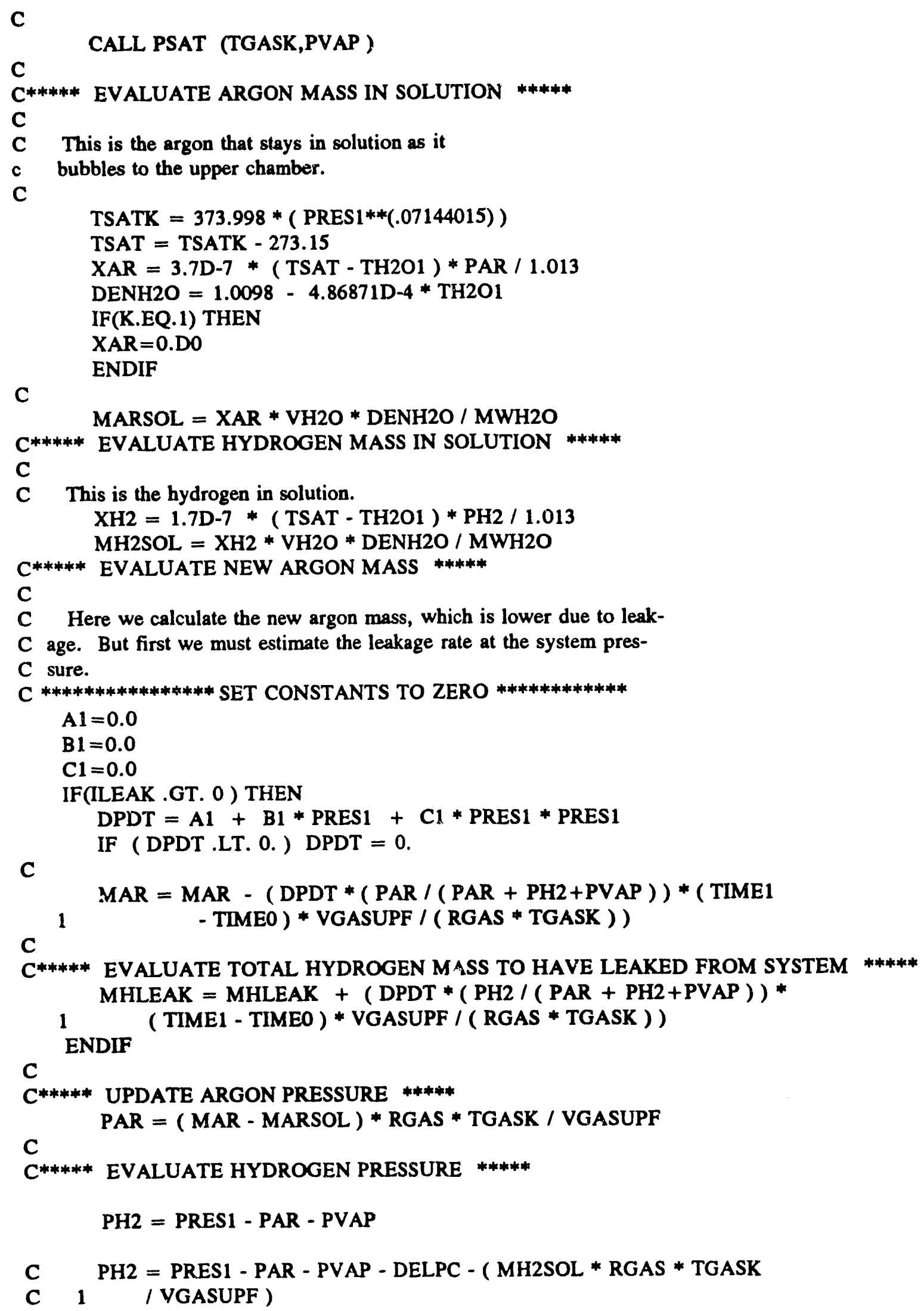




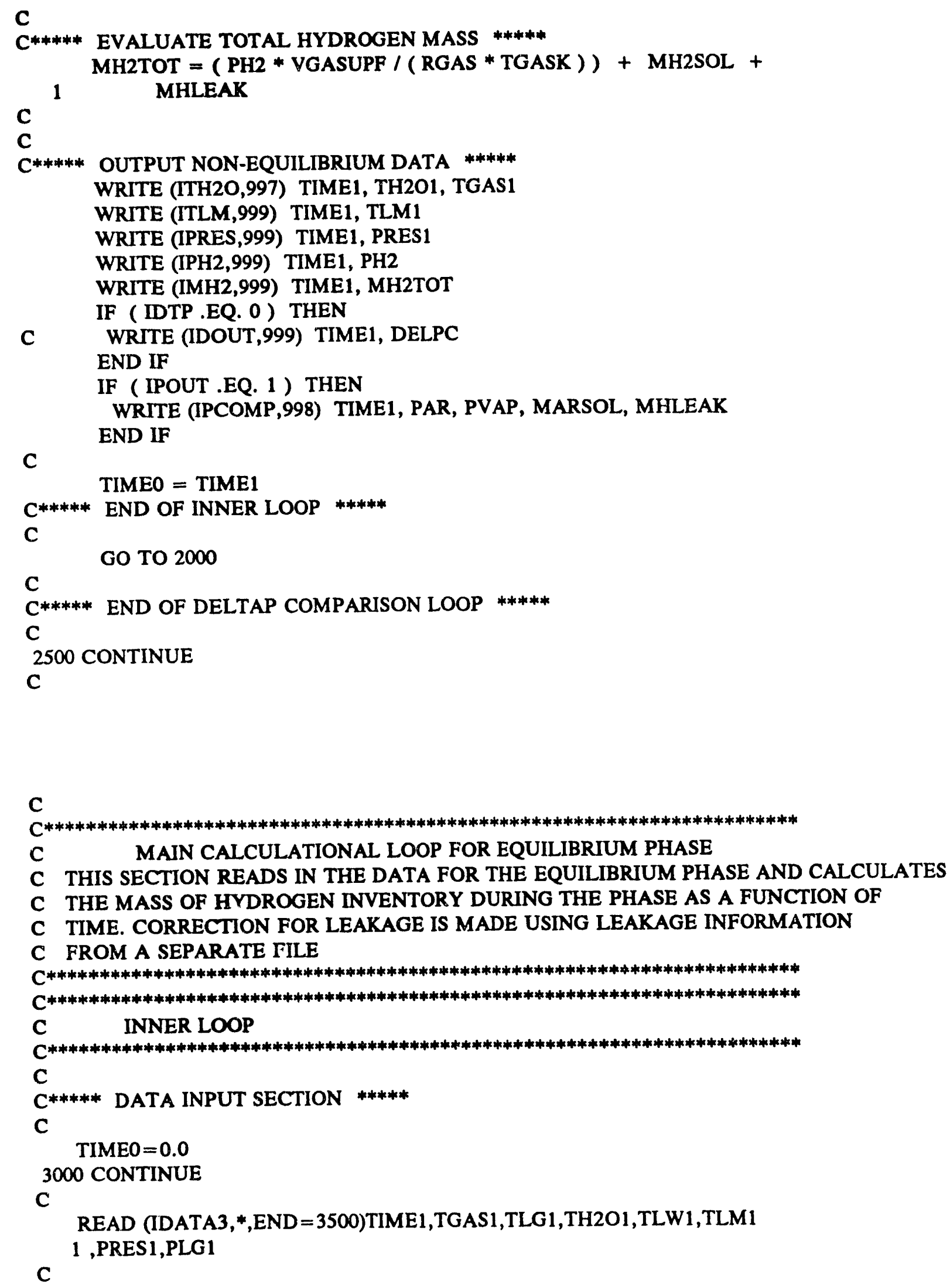




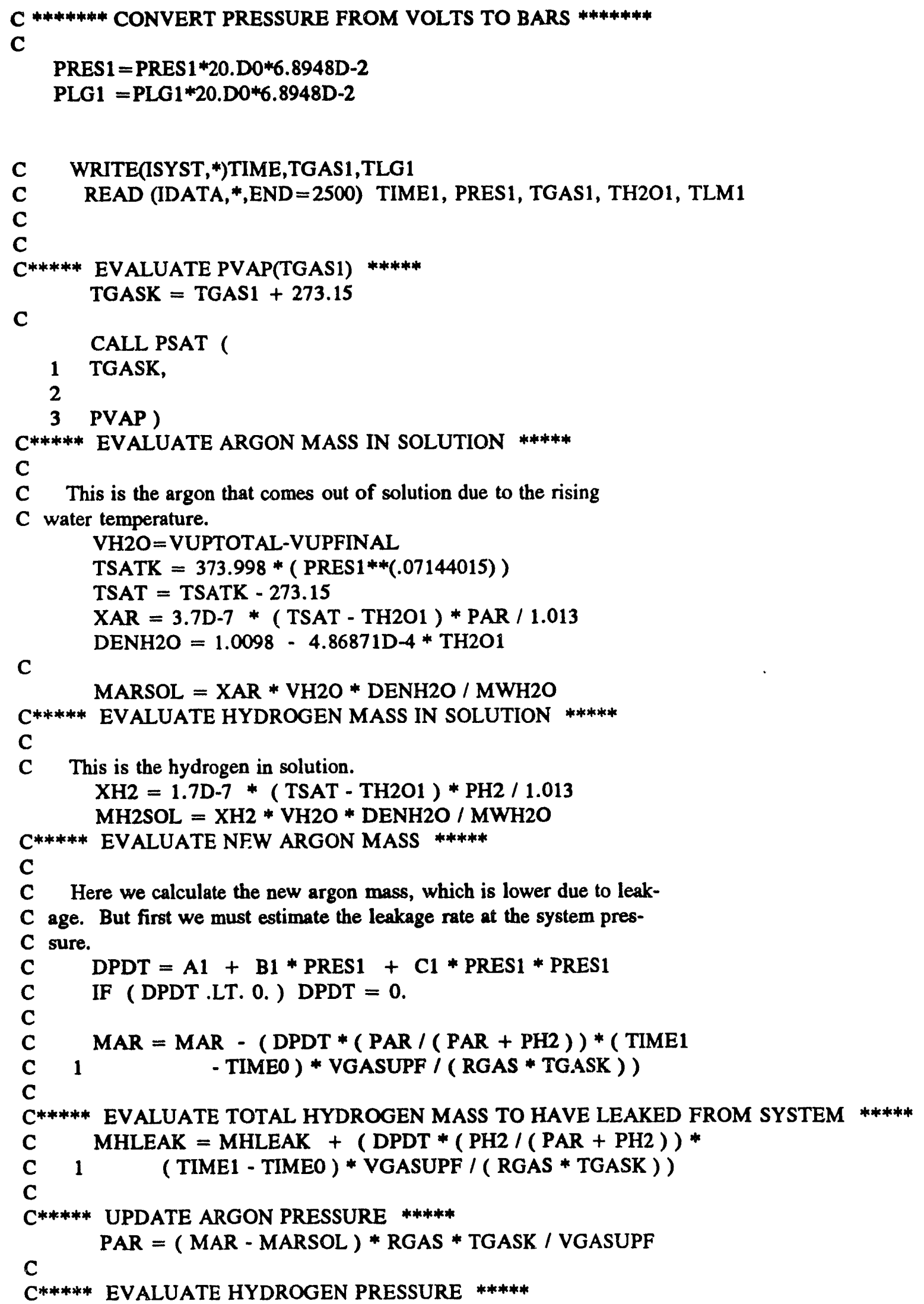




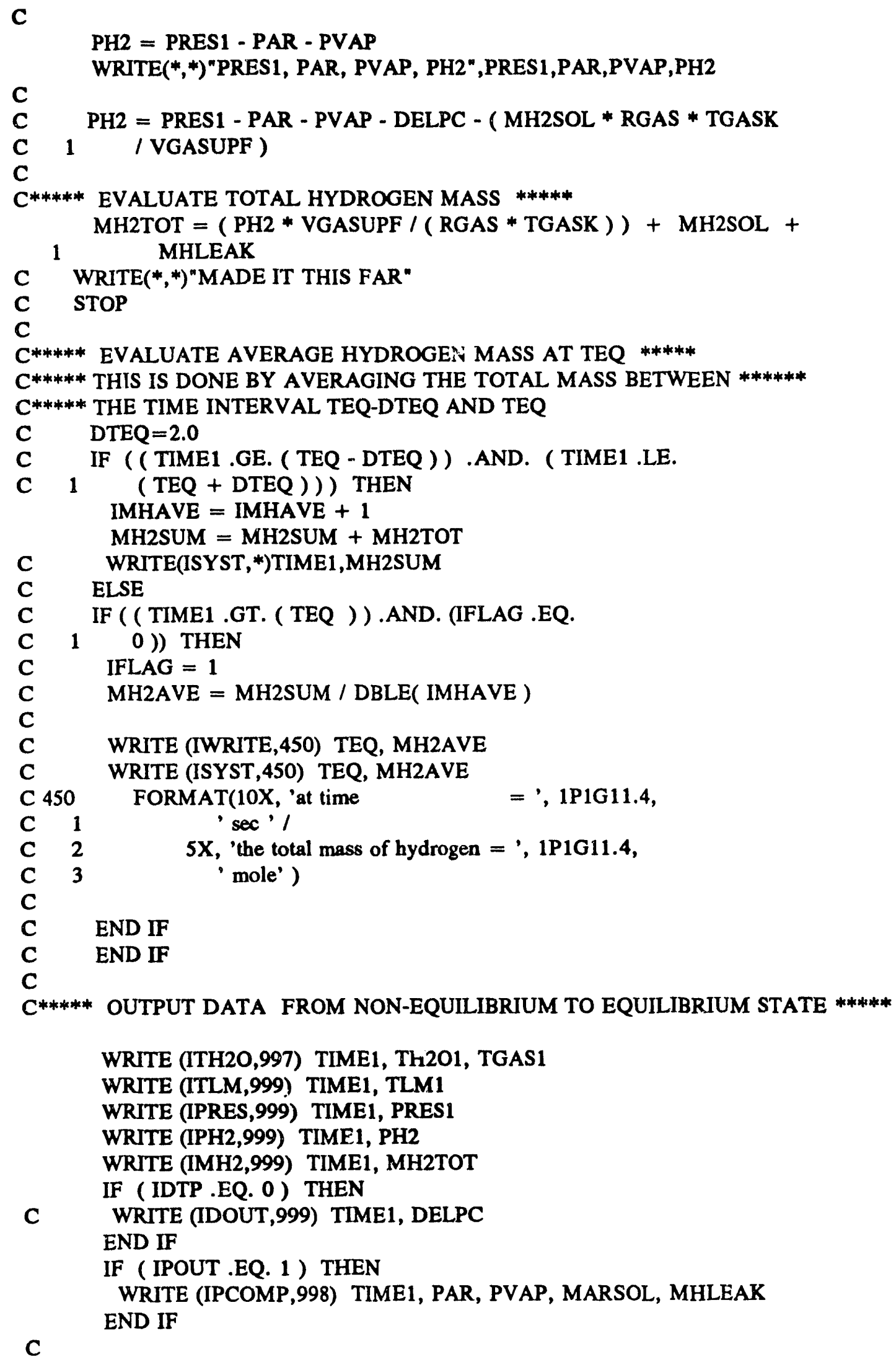




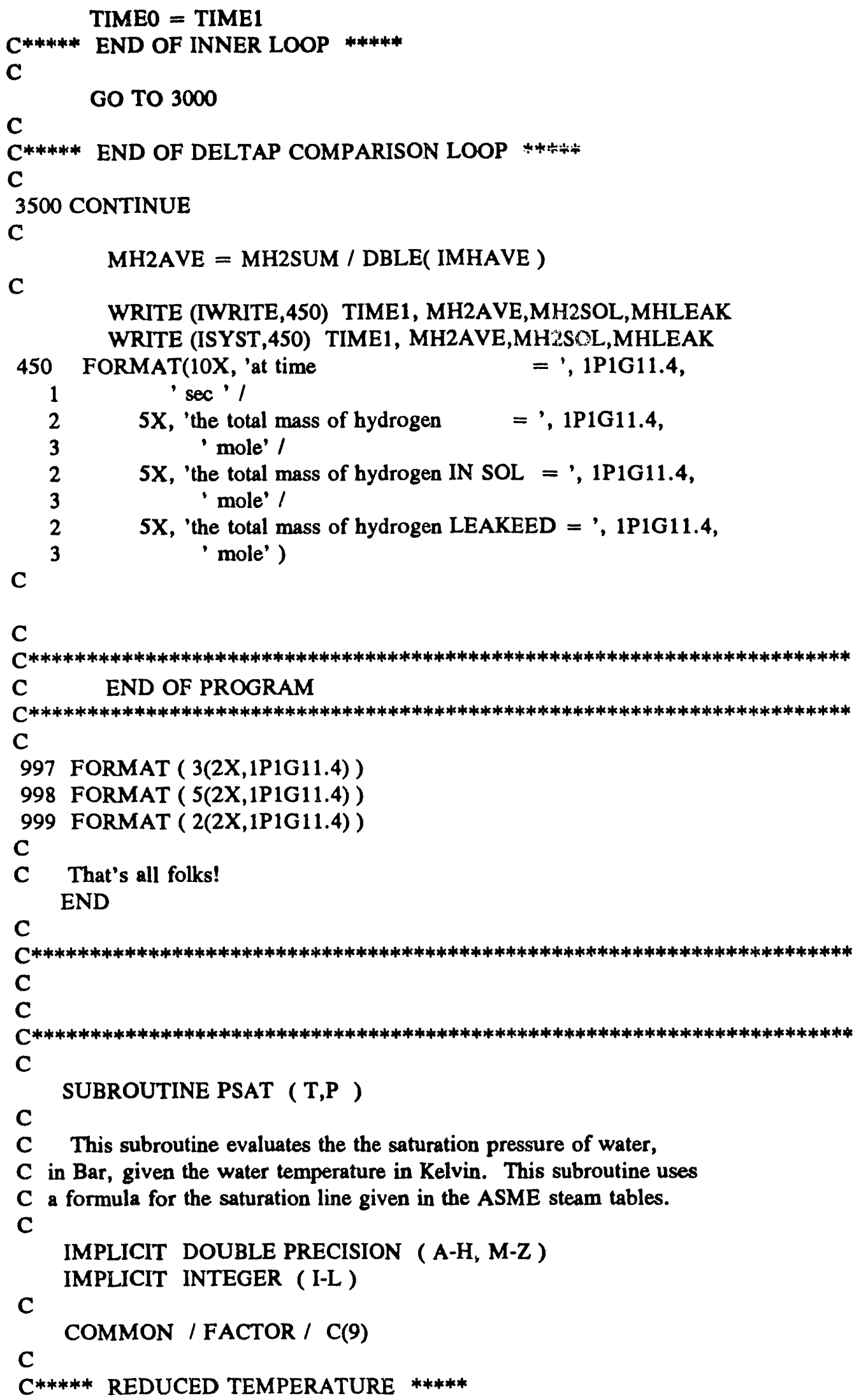


THETA $=\mathrm{T} / 647.3$

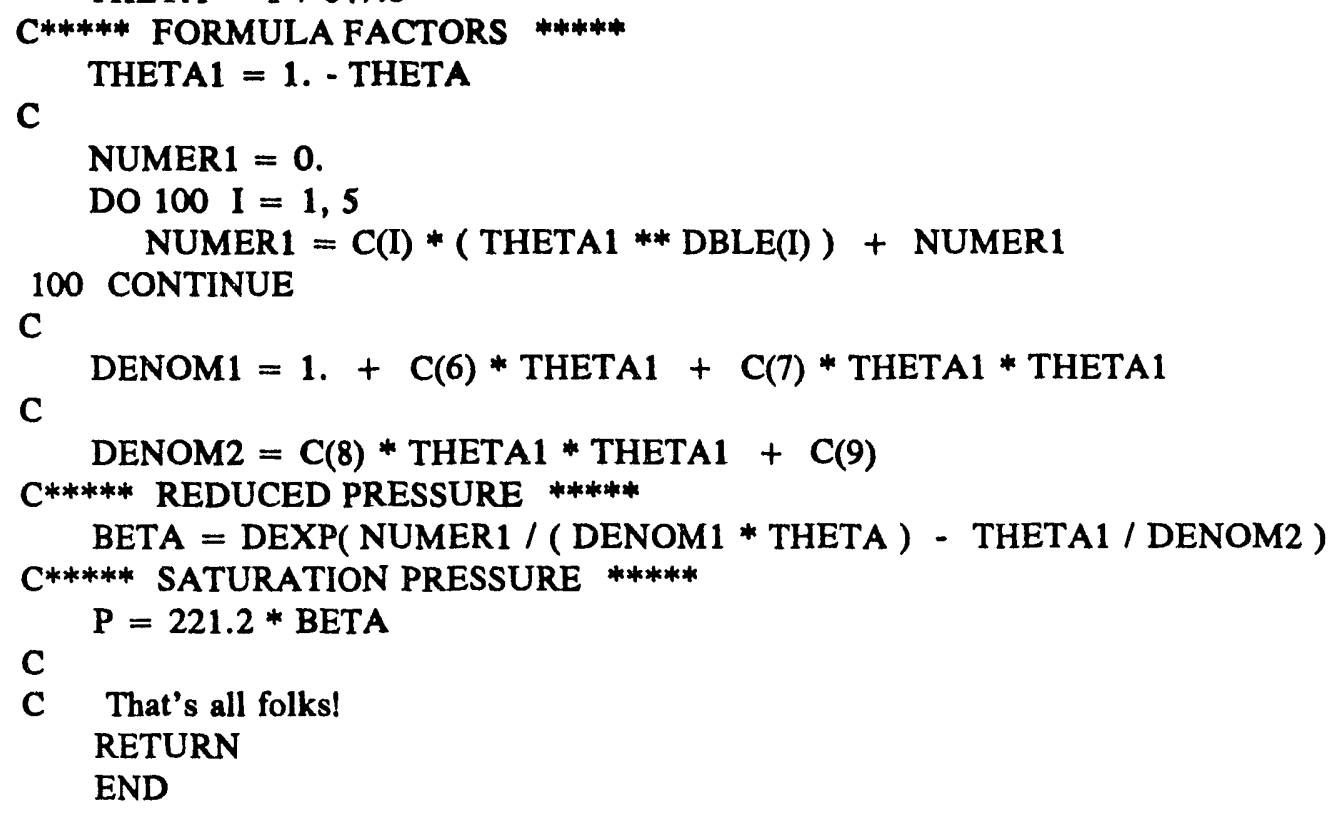




\section{APPENDIX C}

Listing of Data Acquisition and Control Program

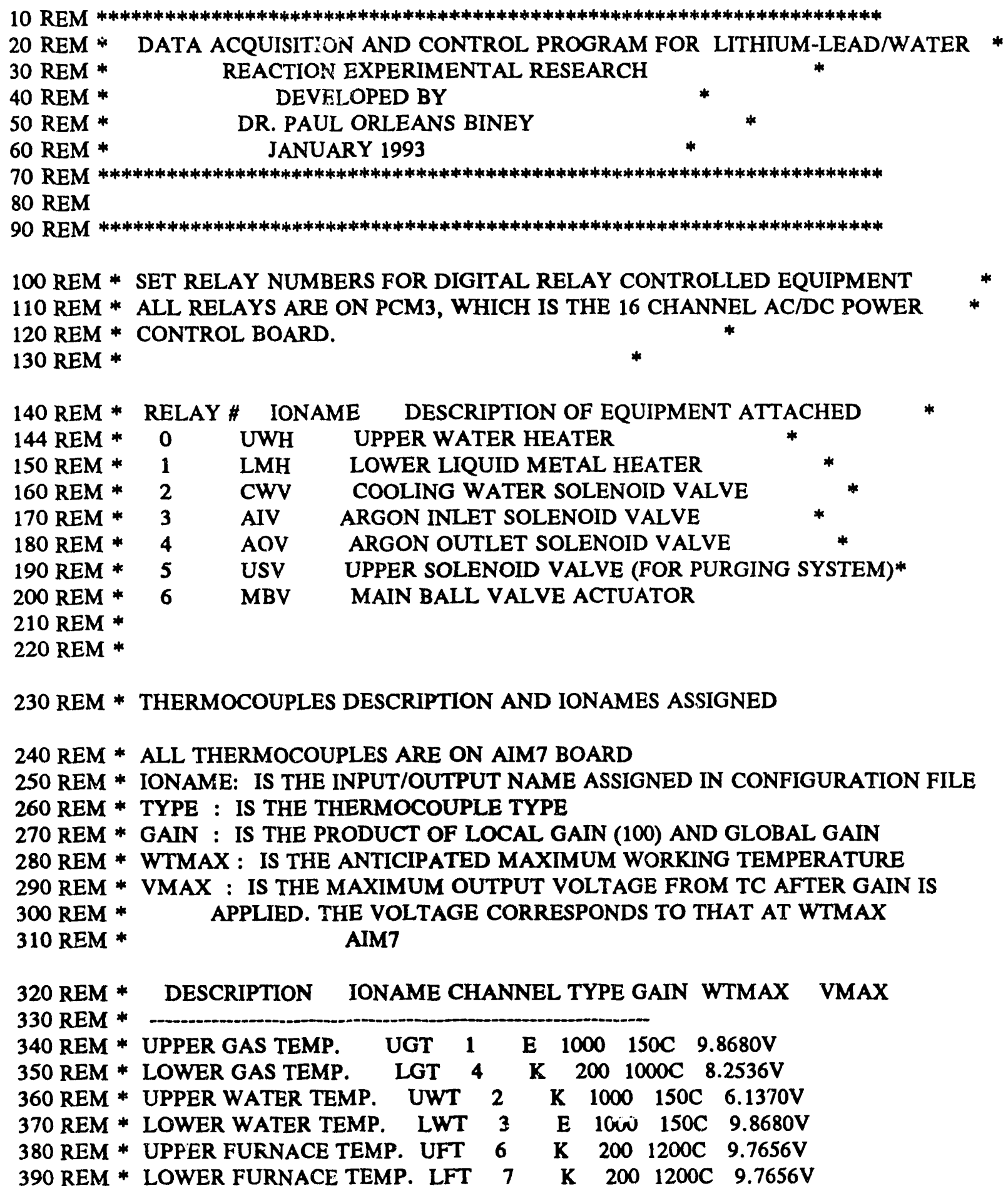



400 REM * LIQUID METAL TEMP. LMT $5 \quad \mathrm{~K} \quad 2001000 \mathrm{C} \quad 8.2536 \mathrm{~V}$
410 REM *

420 REM * PRESSURE TRANSDUCER DESCRIPTION AND IONAMES ASSIGNED IN 430 REM * CONFIGURATION FILE

440 REM * AMM2

450 REM * DESCRIPTION IONAME CHANNEL TYPE GAIN WPMAX VMAX

460 REM *

470 REM * UPPER GAS PRESSURE UGP 1 ABS 2 100 PSI $10.00 \mathrm{~V}$

475 REM * LOWER GAS PRESSURE LGP 2 ABS 2 100 PSI $10.00 \mathrm{~V}$

$477 \mathrm{REM} * * * * * * * * * * * * * * * * * * * * * * * * * * * * * * * * * * * * * * * * * * * * * * * * * * * * * * * * * * * * * * * * * * * *$

479 REM ************************************. **********************************

481 REM * THE EXPERIMENT HAS FIVE MAJOR PHASES. THE DATA ACQUISITION

483 REM * AND CONTROL SYSTEM HAS BEEN SET UP TO AUTOMATICALL CONTROI * *

485 REM * ALL EVENTS AND GO THROUGH ALL FIVE PHASES WITHOUT OPERATOR *

487 REM * INTERFACE. THE FOLLOWING ARE THE MAJOR VARIABLES THAT CAN *

489 REM * BE CHANGED IN THE PROGRAM IF NECESSARY BEFORE RUNNING

491 REM * THE PROGRAM.

492 REM * BACKGROUND BACKGROUND NUMBER NUMBER *

493 REM * PHASE DESCRIPTION INTERVAL INTERVAL OF DATA OF DATA*

494 REM * VARIABLE VALUE VARIABLE VALUE *

495 REM * 1 UPPER WATER HEATING BINT1\% 200 NDP1! 90. *

496 REM * 2 LIQUID METAL HEATING BINT2\% 200 NDP2! 120. *

497 REM * 3 COUNTDOWN TO REACTION BINT3\% 10 NDP3! 60. *

498 REM * 4 CHEMICAL REACTION BINT4\% 2 NDP4! 100. *

499 REM * 5 EQUILIBRIUM PERIOD BINT5\% 200 NDP5! 90. *

500 REM *

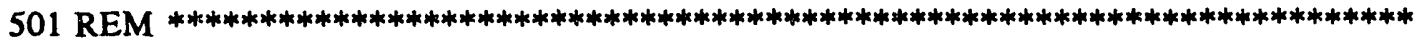

502 REM TIME INTERVAL BETWEEN DATA=BINT*IR*0.001 SECONDS

503 BINT1 $\%=200:$ BINT2 $\%=200:$ BINT3 $\%=10:$ BINT4 $\%=2:$ BINT5 $\%=200:$ BINTC $\%=20$

504 NDP1 $!=110 !:$ NDP2 $!=140 !:$ NDP3 $=80 !:$ NDP4! $=120 !:$ NDP5! $=110 !$ NLPC $!=1800 !$

$505 \mathrm{DTSV}=1 \quad: \mathrm{BOILT}=5 . !: \mathrm{RCDT}=60 .: \mathrm{DTM}=10.0: \mathrm{EQT}=60 .: \mathrm{TSAT}=30$.

506 REM * NRT IS THE NUMBER OF DATA POINTS CORRESPONDING TO REACTION TIME

510 REM * NRT $=$ REACTION TIME/INTERRUPT PERIOD

520 REM *

530 REM * DEFINE DIGITAL ON/OFF VARIABLES

540 REM *

542 IR $\%=100$

544 DTUH $=25:$ UWSETPT $=30 . !:$ LMTSETPT $=100 . !:$ ITESTNO $=1:$ REACTIME $\%=10$

546 UWDT $=10:$ LMDT $=10 \quad:$ UFDT $=50:$ LFDT $=50:$ UFSETPT $=20.0:$ LFSETPT $=650.0$

550 CALL KDINIT

600 DIM ONN\%(1): DIM OFFF\%(1): DIM TIM\%(8): DIM TM\#(8):DIM CDOWN(100,8)

602 DIM REACTT(150,8): DIM EQUIL $(150,8)$

603 DIM UWH1A(1), UWH1B(1), UWH1C(1), UWH1D(1), UWH1E(1): PRINT LP!

604 DIM LGH1A(1), LGH1B(1), LGH1C(1), LGH1D!(1)

$610 \mathrm{ONN} \%(0)=0: \operatorname{OFFF} \%(0)=1:$ ST $\%=10: \mathrm{LP} !=1 !$ 
612 REM CWV $=$ "CWV" : USV\$= "USV" :UWH\$= "UWH" :AIV\$="AIV" :AOV\$= "AOV" 613 REM USV\$= "USV": UGT\$= "UGT" : LGT\$= "LGT": LFT $\$=$ "LFT" :LMT\$ = "LMT"

618 REM CJUFT $=$ "CJN,UFT" $:$ CJLGT $=$ "CJN,LGT" $:$ CILMT $\$=$ "CJN,LMT"

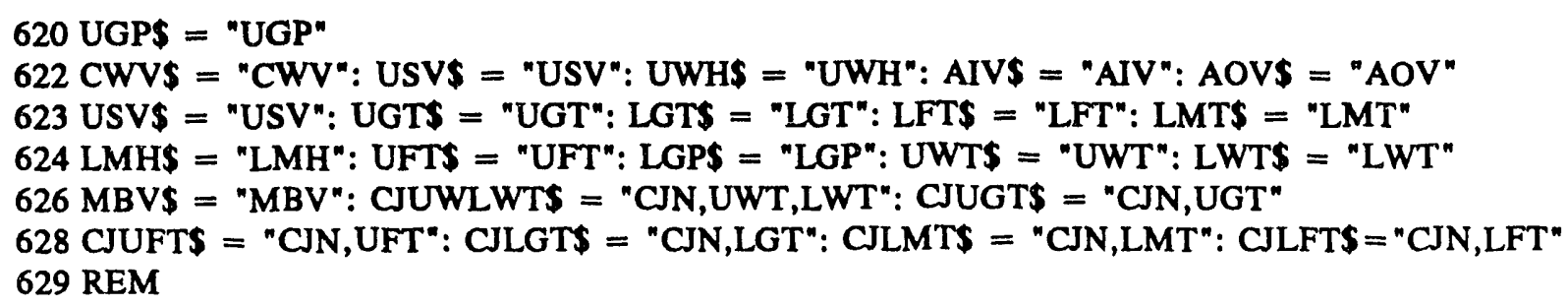

910 REM BEGIN DATA ACQUISITION AND CONTROL 


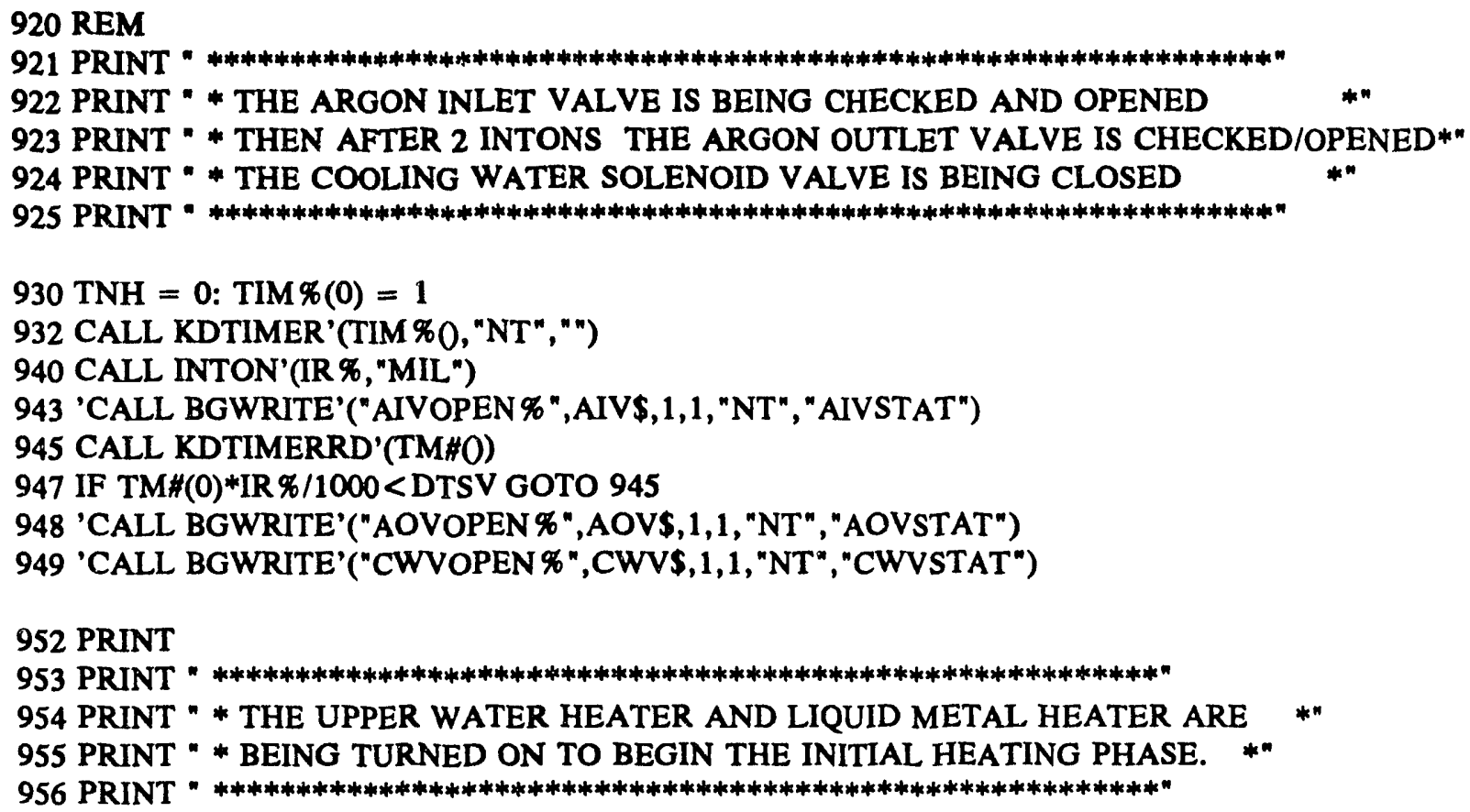


1032 CALL BGREAD'("LDATOA",NDP1!,CJLGT\$, BINT2\%, "NONE",1, "NT", "LDATA0A")

1034 CALL BGREAD'("LDATOB",NDP1!,CJLMT\$, BINT2\%, "NONE", 1, "NT", "LDATAOB")

1035 CALL BGREAD'("LDATOD",NDP1!,CJLFT\$,BINT2\%, "NONE",1, "NT", "LDATAOD")

1036 CALL BGREAD'("LDATOC",NDP1!,LGP\$,BINT2\%, "NONE",1, "NT", "LDATAOC")

1040 REM CALL INTON'(20, "SEC")

1042 REM CALL BGGO'("NT"," ")

1043 REM

$1060 \mathrm{TNH}=\mathrm{TNH}+1$

1102 REM

1110 REM ****** GET LASTPOINT READ AND EXTRACT VALUES USING ARGET ****** 1120 REM

$1125 \mathrm{LP} !=0$.

1128 LPO! = LP!

1130 CALL ARLASTP'("UWHEAT1A",LP!)

1131 IF ABS(LPO! - LP!) < .1 GOTO 1128

1135 CALL ARGET'("UWHEAT1A",LP!,LP!,UWT\$, 1,UWH1 A!0, "C.THCU.K")

1140 CALL ARGET'("UWHEAT1A",LP!,LP!,LWT\$,1,UWH1B!0, "C.THCU.E")

1150 CALL ARGET'("UWHEAT1B",LP!,LP!,UGT\$,1,UWH1C!0, "C.THCU.E")

1160 CALL ARGET'("UWHEAT1C",LP!,LP!,UFT\$,1,UWH1D!0, "C.THCU.K")

1170 CALL ARGET"("UWHEAT1D",LP!,LP!,UGP\$,1,UWH1E!(), "C.VOLTS")

1171 REM ******** GET LOWER DATA ********

1172 CALL ARGET'("LDATOA ",LP!,LP!,LGT\$,1,LGH1A!0, "C.THCU.K")

1173 CALL ARGET'("LDATOB",LP!,LP!,LMT\$, 1,LGH1B!0, "C.THCU.K")

1174 CALL ARGET'("LDATOD",LP!,LP!,LFT\$,1,LGH1D!0, "C.THCU.K")

1175 CALL ARGET'("LDATOC",LP!,LP!,LGP\$,1,LGH1C!0, "C.VOLTS")

1176 REM ************ PRINT DATA *******

1177 'PRINT "UWT,LWT,UGT,UFT,LMT,UGP ARE ", UWH1A(0), UWH1B(0), UWH1C(0), UWH1D(0),LGH1B!(0), UWH1E(0)

1178 UFT $1=$ UWH1D!(0): LWT1 = UWH1B!(0): UWT1 = UWH1A!(0):UWAVG =0.5*(UWT1 + LWT1)

1179 UGP $1=$ UWH1E! (0)*20*6.8948E-2 : LGP1 = LGH1C! $(0) * 20 * 6.8948 E-2:$ UGT $1=$ UWH1C! $(0)$

1180 LGT1 = LGH1A!(0): LMT1 = LGH1B!(0): LFT1 = LGH1D!(0):UFT1 = UWH1D!(0)

1181 PRINT "UWT,LWT,UGT,UFT,UGP ARE ";UWT1;LWT1;UGT1;UFT1;UGP1; "bar"

1182 PRINT "LFT1;LMT1;LGT1;LGP1";LFT1;LMT1;LGT1;LGP1;" bar"

1183 IF( UFT $1>$ UFSETPT + UFDT AND UHST $\%=1$ ) THEN GOSUB 4000

1184 IF( UFT $1<$ UFSETPT-UFDT AND UHST $\%=0$ ) THEN GOSUB 5000

1185 IF ( LFT1 > LFSETPT +LFDT AND LHST $\%=1$ ) THEN GOSUB 4500

1186 IF( LFT1 < LFSETPT-LFDT AND LHST\% =0) THEN GOSUB 5500

1187 'PRINT "LWT,LWT,UGT,UFT,UGP ARE ", UWH1A(0), UWH1B(0), UWH1C(0), UWH1D(0), UWH1E(0)

1190 REM

1200 REM ********* PERFORM TEST TO DETERMINE IF BOILING HAS STARTED **** 1210 REM

1220 IF UWH1A(0) < TSAT! GOTO 1128 
1222 REM IF UWH1E!(0) > 1.5 GOTO 1128

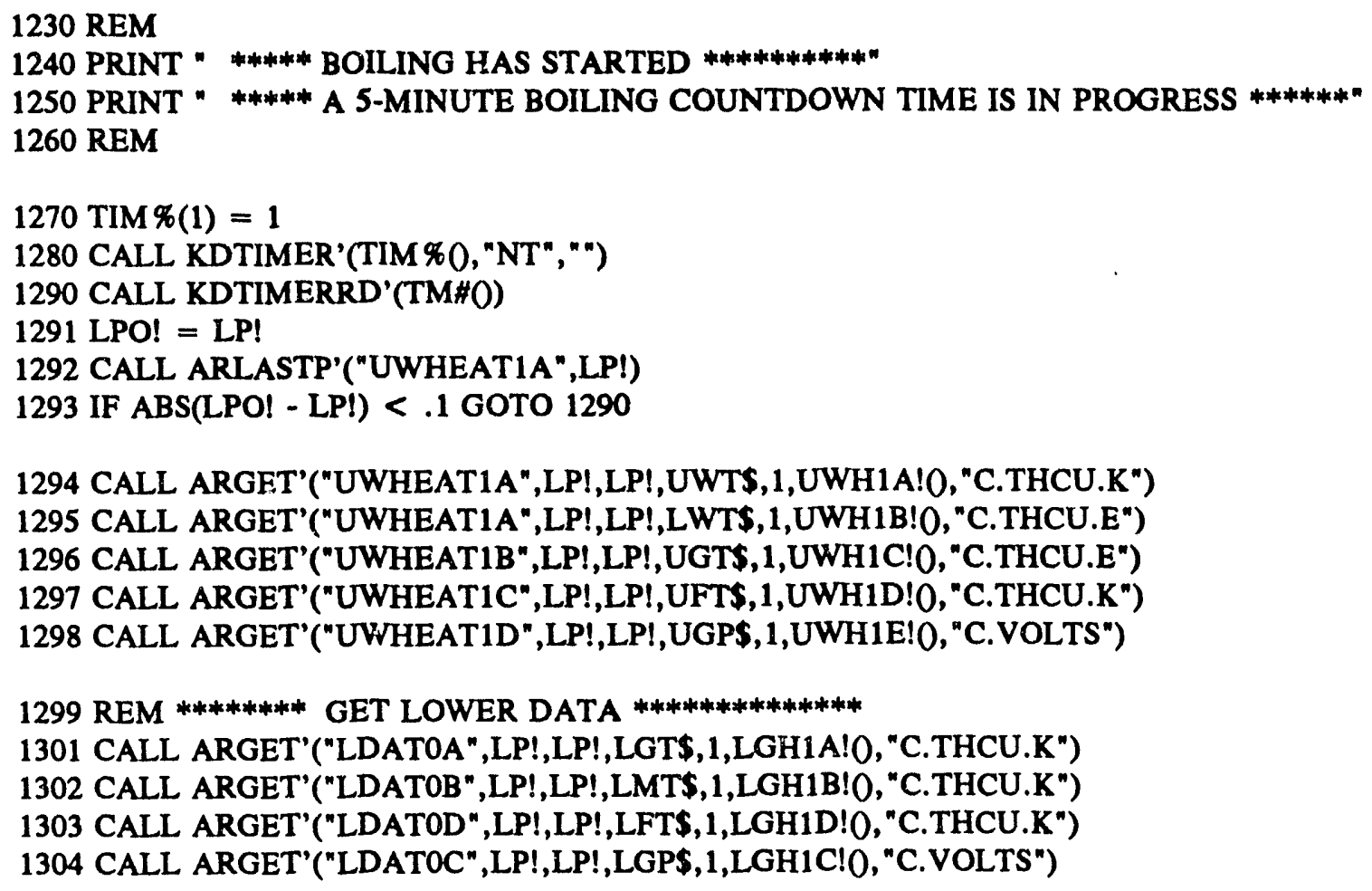

1294 CALL ARGET'("UWHEAT1A",LP!,LP!,UWT\$,1,UWH1A!0, "C.THCU.K")

1295 CALL ARGET"("UWHEAT1A",LP!,LP!,LWT\$,1,UWH1B!0, "C.THCU.E")

1296 CALL ARGET'("UWHEAT1B",LP!,LP!,UGT\$,1,UWH1C!0, "C.THCU.E")

1297 CALL ARGET"("UWHEAT1C",LP!,LP!,UFT\$,1,UWH1D!0, "C.THCU.K")

1298 CALL ARGET'("UWHEAT1D",LP!,LP!,UGP\$,1,UWH1E!0, "C.VOLTS")

1299 REM ******** GET LOWER DATA **************

1301 CALL ARGET'("LDATOA ",LP!,LP!,LGT\$,1,LGH1A!0, "C.THCU.K")

1302 CALL ARGET'("LDATOB",LP!,LP!,LMT\$,1,LGH1B!0, "C.THCU.K")

1303 CALL ARGET'("LDATOD",LP!,LP!,LFT\$,1,LGH1D!0, "C.THCU.K")

1304 CALL ARGET"("LDATOC",LP!,LP!,LGP\$,1,LGH1C!0, "C.VOLTS")

1305 REM ************* PRINT DATA ***********

1306 'PRINT "UWT,LWT,UGT,UFT,LMT,UGP ARE ", UWH1A(0), UWH1B(0), UWH1C(0), UWH1D(0),LGH1B!(0), UWH1E(0)

1307 UFT1 = UWH1D!(0): LWT1 = UWH1B!(0): UWT1 = UWH1A!(0):UWAVG =0.5*(UWT1 + LWT1)

1308 UGP $1=$ UWH1E! $(0) * 20 * 6.8948 \mathrm{E}-2:$ LGP1 $=$ LGH1C! $(0) * 20 * 6.8948 \mathrm{E}-2:$ UGT $1=\mathrm{UWH} 1 \mathrm{C} !(0)$

1309 LGT1 = LGH1A!(0): LMT1 = LGH1B!(0): LFT1 = LGH1D!(0):UFT1 = UWH1D!(0)

1310 PRINT "UWT,LWT,UGT,UFT,UGP ARE ";UWT1;LWT1;UGT1;UFT1;UGP1; "bar"

1311 PRINT "LFT1;LMT1;LGT1;LGP1";LFT1;LMT1;LGT1;LGP1;" bar"

1312 IF( UFT $1>$ UFSETPT + UFDT AND UHST $\%=1$ ) THEN GOSUB 4000

$1313 \mathrm{IF}$ ( UFT $1<$ UFSETPT-UFDT AND UHST $\%=0$ ) THEN GOSUB 5000

1314 IF ( LFT1 > LFSETPT + LFDT AND LHST $\%=1$ ) THEN GOSUB 4500

1315 IF( LFT1 < LFSETPT-LFDT AND LHST\% =0) THEN GOSUB 5500

1316 'PRINT "UWT,LWT,UGT,UFT,UGP ARE ", UWH1A(0), UWH1B(0), UWH1C(0), UWH1D(0), UWH1E(0)

1317 IF TM\#(1)*IR\%/1000 < BOILT GOTO 1290

1318 REM

1319 PRINT " *** COUNTDOWN TIME IS OVER *

1320 PRINT * *** THE UPPER SOLENOID VALVE IS BEING CLOSED"

1330 PRINT " *** THE COOLING WATER VALVE IS BEING OPENED"

1332 REM

1360 'CALL BGWRITE'("USVCLOSE\%",USV\$,1,1, "NT", "USVSTAT2") 
1370 CALL BGWRITE'("CWVOPEN\%",CWV\$,1,1, "NT", "CWVSTAT2")

1371 CALL BGWRITE'("UWHOFFF \% ",UWH\$,1,1, "NT", "UWHSTAT2")

1372 TIM $\%(2)=1$ :REM MAY HAVE TO INSERT COOLING PERIOD FOR UPPER WATER

1374 CALL KDTIMER'(TIM\%0, "NT"," ")

1380 CALL KDTIMERRD'(TM\#0)

1390 IF TM\#(2)*IR\%/1000 < DTSV GOTO 1380

1400 REM

1410 PRINT " **** THE UPPER WATER HEATER IS BEING TURNED ON ******* *

1420 PRINT * **** THE LIQUID METAL HEATER IS BEING TURNED ON*******

1430 REM STOP

1440 CALL BGWRITE'("UWHONN\% ",UWH\$,1,1, "NT", "UWHSTAT2")

1442 UHST $\%=1$

1450 CALL BGWRITE'("LMHONN\% ",LMH\$, 1,1, "NT", "LMHSTAT2")

1452 LHST $\%=1$

1460 'CALL BGHALT'("UWHDAT1A,UWHDAT1B,UWHDAT1C,UWHDAT1D", "NT", "HALT1")

1470 REM

1480 PRINT * ****** NOW ACQUIRING DATA FOR LIQUID METAL HEATING *

1482 PRINT * ****** AND TEMPERATURE CONTROL

1485 PRINT " ****** PHASE ON BACKGROUND GO *

1490 REM ****** ACQUIRE UPPER DATA ******

1500 CALL BGREAD'("UWHEAT2A",NDP2!,CJUWLWT\$,BINT2\%, "NONE",1, "NT", "UWHDAT2A")

1510 CALL BGREAD'("UWHEAT2B",NDP2!,CJUGT\$,BINT2\%, "NONE",1, "NT", "UWHDAT2B")

1530 CALL BGREAD'("UWHEAT2C",NDP2!,CJUFT\$,BINT2\%, "NONE", 1, "NT", "UWHDAT2C")

1535 CALL BGREAD'("UWHEAT2D",NDP2,UGPS,BINT2\%, "NONE",1, "NT", "UWHDAT2D")

1537 REM ****** ACQUIRE LOWER DATA ********

1540 CALL BGREAD'("LDAT1A",NDP2!,CJLGT\$,BINT2\%, "NONE",1, "NT", "LDATA1A")

1544 CALL BGREAD' ("LDAT1B",NDP2!,CJLMT\$,BINT2\%, "NONE",1, "NT","LDATA1B")

1545 CALL BGREAD'("LDAT1C",NDP2!,LGP\$,BINT2\%, "NONE",1, "NT", "LDATA1C")

1548 CALL BGREAD'("LDAT1D",NDP2!,CJLFT\$,BINT2\%,"NONE",1,"NT","LDATA1D")

1550 REM CALL INTON'(20, "SEC")

1552 REM CALL BGGO'("NT"," ")

1560 REM

1570 REM ****** GET LASTPOINT READ AND EXTRACT VALUES USING ARGET ******

1580 REM

$1592 \mathrm{LP} !=0$ !

$1600 \mathrm{LPO} !=\mathrm{LP} !$

1602 CALL ARLASTP'("LDAT1C",LP!)

1603 IF ABS(LPO! - LP!) < .1 GOTO 1600

1604 REM **** GET UPPER DATA ******

1610 CALL ARGET'("UWHEAT2A",LP!,LP!,UWT\$,1,UWH1A!O, "C.THCU.K")

1620 CALL ARGET"("UWHEAT2A",LP!,LP!,LWT\$,1,UWH1B!0, "C.THCU.E")

1630 CALL ARGET"("UWHEAT2B",LP!,LP!,UGT\$,1,UWH1C!0, "C.THCU.E")

1640 CALL ARGET'("UWHEAT2C",LP!,LP!,UFT\$,1,UWH1D!0, "C.THCU.K")

1650 CALL ARGET'("UWHEAT2D",LP!,LP!,UGP\$,1,UWH1F! 0, "C.VOLTS") 
1652 REM ****** GET LOWER DATA *******

1660 CALL, ARGET'("LDAT1A ",LP!,LP!,LGT\$, 1,LGH1A!O, "C.THCU.K")

1670 CALL ARGET'("LDAT1B",LP!,LP!,LMT\$, 1,LGH1B!0, "C.THCU.K")

1672 CAILL ARGET'("LDAT1D",LP!,LP!,LFT\$, 1,LGHID!0, "C.THCU.K")

1673 CALL ARGET"("LDAT1C",LP!,LP!,LGP\$,1,LGH1C!O, "C.VOLTS")

1674 REM *********** PRINT DATA *******

1675 PRINT "UWT,LWT,UGT,UFT,LMT,UGP ARE ", UWH1A(0), UWH1B(0), UWH1C(0), UWH1D(0),LGH1B!(0), UWH1E(0)

1676 UFT1 = UWH1D!(0): LWT1 = UWH1B!(0): UWT1 = UWH1A!(0):UWAVG =0.5*(UWT1 +LWT1)

1677 UGP1 = UWH1E!(0)*20*6.8948E-2 : LGP1 = LGH1C!(0)*20*6.8948E-2: UGT1 = UWH1C!(0)

1678 LGT1 = LGH1A!(0): LMT1 = LGH1B!(0): LFT1 = LGH1D!(0):UFT1 = UWH1D!(0)

1679 PRINT "UWT,LWT,UGT,UFT,UGP ARE ";UWT1;LWT1;UGT1;UFT1;UGP1;"bar"

1680 PRINT "LFT1;LMT1;LGT1;LGP1 ";LFT1;LMT1;LGT1;LGP1;" bar"

1681 IF ( UFT1 > UFSETPT + UFDT AND UHST $\%=1$ ) THEN GOSUB 4000

1682 IF( UFT $1<$ UFSETPT-UFDT AND UHST $\%=0$ ) THEN GOSUB 5000

1683 IF ( LFT $1>$ LFSETPT + LFDT AND LHST $\%=1$ ) THEN GOSUB 4500

1684 IF( LFTI < LFSETPT-LFDT AND LHST \% =0) THEN GOSUB 5500

1722 IF LMT1 < (LMTSETPT - DTM) GOTO 1600

1724 REM

1726 PRINT " ****************************************************************

1728 PRINT * * THE LIQUID METAL HAS ALMOST REACHED ITS SET TEMPERATURE * *

1730 PRINT * * THE ARGON OUTLET VALVE IS BEING CLOSED

1732 PRINT * * THE ARGON INLET VALVE IS BEING CLOSED 1 SEC LATER * *

1734 PRINT * * A 60 SECONDS COUNTDOWN TIME IS BEING STARTED TO ACQUIRE * *

1736 PRINT * * DATA FOR CALCULATING THE LOWER ARGON MASS AND FOR * "

1738 PRINT * * ESTABLISHING INITIAL CONDITIONS

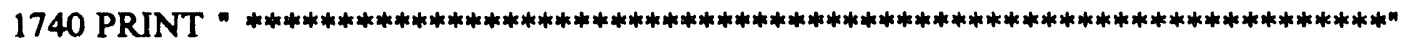

1742 REM

1744 REM *** CLOSE THE ARGON OUTLET VALVE AND THE INLET VALVE

1746 REM

1748 'CALL BGWRTTE'("AOVCLOSE $\% ", A O V \$, 1,1, " N T ", " A O V S T A T 2 ")$

1750 TIM $\%(3)=1$

1752 CALL KDTIMER'(TIM\%0,"NT"," ")

1754 CALL KDTIMERRD'(TM\#0)

1756 IF TM $\#(3) *$ IR $\% / 1000<$ DTSV GOTO 1754

1758 'CALL BGWRITE'("AIVCLOSE\%",AIV\$,1,1, "NT", "AIVSTAT2")

1760 CALL. BGHALT'("UWHDAT2A,UWHDAT2B,UWHDAT2C,UWHDAT2D", "NT", "HALT1")

1762 CALL BGHALT'("LDATA1A,LDATA1B,LDATA1C","NT","HALT2")

1764 PRINT

1766 PRINT " PROIGRAM IS NOW CONTROLLING THE UPPER WATER"

1768 PRINT " TEMPERATURE, AND THE LIQUID METAL TEMPERATURE"

1770 PRINT " UNTIL THEY ARE IN THE PROPER SETPOINTS"

1772 PRINT

1774 REM 
1775 CALL BGREAD'("UWHEATCA",NDPCl,CJUWLWT\$,BINT2\%, "NONE",1, "NT", "UWHDATCA")

1776 CALL BGREAD'("UWHEATCB",NDPC!,CJUGT\$,BINT2\%,"NONE", 1,"NT","UWHDATCB")

1777 CALL BGREAD'("UWHEATCC",NDPCl,CJUFT\$,BINT2\%, "NONE", 1, "NT","UWHDATCC") 1778 CALL BGREAD'("UWHEATCD",NDPC,UGPS, BINT2\%, "NONE", 1, "NT", "UWHDATCD")

1779 REM ****** ACQUIRE LOWER DATA ********

1780 CALL BGREAD'("LDATCA",NDPC!,CJLGT\$,BINT2\%, "NONE", 1, "NT", "LDATACA")

1781 CALL BGREAD'("LDATCE",NDPC!,CJLMT\$,BINT2\%, "NONE", 1, "NT", "LDATACB")

1782 CALL BGREAD'("LDATCC",NDPC!,LGPS, BINT2\%, "NONE", 1, "NT", "LDATACC")

1783 CALL BGREAD'("LDATCD",NDPC!,CJLFTS,BINT2\%, "NONE",1, "NT", "LDATACD")

1784 REM CALL INTON'(20, "SEC")

1785 REM CALL BGGO'("NT"," ")

1860 REM

1870 REM ****** GET LASTPOINT READ AND EXTRACT VALUES USING ARGET ****** 1880 REM

1882 REM DIM LGH1A(1), LGH1B(1), LGH1C(1)

$1884 \mathrm{LP} !=0$ !

$1886 \mathrm{LPO} !=\mathrm{LP} !$

1888 CALL ARLASTP'("LDATCD",LP!)

$1890 \mathrm{JF}$ ABS(LPO! - LP!) < .1 GOTO 1886

1891 REM **** GET UPPER DATA *******

1892 CALL ARGET"("UWHEATCA ",LP!,LP!,UWT\$, 1,UWH1A!0, "C.THCU.K")

1893 CALL ARGET'("UWHEATCA",LP!,LP!,LWTS,1,UWH1B!0, "C.THCU.E")

1894 CALL ARGET'("UWHEATCB",LP!,LP!,UGTS, 1,UWH1C!0, "C.THCU.E")

1895 CALL ARGET'("UWHEATCC",LP!,LP!,UFTS, 1,UWH1D!0, "C.THCU.K")

1896 CALL ARGET"("UWHEATCD",LP!,LP!,UGPS, 1,UWH1E!O, "C.VOLTS")

1897 REM ****** GET LOWER DATA *******

1898 CALL ARGET'("LDATCA",LP!,LP!,LGT\$,1,LGH1A!0, "C.THCU.K")

1899 CALL ARGET'("LDATCB",LP!,LP!,LMT\$,1,LGH1B!0,"C.THCU.K")

1900 CALL ARGET'("LDATCC",LP!,LP!,LGP\$,1,LGH1C!0, "C.VOLTS")

1901 CALL ARGET'("LDATCD",LP!,LP!,LFT\$,1,LGH1D!0, "C.THCU.K")

1902 REM *********** PRINT DATA *******

1903 PRINT "UWT,LWT,UGT,UFT,LMT,UGP ARE ", UWH1A(0), UWH1B(0), UWH1C(0), UWH1D(0),LGH1B!(0), UWH1E(0)

1904 UFT1 = UWH1D!(0): LWT1 = UWH1B!(0): UWT1 = UWH1A!(0):UWAVG =0.5*(UWT1 + LWT1)

1905 UGP1 $=$ UWH1E! $(0) * 20 * 6.8948 E-2:$ LGP1 $=$ LGH1C! $(0) * 20 * 6.8948 \mathrm{E}-2:$ UGT $1=$ UWH1C! $(0)$

1906 LGT1 = LGH1A!(0): LMT1 = LGH1B!(0): LFT1 = LGH1D!(0):UFT1 = UWH1D!(0)

1907 PRINT "UWT,LWT,UGT,UFT,UGP ARE ";UWT1;LWT1;UGT1;UFT1;UGP1;"bar"

1908 PRINT "LFT1;LMT1;LGT1;LGP1";LFT1;LMT1;LGT1;LGP1;" bar"

1909 IF( UFT $1>$ UFSETPT + UFDT AND UHST $\%=1$ ) THEN GOSUB 4000

$1910 \mathrm{IF}$ ( UFT1 < UFSETPT-UFDT AND UHST $\%=0$ ) THEN GOSUB 5000

1911 IF ( LFT1 > LFSETPT + LFDT AND LHST $\%=1$ ) THEN GOSUB 4500

1912 IF( LFT1 <LFSETPT-LFDT AND LHST $\%=0$ ) THEN GOSUB 5500

1913 REM ******* PERFORM MAJOR TEST TO BEGIN REACTION ************ 
1914 IF ABS(UWT1-LWT1) < UWDT AND ((UWAVG<UWSETPT + UWDT)) AND (UWAVG > (UWSETPT-UWDT)) AND (LMT1 <LMTSETPT + LMDT) AND (LMT1 > LMTSETPT-LMDT) GOTO 1929

\section{GOTO 1886}

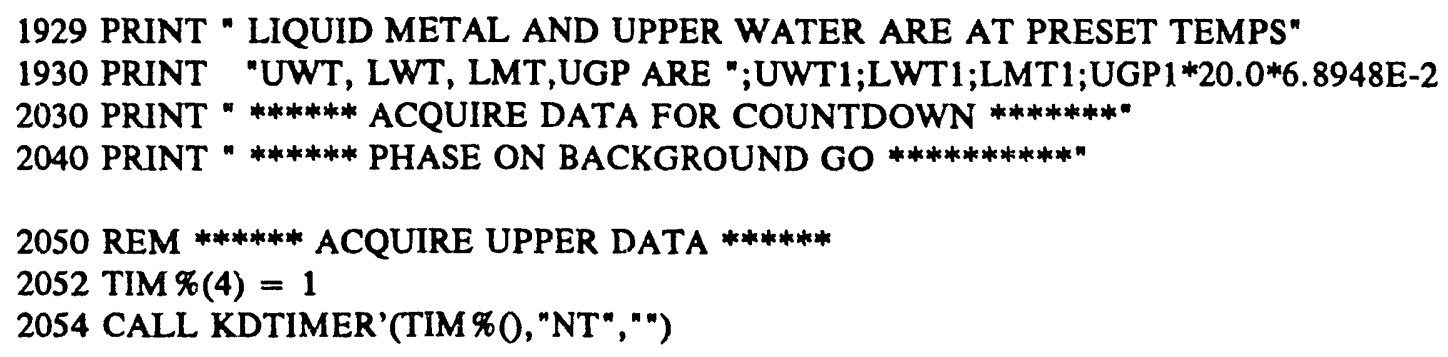

2057 CALL BGREAD'("UWHEAT3A",NDP3!,CJUWLWT\$, BINT3 $\%$, "NONE", 1, "NT", "UWHDAT3A") 2058 CALL BGREAD'("UWHEAT3B",NDP3!,CJUGTS, BINT3\%, "NONE", 1, "NT", "UWHDAT3B") 2059 CALL BGREAD'("UWHEAT3C",NDP3!,CIUFT\$, BINT3\%, "NONE", 1, "NT", "UWHDAT3C") 2060 CALL BGREAD'("UWHEAT3D",NDP3, UGP\$, BINT3\%, "NONE",1, "NT", "UWHDAT3D")

2061 REM ****** ACQUIRE LOWER DATA ********

2062 CALL BGREAD'("LDAT2A",NDP3!,CJLGT\$,BINT3\%, "NONE", 1, "NT", "LDATA2A")

2063 CALL BGREAD'("LDAT2B",NDP3!,CILMT\$,BINT3\%, "NONE",1, "NT", "LDATA2B")

2064 CALL BGREAD'("LDAT2C",NDP3!,LGPS,BINT3\%, "NONE", 1, "NT", "LDATA2C")

2065 CALL BGREAD'("LDAT2D",NDP3!,CILFT\$, BINT3\%, "NONE", 1, "NT", "LDATA2D") 2066 REM CALL INTON'(20, "SEC")

2067 REM CALL BGGO'("NT", " ")

2144 LP3! $=0$ !

$2145 \mathrm{LPO} !=\mathrm{LP} 3$ !

2147 CALL ARLASTP'("LDAT2D",LP3!)

2149 IF ABS(LPO! - LP3!) < .1 GOTO 2145

2150 REM **** GET UPPER DATA ******

2151 CALL KDTIMERRD'(TM\#0)

2152 CALL ARGET"("UWHEAT3A",LP3!,LP3!,UWT\$, 1,UWH1A!0, "C.THCU.K")

2154 CALL ARGET"("UWHEAT3A",LP3!,LP3!,LWT\$, 1,UWH1B!0, "C.THCU.E")

2156 CALL ARGET"("UWHEAT3B",LP3!,LP3!,UGT\$, 1,UWH1C!0, "C.THCU.E")

2158 CALL ARGET"("UWHEAT3C",LP3!,LP3!,UFT\$, 1,UWH1D!0, "C.THCU.K.")

2160 CALL ARGET'("UWHEAT3D",LP3!,LP3!,UGP\$,1,UWH1E!0, "C.YÚLT'S")

\section{REM ****** GET LOWER DATA *******}

2162 CALL ARGET"("LDAT2A",LP3!,LP3!,LGTS,1,LGH1A!0, "C.THCU.K")

2163 CALL ARGET"("LDAT2B",LP3!,LP3!,LMTS,1,LGH1B!0, "C.THCU.K")

2164 CALL ARGET'("LDAT2C",LP3!,LP3!,LGP\$,1,LGH1C!0, "C.VOLTS")

2165 CALL ARGET'("LDAT2D",LP3!,LP3!,LFT\$, 1,LGH1D!0, "C.THCU.K")

2166 UFT1 = UWH1D!(0): LWT1 = UWH1B!(0): UWT1 $=$ UWH1A!(0):UWAVG $=0.5 *(U W T 1+L W T 1)$

2167 UGP $1=$ UWH1E!(0)*20*6.8948E-2 : LGP $1=$ LGH1C!(0)*20*6.8948E-2: UGT1 = UWH1C!(0) 
2168 LGT1 = LGH1 A!(0): LMT1 = LGH1B!(0): LFT1 = LGH1D!(0):UFT1 = UWH1D!(0)

2169 'PRINT "UWT,LWT,UGT,UFT,UGP ARE ";UWT1;LWT1;UGT1;UFT1;UGP1;"bar"

2170 'PRINT "LFT1;LMT1;LGT1;LGP1 ";LFT1;LMT1;LGT1;LGP1;" bar"

2171 IF( UFT1 > UFSETPT + UFDT AND UHST $\%=1$ ) THEN GOSUB 4000

2172 IF( UFT1 <UFSETPT-UFDT AND UHST $\%=0$ ) THEN GOSUB 5000

2173 IF ( LFT $1>$ LFSETPT + LFDT AND LHST $\%=1$ ) THEN GOSUB 4500

2174 IF( LFT1 <LFSETPT-LFDT AND LHST $\%=0$ ) THEN GOSUB 5500

2175 TIME3 $=$ TMH(4)*IR $\% / 1000$

$2176 \operatorname{CDOWN}(L P 3,1)=$ TIME3: $\quad \operatorname{CDOWN}(L P 3,2)=\mathrm{UWH} 1 \mathrm{C} !(0) \quad: \operatorname{CDOWN}(L P 3,3)=\mathrm{LGH} 1 \mathrm{~A} !(0)$ :

CDOWN $(L P 3,4)=$ UWH1A!(0)

$2177 \operatorname{CDOWN}(\mathrm{LP} 3,5)=\mathrm{UWH} 1 \mathrm{~B} !(0): \quad \operatorname{CDOWN}(\mathrm{LP} 3,6)=\mathrm{LGH} 1 \mathrm{~B} !(0): \quad \operatorname{CDOWN}(L P 3,7)=\mathrm{UWH} 1 \mathrm{E} !(0)$ :

$\operatorname{CDOWN}(\mathrm{LP} 3,8)=\mathrm{LGH} 1 \mathrm{C} !(0)$

2178 REM PRINT DATA *******

2179 PRIN T "TIME 3, UWT, LWT, UGT, UFT, LGT, LMT, UGP, LGP ARE ",TIME3,UWH1A(0),UWH1B(0),UWH1C(0),UWH1D(0),LGH1A!(0),LGH1B!(0),UWH1E(0),LGH1C!(0)

2180 REM

2181 REM

2182 'CALL KDTIMERRD'(TM\#())

2190 IF TM\#(4)*IR $\% / 1000<$ RCDT GOTO 2145

2200 REM

2210 PRINT : PRINT * *** COUNTDOWN TIME IS OVER*******

2220 PRINT * *** THE MAIN BALL VALVE IS BEING OPENED *****

2222 REM

2230 REM CALL BGWRITE'("MBVOPEN\% ",MBV\$,1,1, "WGO", "MBVSTAT1")

2240 CALL BGHALT'("UWHDAT3A,UWHDAT3B,UWHDAT3C,UWHDAT3D", "WGO", "HALT3")

2250 CALL BGHALT'("LDATA2A,LDATA2B,LDATA2C", "WGO", "HALT4")

$2260 \operatorname{TIM} \%(5)=1$

2270 CALL KDTIMER'(TIM\%0, "WGO"," )

2280 REM

2290 PRINT : PRINT * ****** ACQUIRING DATA FOR REACTION*****

2300 PRINT * ******* PHASE ON BACKGROUND GO *****

2302 REM

2310 REM ****** ACQUIRE UPPER DATA ******

2312 REM

2320 CALL BGREAD'("UWHEAT4A",NDP4!,CJUWLWT\$, BINT4\%, "NONE", 1, "WGO", "UWHDAT4A")

2330 CALL BGREAD'("UWHEAT4B",NDP4!,CJUGT\$,BINT4\%, "NONE",1, "WGO", "UWHDAT4B")

2340 CALL BGREAD'("UWHEAT4C",NDP4!,CJUFT\$,BINT4\%, "NONE",1, "WGO", "UWHDAT4C")

2350 CALL BGREAD'("UWHEAT4D",NDP4!,UGP\$,BINT4\%,"NONE", 1, "WGO","UWHDAT4D")

2352 REM

2360 REM ****** ACQUIRE LOWER DATA ********

2361 REM 
2362 CALL BGREAD'("LDAT3A",NDP4!,CJLGT\$,BINT4\%, "NONE", 1, "WGO", "LDATA3A")

2363 CALL BGREAD'("LDAT3B",NDP4!,CILMT\$, BINT4\%, "NONE", 1, "WGO", "LDATA3B")

2364 CALL BGREAD'("LDAT3C",NDP4!,LGPS,BINT4\%, "NONE", 1, "WGO", "LDATA3C")

2365 CALL BGREAD'("LDAT3D",NDP4!,CJLFT\$, BINT4\%, "NONE",1,"WGO","LDATA3D")

2366 REM CALL INTON'(100, "MIL")

2367 CALL BGGO'("NT"," ")

2368 REM

$2369 \mathrm{LP} 4 !=0$ !

2370 LPO! = LP4!

2371 CALL ARLASTP"("LDAT3D",LP4!)

2372 IF ABS(LPO! - LP4!) < .1 GOTO 2370

2373 CALL KDTIMERRD'(TM\#O)

2374 REM **** GET UPPER DATA ******

2376 CALL ARGET'("UWHEAT4A",LP4!,LP4!,UWT\$, 1,UWH1A!0, "C.THCU.K")

2378 CALL ARGET"("UWHEAT4A",LP4!,LP4!,LWTS, 1,UWH1B!0, "C.THCU.E")

2380 CALL ARGET'("UWHEAT4B",LP4!,LP4!,UGT\$, 1,UWH1C!0, "C.THCU.E")

2381 'CALL ARGET"("UWHEAT4C",LP4!,LP4!,UFT\$,1,UWH1D!0, "C.THCU.K")

2382 CALL ARGET'("UWHEAT4D",LP4!,LP4!,UGP\$,1,UWH1E!0, "C.VOLTS")

2383 REM ****** GET LOWER DATA *******

2384 CALL ARGET'("LDAT3A",LP4!,LP4!,LGTS, 1,LGH1A!0, "C.'THCU.K")

2385 CALL ARGET'("LDAT3B",LP4!,LP4!,LMT\$, 1,LGH1B!0, "C.THCU.K")

2386 CALL ARGET'("LDAT3C",LP4!,LP4!,LGPS,1,LGH1C!0, "C.VOLTS")

2386 'CALL ARGET'("LDAT3D",LP4!,LP4!,LFT\$,1,LGH1D!0, "C.THCU.K")

2387 TIME4 $=$ TM $\#(5) * I R \% / 1000$

2388 UFT1 $=$ UWH1D!(0): LWT1 = UWH1B!(0): UWT1 = UWH1A!(0):UWAVG $=0.5 *(\mathrm{UWT} 1+\mathrm{LWT} 1)$

2389 UGP1 $=$ UWH1E! $(0) * 20 * 6.8948 \mathrm{E}-2:$ LGP $1=$ LGH1C! $(0) * 20 * 6.8948 \mathrm{E}-2:$ UGT1 $=$ UWH1C! $(0)$

2390 LGT1 = LGH1 A!(0): LMT1 = LGH1B!(0): LFT1 = LGH1D!(0):UFT1 = UWH1D!(0)

2391 'PRINT "UWT,LWT,UGT,UFT,UGP ARE ";UWT1;LWT1;UGT1;UFT1;UGP1;"bar"

2392 'PRINT "LFT1;LMT1;LGT1;LGP1 ";LFT1;LMT1;LGT1;LGP1;" bar"

2394 'IF( UFT1 > UFSETPT + UFDT AND UHST $\%=1$ ) THEN GOSUB 4000

2395 'IF( UFT1 < UFSETPT-UFDT AND UHST $\%=0$ ) THEN GOSUB $500 \mathrm{O}$

2396 'IF( LFT1 > LFSETPT + LFDT AND LHST $\%=1$ ) THEN GOSUB 4500

2397 'IF( LFT1 < LFSETPT-LFDT AND LHST $\%=0$ ) THEN GOSUB 5500

2398 REACTT $($ LP4, 1) = TIME4: $\quad$ REACTT(LP4, 2)=UWH1C!(0) $\quad:$ REACTT $(L P 4,3)=$ LGH 1 A $(0)$ : REACTT(LP4,4) $=$ UWHIA! (0)

$2399 \operatorname{REACTT}(\mathrm{LP} 4,5)=$ UWH1B!(0): REACTT(LP4,6)=LGH1B!(0): REACTT(LP4,7)=UWH1E!(0):

REACTT(LP4,8)=LGH1C!(0)

2400 REM PRINT DATA *******

2401 'PRINT TIME 4, UWT, LWT, UGT, UFT, LGT, LMT, UGP, LGP ARE

",TIME4,UWH1A(0),UWH1B(0),UWH1C(0),UWH1D(0),LGH1A!(0),LGH! B!(0),UWH1E(0),LGH1C!(0) 2402 REM

2430 'CALL KDTIMERRD'(TM\#0)

2440 IF TM $\#(5) *$ IR \% $/ 1000<$ REACTIME\% GOTO 2370 


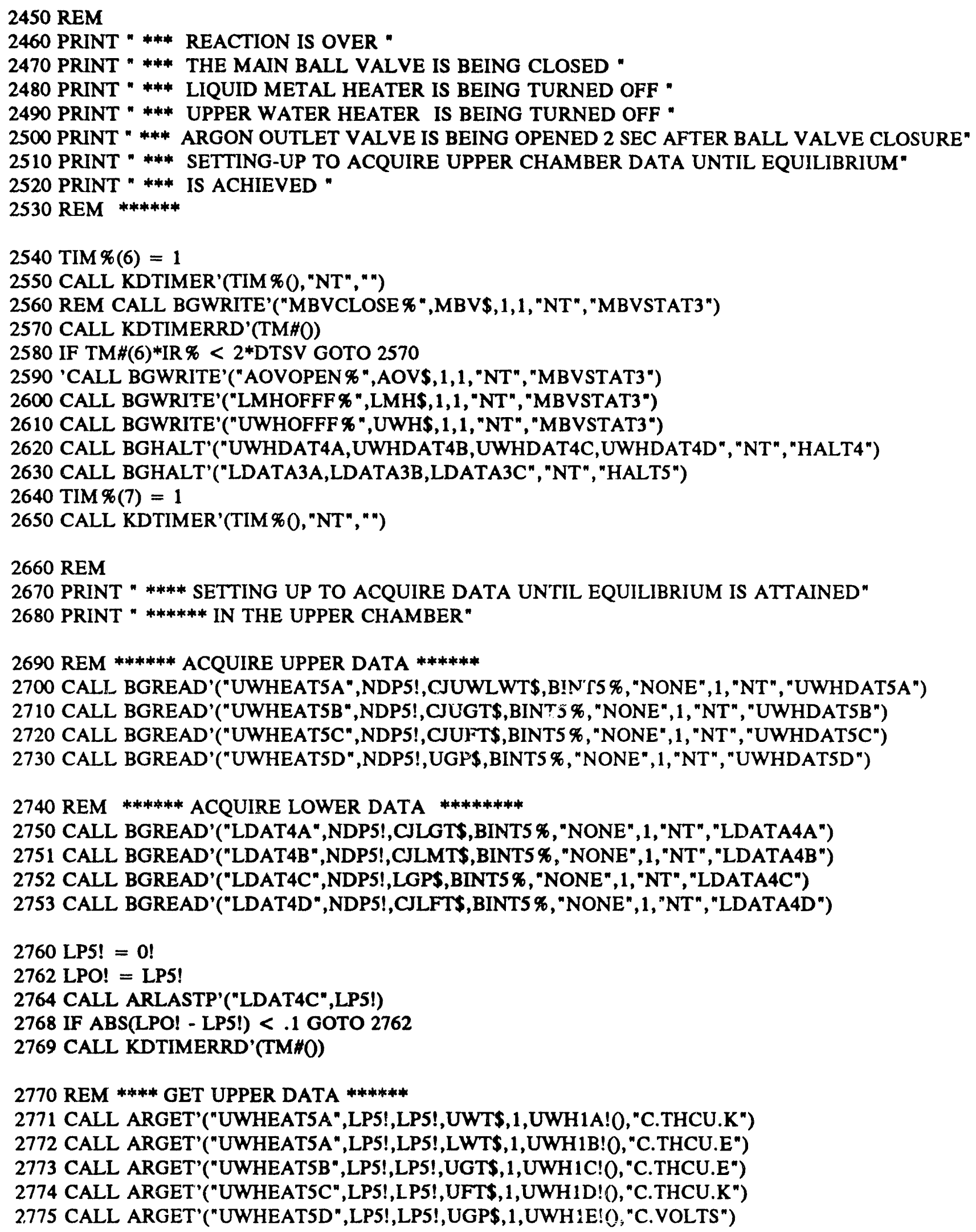


2776 REM ****** GET LOWER DATA *******

2777 CALL ARGET'("LDAT4A",LP5!,LP5!,LGT\$, 1,LGH1A!O, "C.THCU.K")

2778 CALL ARGET'("LDAT4B",LP5!,LP5!,LMT\$,1,LGH1B!0, "C.THCU.K")

2779 CALL ARGET'("LDAT4C",LP5!,LP5!,LGP\$,1,LGH1C!O, "C. VOLTS")

2780 CALL ARGET'("LDAT4D",LP3!,LP3!,LFT\$,1,LGH1D!0, "C.THCU.K")

2781 TIMES $=$ TM\#(7)*IR $\% / 1000$

2782 PRINT "UWT,LWT,UGT,UFT,LMT,UGP ARE ", UWH1A(0), UWH1B(0), UWH1C(0), UWH1D(0),LGH1B!(0), UWH1E(0)

2783 UFT1 = UWH1D!(0): LWT1 = UWH1B!(0): UWT1 = UWH1A!(0):UWAVG =0.5*(UWT1 + LWT1)

2784 UGP1 = UWH1E!(0)*20*6.8948E-2 : LGP1 = LGH1C!(0)*20*6.8948E-2: UGT1 =UWH1C!(0)

2785 LGT1 =LGH1 A!(0): LMT1 = LGH1B!(0): LFT1 = LGH1D!(0):UFT1 = UWH1D!(0)

2786 PRINT "UWT,LWT,UGT,UFT,UGP ARE ";UWT1;LWT1;UGT1;UFT1;UGP1;"bar"

2787 PRINT "LFT1;LMT1;LGT1;LGP1 ";LFT1;LMT1;LGT1;LGP1;" bar"

2788 IF ( UFT1 > UFSETPT + UFDT AND UHST $\%=1$ ) THEN GOSUB 4000

2789 IF( UFT1 <UFSETPT-UFDT AND UHST $\%=0$ ) THEN GOSUB 5000

2790 IF ( LFT1 > LFSETPT + LFDT AND LHST $\%=1$ ) THEN GOSUB 4500

2791 IF ( LFT1 <LFSETPT-LFDT AND LHST $\%=0$ ) THEN GOSUB 5500

2792 EQUIL(LP5,1)= TIME5: EQUIL(LP5,2)=UWH1C!(0) :EQUIL(LP5,3)=LGH1A!(0): EQUIL(LP5,4) =UWH1A!(0)

2793 EQUIL(LP5,5)=UWH1B!(0): $\quad$ EQUIL(LP5,6)=LGH1B!(0): $\quad$ EQUIL(LP5,7)=UWH1E!(0):

EQUIL(LP5,8) =LGH1C!(0)

2794 REM PRINT DATA *******

2795 P R I N T "T I M E 5, U W T, L W T, U G T, U F T, L G T, L M T, U G P, L G P ARE",TIME5,UWH1A(0), UWH1B(0),UWH1C(0),UWH1D(0),LGH1A!(0),LGH1B!(0), UWH1E(0),LGH1C!(0) 2796 REM

2797 CALL KDTIMERRD'(TM\#0)

2798 IF TM\#(7)*IR $\% / 1000<$ EQT GOTO 2762

2800 REM

2802 PRINT " REACTION IS OVER FOLKS! "

2810 PRINT " ******************************************************

2820 PRINT " * TRANSFERRIN ALL KDAC DATA ARRAYS TO DISK *"

2830 PRINT $" * * * * * * * * * * * * * * * * * * * * * * * * * * * * * * * * * * * * * * * * * * * * * * * * * * * * * * \pi$

2840 REM

2841 REM ****** REACTION IS OVER

2842 SR $1 \%=$ BINT1\% * IR $\% / 1000$

2843 CALL ARSAVE'("UWHEAT1A", "UWT1.DAT","C.THCU.K", "FT.ASCII",SR1\%, "SEC")

2844 CALL ARSAVE'("UWHEAT1B", "UGT1.DAT", "C.THCU.E","FT.ASCII",SR1\%, "SEC")

2845 CALL ARSAVE'("UWHEAT1C", "UFT1.DAT", "C.THCU.K","FT.ASCII",SR1 \%, "SEC")

2846 CALL ARSAVE'("UWHEAT1D","UGP1.DAT","C.VOLTS", "FT.ASCII",SR1\%, "SEC")

2847 CALL ARSAVE'("LDATOA", "LGT1.DAT","C.THCU.K","FT.ASCII",SR1\%, "SEC")

2848 CALL ARSAVE'("LDATOB","LMT1.DAT", "C.THCU.K","FT.ASCII",SR1\%,"SEC")

2849 CALL ARSAVE'("LDATOC","LGP1.DAT","C.VOLTS", "FT.ASCII",SR1\%, "SEC")

2850 CALL ARSAVE'("LDATOD","LFT1.DAT", "C.THCU.K","FT.ASCII",SR1\%, "SEC")

2900 REM 
2902 SR2 $\%=$ BINT2\% * IR $\% / 1000$

2910 CALL ARSAVE'("UWHEAT2A","UWT2.DAT", "C.THCU.K", "FT.ASCII",SR2\%, "SEC")

2920 CALL ARSAVE'("UWHEAT2B","UGT2.DAT","C.THCU.E", "FT.ASCII",SR2\%, "SEC")

2930 CALL ARSAVE'("UWHEAT2C","UFT2.DAT", "C.THCU.K","FT.ASCII",SR2\%, "SEC")

2940 CALL ARSAVE'("UWHEAT2D", "UGP2.DAT", "C.VOLTS", "FT.ASCII",SR2\%, "SEC")

2950 CALL ARSAVE'("LDAT1A","LGT2.DAT", "C.THCU.K", "FT.ASCII",SR2\%, "SEC")

2960 CALL ARSAVE'("LDAT1B","LMT2.DAT","C.THCU.K","FT.ASCII",SR2\%, "SEC")

2970 CALL ARSAVE'("LDAT1C", "LGP2.DAT","C.VOLTS", "FT. ASCII",SR2\%, "SEC")

2972 CALL ARSAVE'("LDAT1D","LFT2.DAT","C.THCU.K","FT.ASCII",SR2\%, "SEC")

\section{REM}

2982 SR3 $\%=$ BINT3\% * IR\% $/ 1000$

2990 CALL ARSAVE'("UWHEAT3A", "UWT3.DAT", "C.THCU.K", "FT.ASCII",SR3\%, "SEC") 3000 CALL ARSAVE'("UWHEAT3B","UGT3.DAT", "C.THCU.E", "FT.ASCII",SR3\%, "SEC") 3010 CALL ARSAVE'("UWHEAT3C", "UFT3.DAT", "C.THCU.K", "FT.ASCII",SR3\%, "SEC") 3020 CALL ARSAVE'("UWHEAT3D", "UGP3.DAT", "C.VOLTS", "FT.ASCII",SR3\%, "SEC") 3030 CALL ARSAVE'("LDAT2A", "LGT3.DAT", "C.THCU.K", "FT.ASCII",SR3\%, "SEC") 3040 CALL ARSAVE'("LDAT2B", "LMT3.DAT","C.THCU.K","FT.ASCII",SR3\%, "SEC") 3050 CALL ARSAVE'("LDAT2C", "LGP3.DAT","C.VOLTS", "FT.ASCII",SR3\%, "SEC") 3052 CALL ARSAVE'("LDAT2D", "LFT3.DAT","C.THCU.K", "FT.ASCII",SR3\%, "SEC")

3060 REM

3062 SR $4 \%=$ BINT $4 \% *$ IR $\% / 1000$

3070 CALL ARSAVE'("UWHEAT4A", "UWT4.DAT", "C.THCU.K", "FT.ASCII",SR4\%, "SEC") 3080 CALL ARSAVE'("UWHEAT4R", "UGT4.DAT", "C.THCU.E", "FT.ASCII",SR4\%, "SEC") 3090 CALL ARSAVE'("UWHEAT4C", "UFT4.DAT", "C.THCU.K", "FT.ASCII",SR4\%, "SEC") 3100 CALL ARSAVE'("UWHEAT4D", "UGP4.DAT", "C.VOLTS", "FT.ASCII",SR4\%, "SEC") 3110 CALL ARSAVE'("LDAT3A", "LGT4.DAT","C.THCU.K","FT.ASCII",SR4\%, "SEC") 3120 CALL ARSAVE'("LDAT3B", "LMT4.DAT","C.THCU.K", "FT.ASCII",SR4\%, "SEC") 3130 CALL ARSAVE'("LDAT3C", "LGP4.DAT", "C.VOLTS", "FT.ASCII",SR4\%, "SEC") 3132 CALL ARSAVE'("LDAT3D", "LFT4.DAT", "C.THCU.J", "FT.ASCII",SR4\%, "SEC")

\section{REM}

3142 SR5\% = BINT5\% * IR\% / 1000

3150 CALL ARSAVE'("UWHEAT5A","UWT5.DAT", "C.THCU.K", "FT.ASCIF",SR5\%, "SEC") 3160 CALL ARSAVE'("UWHEAT5B", "UGT5.DAT", "C.THCU.E", "FT.ASCII",SR5\%, "SEC") 3170 CALL ARSAVE'("UWHEAT5C","UFT5.DAT","C.THCU.K", "FT.ASCII",SR5\%, "SEC") 3180 CALL ARSAVE'("UWHEATSD", "UGP5.DAT", "C. VOLTS", "FT.ASCII",SR5\%, "SEC") 3190 CALL ARSAVE'("LDAT4A","LGT5.DAT","C.THCU.K","FT.ASCII",SR5\%, "SEC") 3200 CALL ARSAVE'("LDAT4B","LMT5.DAT","C.THCU.K","FT.ASCII",SR5\%, "SEC") 3210 CALL ARSAVE'("LDAT4C","LGP5.DAT","C.VOLTS","FT.ASCII",SR5\%, "SEC") 3212 CALL ARSAVE'("LDAT4D","LFT5.DAT","C.THCU.K","FT. ASCII",SR5\%, "SEC")

3220 PRINT

3230 PRINT " LITHIUM-LEAR TEST NO ", ITESTNO, " IS OVER" 3240 PRINT " RELOAD THE LOWER CHAMBER AND BEGIN A NEW TEST" 3250 PRINT

3260 PRINT "TRANSFERRING DATA ARRAYS TFOR PHASES 3,4 AND 5 TO DISK FILE" 3270 REM

3280 OPEN "COUNTD.DAT" FOR OUTPUT AS \#1 3290 OPEN "REACTION.DAT" FOR OUTPUT AS $\# 2$ 
3300 OPEN "EQUIL.DAT" FOR OUTPUT AS \#3

3310 FOR I $=1$ TO LP3

3320 PRINT \#1, CDOWN(I,1); CDOWN(I,2); CDOWN(I,3); CDOWN(I,4);CDOWN(I,5); CDOWN(I,6); CDOWN(I,7);CDOWN(I,8)

3330 NEXT I

3340 FOR I= 1 TO LP4

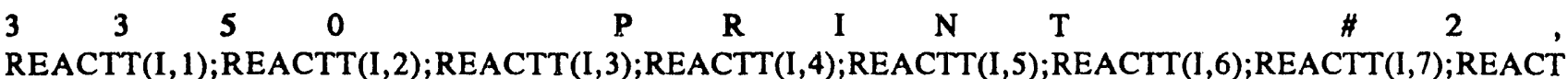
$\mathrm{T}(\mathrm{I}, 8)$

3360 NEXT I

3370 FOR I $=1$ TO LP5

$\begin{array}{lllllllllll}3 & 3 & 8 & 0 & P & R & I & N & T & 3\end{array}$,

EQUIL(I,1);EQUIL(I,2);EQUIL(I,3);EQUIL(I,4);EQUIL(I,5);EQUIL(I,6);EQUIL(I,7);EQUIL(I,8)

3390 NEXT I

3460 PRINT " THAT'S THE END OF DATA ACQUISITION, FOLKS!"

3470 CALL INTOFF

3480 END

4000 CALL BGWRITE'("UWHOFFF \% ",UWH\$, 1,1, "NT", "ST1")

4100 UHST $\%=0$

4200 RETURN

4500 CALL BGWRITE'("LMHOFFF \% ",LMH\$, 1,1, "NT", "ST2")

4600 LHST $\%=0$

4700 RETURN

5000 CALL BGWRITE'("UWHONN \% ",UWH\$, 1,1, "NT", "ST1")

5100 UHST $\%=1$

5200 RETURN

5500 CALL BGWRITE'("LMHONN\% ",LMH\$,1,1, "NT", "ST1")

5600 LHST $\%=1$

5700 RETURN 

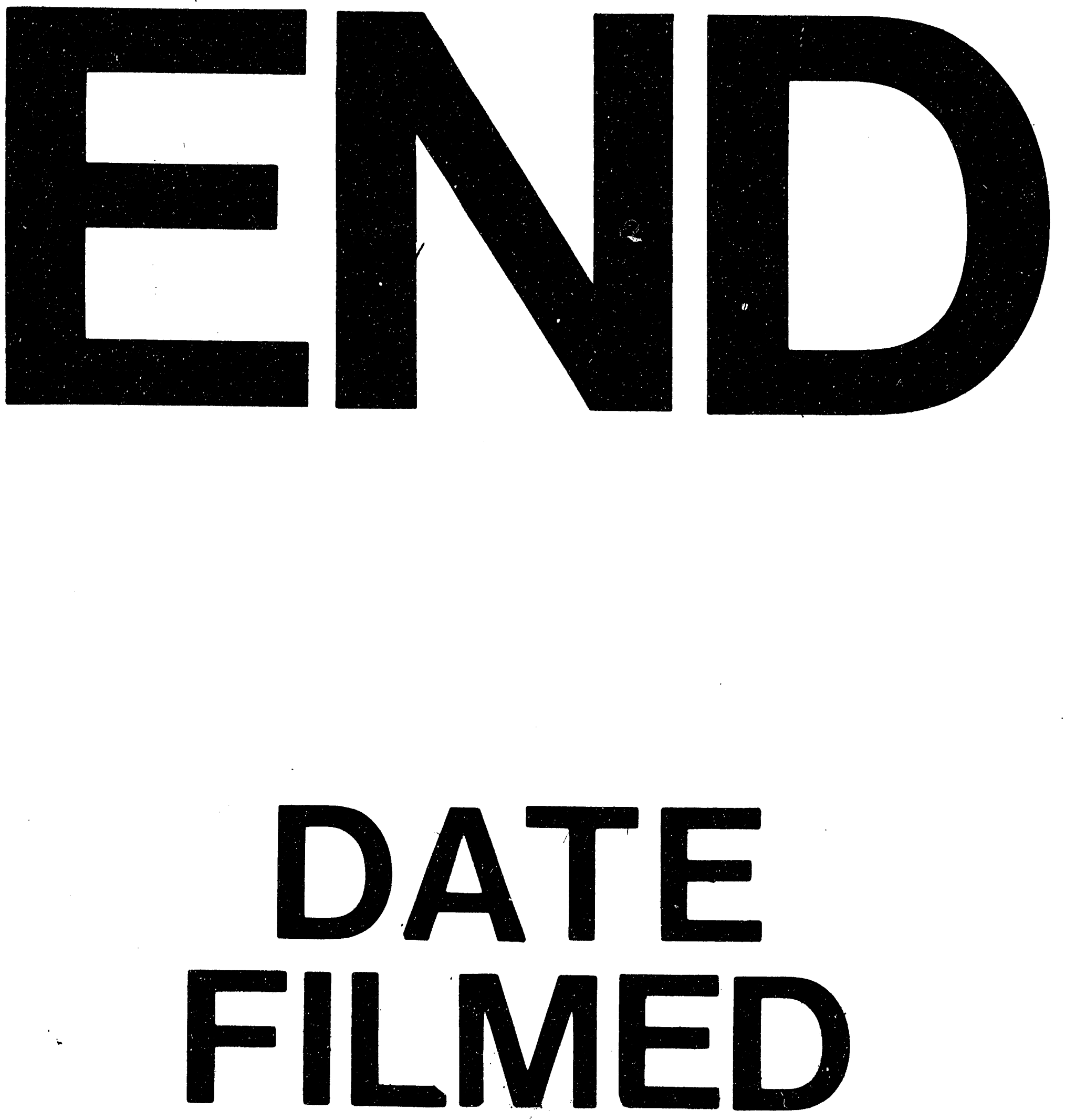

1

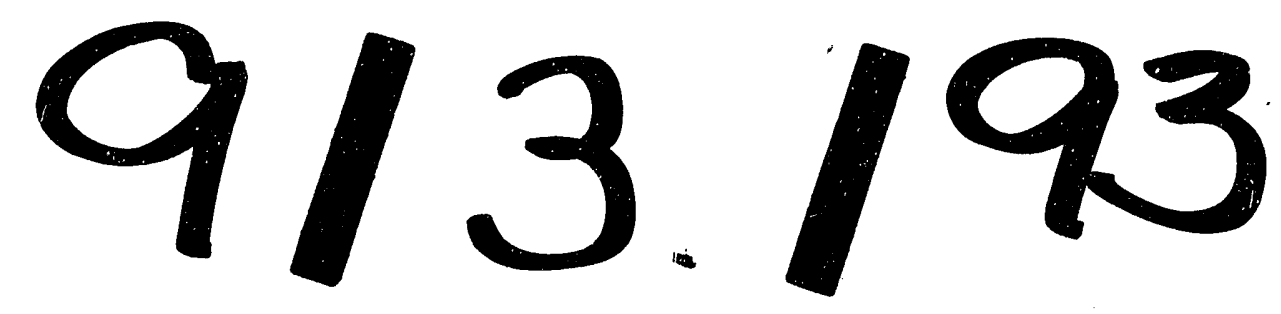


* $\because$ 